\title{
IDENTITY AND HELP IN CALLS TO VICTIM SUPPORT
}

\author{
BY \\ EMMA GABRIELLE TENNENT
}

\begin{abstract}
A thesis
submitted to Victoria University of Wellington

in fulfilment of the requirements for the degree of

Doctor of Philosophy
\end{abstract}

Victoria University of Wellington

2019 


\section{ABSTRACT}

The link between identity and action is a fundamental topic across the social sciences. A key site to investigate this relationship is social interaction, where identities and social relations are built and used to accomplish action. In this thesis, I used discursive psychology to analyse the relationship between identity and the action of help in recorded calls to a victim support helpline. Victim is a contentious identity, with feminists and other critical scholars pointing to the politics involved when certain people are categorised as victims and others are overlooked. The name of the organisation that was the setting for my research, 'Victim Support,' explicitly links a victim identity with rights to access the help the service offers. Drawing on concepts in discursive psychology and using conversation analysis and membership categorisation analysis, I examined how participants oriented to the contentious questions of who victims are and how they should be helped. Drawing on contemporary interactional research which theorises the epistemic, deontic, and affective basis of human social relations, I examined how participants used self-other relations as a resource to build and interpret actions as help.

The findings provide evidence for the mutually constitutive relationship between identity and action. Counter-intuitively, most callers did not explicitly categorise themselves as victims when asking for help. My analyses show how call-takers understood callers' identities as victims even when they did not say so directly. The act of asking for help from Victim Support constituted callers' identities as victims; and their identities rendered their requests accountable.

Call-takers on the victim helpline act as gate-keepers, determining callers' eligibility before providing help. I analysed how call-takers denied callers' requests by implicitly or explicitly disavowing their identities as victims. Conversely, I showed that 
offers of help constituted callers as legitimate victims. Yet even once participants had accomplished joint understanding of callers as victims, they negotiated their respective epistemic and deontic rights to determine what help was needed and how it should be provided.

The negotiation of how victims should be helped was particularly salient when callers sought help on behalf of others. Participants negotiated whether the moral obligation to help victims was associated with friends and family members, or institutions. The emotional support and practical advice offered by Victim Support is delivered by volunteer support workers, reflecting a common-sense assumption that these forms of help are normatively available to any competent person. My analyses attend to the dilemmas involved when callers sought help for others rather than providing it themselves.

The findings contribute to three main areas of research: conversation analytic study of help as social action; membership categorisation analysis research on categorically organised rights and obligations; and the re-specification of psychological phenomenon as interactional objects within discursive psychology. The mutually constitutive link between identity and help is consequential, as the provision or withholding support can have material effects when callers are highly distressed or in fear for their lives. Thus, studying real-life interaction demonstrates the practical ways identity matters for seeking help. 


\section{ACKNOWLEDGMENTS}

Writing this thesis has coincided with some of the most difficult years in my life. Throughout it all, the thesis has been a welcome challenge and a source of joy, thanks in no small part to the people I have been lucky enough to work with along the way. I am grateful to Victoria University of Wellington for providing me with a scholarship throughout my PhD. I feel incredibly fortunate to have been supported to undertake postgraduate study and can honestly say I would not be here without it.

First thanks must go to my wonderful supervisor, Ann Weatherall. Ann, you are everything that could be wanted in a supervisor. Your passion for research is infectious. Thank you for your genuine warmth and kindness. Thanks for recognising that family comes first, for challenging me to think differently, and for actively supporting me at every turn. Your encouragement and compassion have meant the world to me.

Jessica La, my office-buddy and intellectual soulmate. Thanks for fostering my coffee habit, for long talks about life, love and politics, for your effervescent and constructive comments in the margins, and for always being there when I needed someone to talk to. Gates Henderson and Fiona Grattan, thanks for continuing to make our office a CA haven (coven?). Thanks for the long rants, puzzling together over extracts, cake on birthdays, office decorations and all-round camaraderie.

Thanks to all the wonderful members of the postgrad community - particularly Gloria Fraser, Sophie Hedley, Kealagh Robinson, Kate McLeod, and Emma Ashcroft. Thanks for the lunchtimes shared, the drinks on and off campus, the titbits of wisdom, and collective commiseration and celebration. The warmth and support amongst students have been one of the best parts of my postgraduate study and has made my time in Easterfield building immeasurably easier.

Thanks to members of the Wellington Interactional Data Analysis group - particularly Maria Stubbe, Isobel Ross, and Jo Hilder - for 
welcoming me to the small-but-connected community of interactional researchers. Thanks to members past and present of the Discursive Psychology Research Group - your insights have helped shape what are now in these pages. The analytic rigour and collegiality of data sessions are one of the things I love most about conversation analysis. Further afield, thanks to the Transcript Analysis Group in Brisbane for helping me refine my early thoughts on the data. Thanks particularly to Nathaniel Mitchell and Susan Danby for making me feel at home in the Australasian research community.

To my secondary supervisor, Carol Harrington, thank you for your supportive words and encouragement. To Kathryn Sutherland, thanks for your warmth and care, your editor's eye, and your generous offer to read the whole thing!

To my dear friend Radhika Patel-Cornish, thanks for being someone I can always count on. Thanks for showing me that true courage can sometimes mean walking away. Thanks for the dinner dates, long walks, Turkish melodramas, and general life musings. To my flatmates, Alex Just and Ethan Childs - thanks for making our flat a family and our apartment a home. Thanks for the dinners, board-games, and your love and support. Thanks to you all for making my birthday a night of calm and joy amongst the writing chaos of the last weeks.

To Mum and Dad, thanks for indulging me as I waxed lyrical about my project in nearly every phone call. Thanks for encouraging me to study what I loved and for teaching me what really matters. To darling Jo, thanks always for your love and affection. I strive to see myself as you do. To the Taranaki whānau and those further north, thanks for showing me that life is for the living. Thanks all for your encouragement and faith in my abilities.

Paula, Scott, and Zoe MacLachlan - thanks for welcoming me into your family. Thanks for dropping everything when we needed you, 
company during long nights in hospital, always-delicious baking, nights by the fire, and pinecone hunting with Cooper.

Finally, to my partner Jordan MacLachlan, the strongest person I know. Thanks for choosing to keep going even in the darkest of times. Thanks for your unwavering belief in me. Thanks for the hot dinners when I arrived late, massages when my shoulders ached, and the tight hugs when I worried. Thanks for celebrating my successes and your pride in my accomplishments.

I feel such deep gratitude for all the people who have helped me through this. From the bottom of my heart, thank you all. 


\section{CONTENTS}

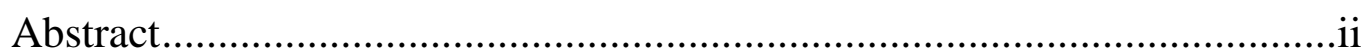

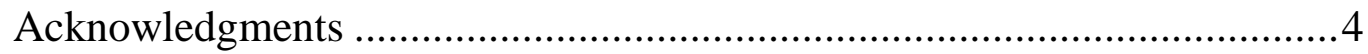

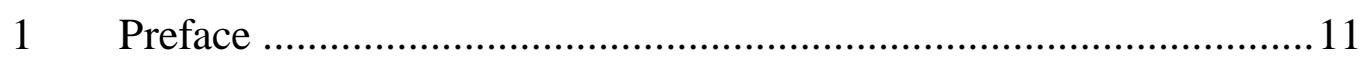

$1.1 \quad$ Who is a victim?

1.2 How should victims be helped?.............................................. 15

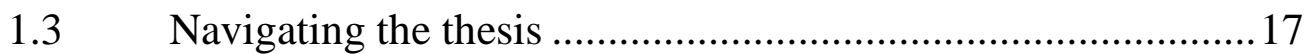

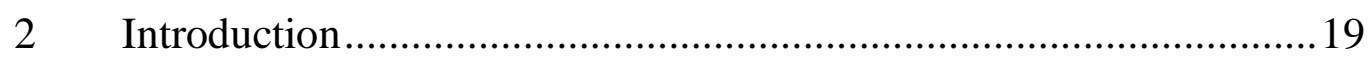

2.1 Identity and help in cognitive social psychology ......................19

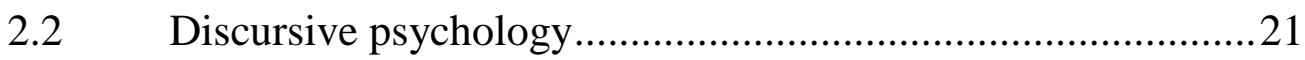

2.2.1 Interpretative repertories and common-sense knowledge 23

2.2.2 Ethnomethodology, practical reasoning, and social action 25

2.3 Self-other relations and moral accountability ..........................28

2.3.1 Social organisation of knowledge, power, and emotion.29

2.3.2 Sequential organisation of help ........................................32

2.3.3 Categorical organisation of help .....................................35

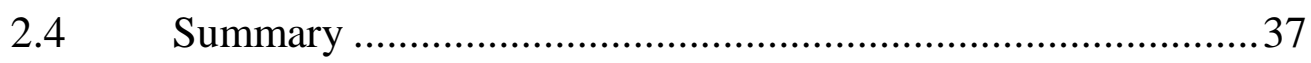

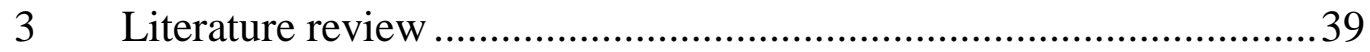

3.1 Everyday help and social relations ……………......................39

3.2 Constituting social contexts .....................................................41

3.2.1 Identity and help online …………………....................41

3.2.2 Institutional help ...................................................... 43

3.3 The moral accountability of institutional help .........................4

3.3.1 Knowledge and rights to help .........................................47

3.3.2 Determining how help will be given ...............................49

3.3.3 Displaying and responding to emotion ...........................51 


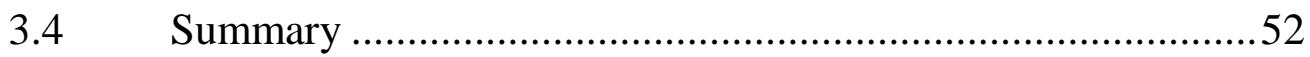

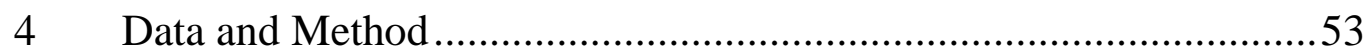

4.1 Background to the setting ..................................................53

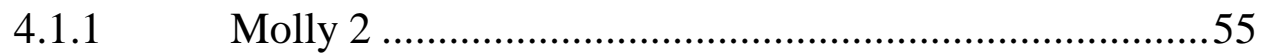

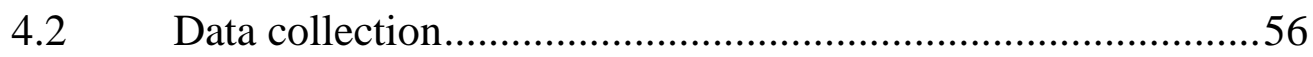

4.3 Ethics and confidentiality ............................................57

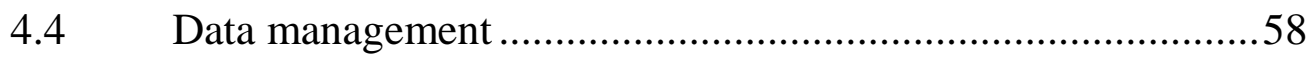

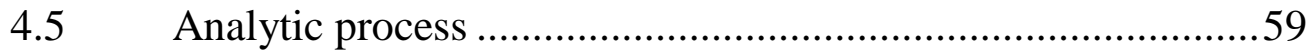

4.5.1 Analysing social interaction......................................59

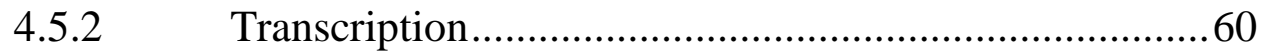

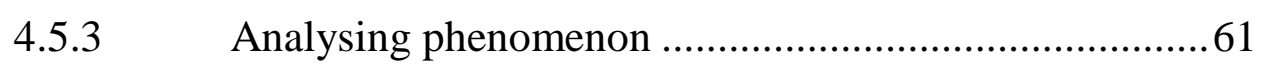

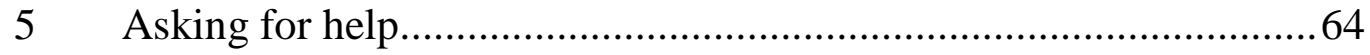

5.1 Seeking a support worker ..............................................64

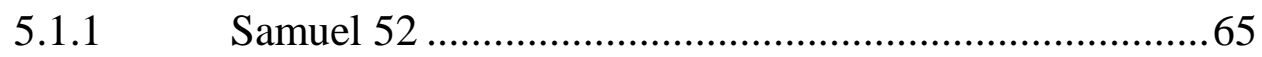

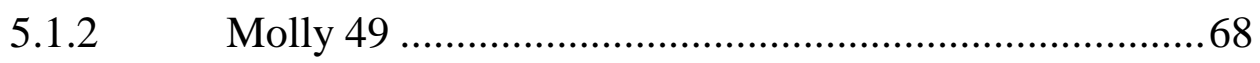

5.1.3 Adrian 32 .......................................................... 71

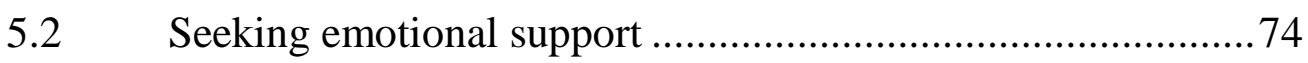

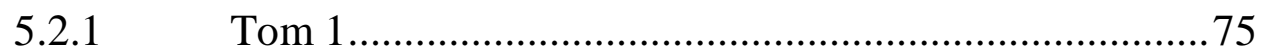

Sharika 2 ......................................................... 78

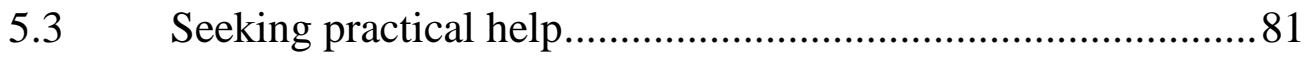

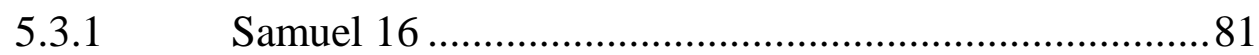

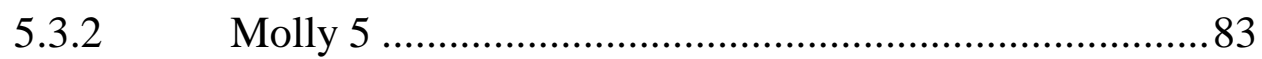

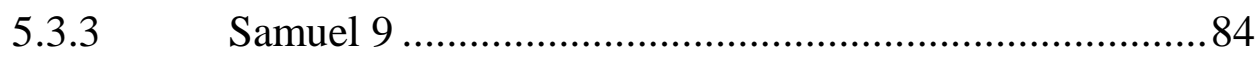

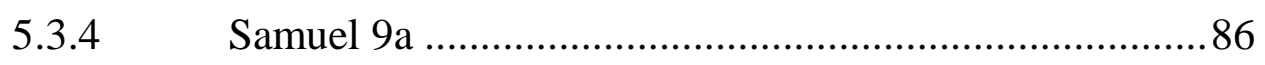

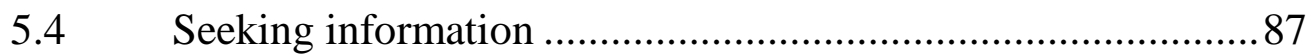

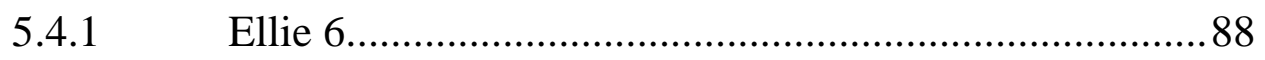

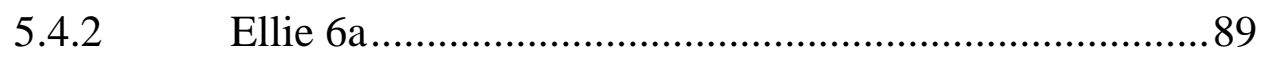

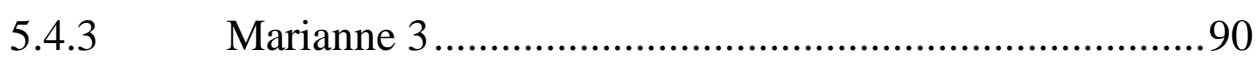




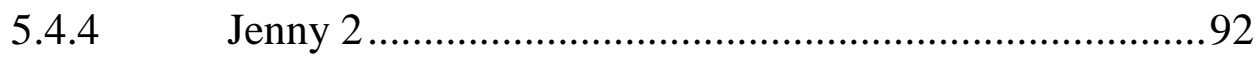

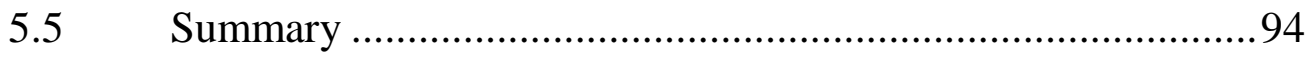

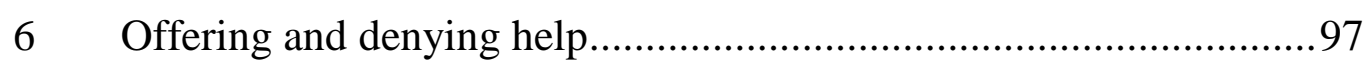

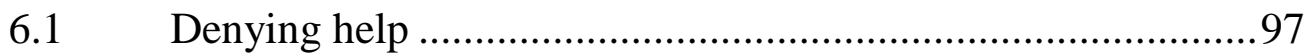

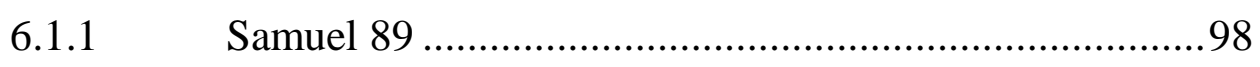

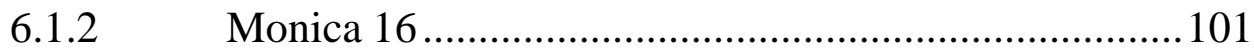

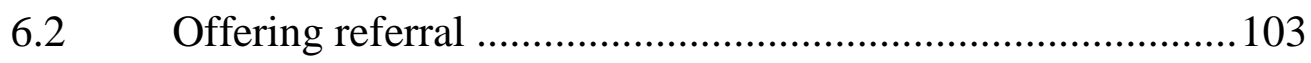

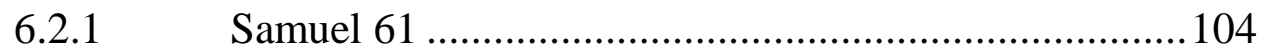

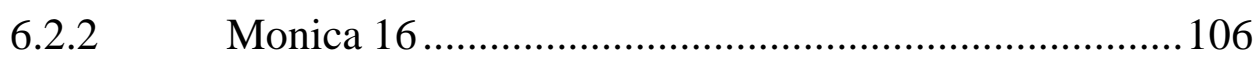

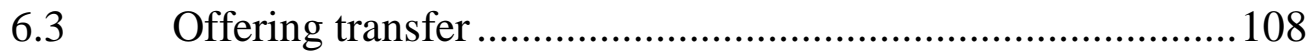

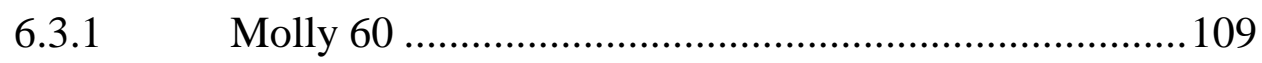

6.3.2 Samuel 83 ..........................................................111

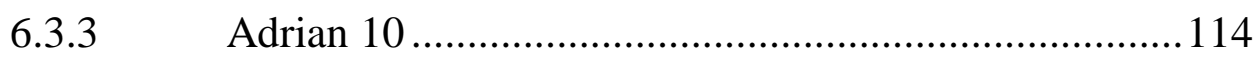

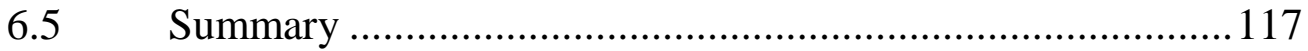

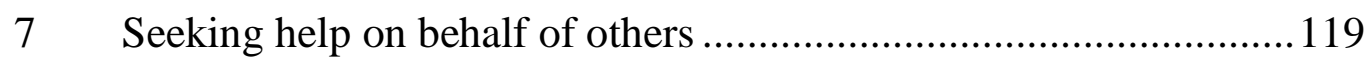

7.1 Formulating 'No one to turn to' for another ...........................120

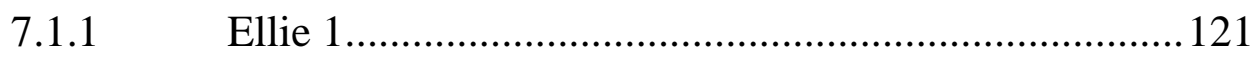

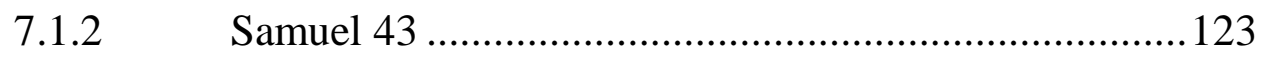

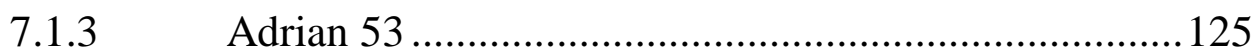

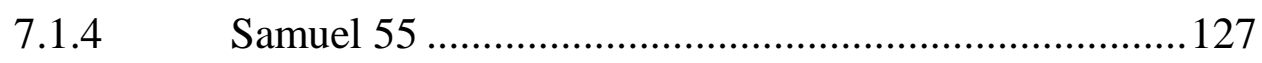

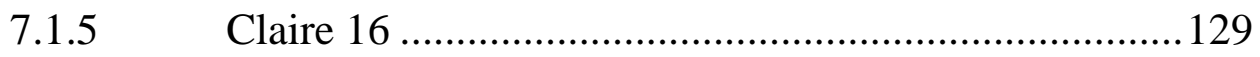

7.2 rights and obligations of seeking or providing support...........131

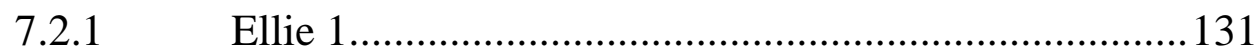

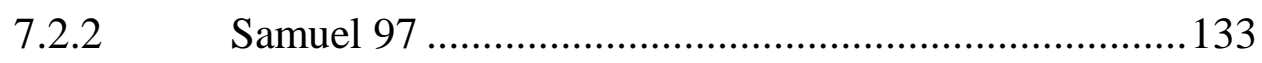

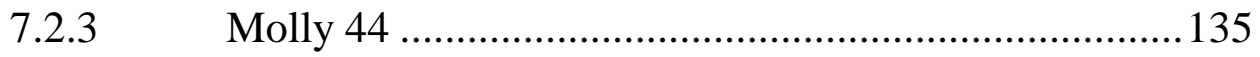

7.3 Denying a request for help on behalf ......................................137

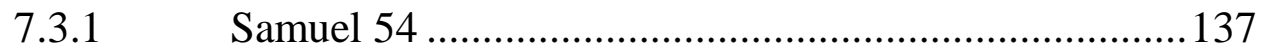

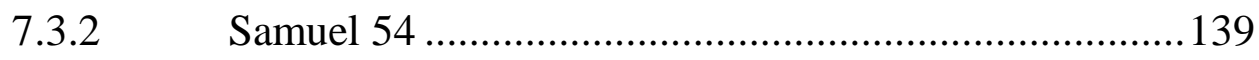




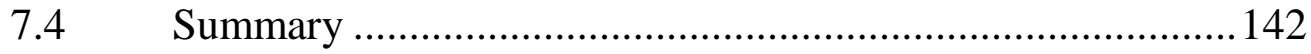

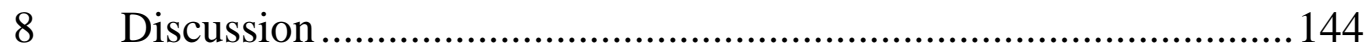

8.1 Identifying as a victim in requests for help............................. 144

8.1.1 Displaying knowledge and entitlement .........................145

8.1.2 Describing experiences and displaying emotion ...........146

8.1.3 Self-categorisation ...................................................... 147

8.1.4 Claiming rights to information......................................148

8.2 Helping victims ............................................................... 149

8.2.1 Gate-keeping access to help .......................................149

8.2.2 Identifying potential clients .........................................151

8.2.3 Negotiating an obligation to help callers.......................151

8.3 Seeking help on behalf of others ..........................................153

8.3.1 No one to turn to ............................................................

8.3.2 The rights to provide help to others …………………....154

8.3.3 The rights to seek help for others....................................156

8.4 Discursive psychology, help, and self-other relations ............158

8.4.1 Self-other relations in action ..........................................158

8.4.2 Participants' orientations to identity ...............................161

8.4.3 The dilemma of seeking help as a victim......................162

8.4.4 Feminist interrogation of victimhood............................165

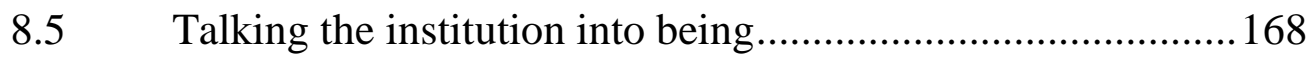

8.5.1 The limitations of audio recordings ............................... 168

8.5.2 Getting institutional help..............................................169

8.5.3 Implications for practice ..............................................171

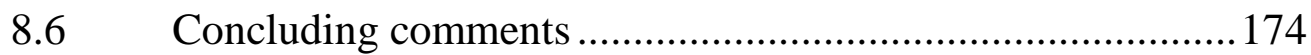

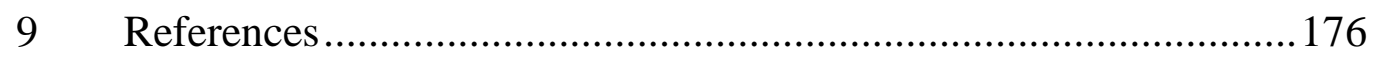

10 Appendix: Transcription Key ................................................200 


\section{Preface}

On 15 March 2019, two mosques in Christchurch were attacked in the deadliest mass shooting in New Zealand's history. In the aftermath, national self-reflection about the causes of such a devasting event and a shared sense of responsibility for the victims led to questions about what could and should be done. On the same day of the attack, Victim Support established an official donation page for the victims. At the time of writing, over 90, 000 people had donated $\$ 8.3$ million to support the victims of the shootings and their families (New Zealand Council of Victim Support Groups, 2019). This part of the national response highlights the intersecting role of victims, support services, and moral arguments about help.

Victim Support New Zealand - whose helpline calls I analyse in this thesis - is a community organisation that provides free services to victims of crime and trauma. Victim Support's ideological approach to victims, exemplified in the response to the terrorist attack, is that victims have needs which can be met by members of a caring society (Mawby, 1988; van Dijk, 1988). Although meeting needs is sometimes conceptualised as a technical problem of serviceprovision, determining what victims need is a contentious and political undertaking (Simmonds, 2009). Alternative approaches are expressly political and focus on victims' rights (Fattah, 2010; Mawby, 2007). Explicitly political support organisations like Women's Refuge conceptualise society's moral obligation towards victims quite differently (Walklate, 1989). A focus on rights rather than needs suggests citizens have moral claims to help which governments are obligated to provide (Mawby, 1988). For example, the Islamic Women's Council argued that New Zealand government and society must address the systemic racism, Islamophobia, and security oversights that led to the terror attack (Rahman, 2019). 
How members of society and support services recognise a moral obligation to help victims is influenced by whether victims' relationships to help are conceptualised in terms of needs or rights. Yet determining how victims should be helped first requires an understanding of who victims are. This is no straightforward matter.

\subsection{WHO IS A VICTIM?}

Different academic disciplines, activist groups, and support services recognise different kinds of people as victims. The criminological subdiscipline of victimology largely treats victims as people harmed by crimes (Daigle, 2018). Yet defining which acts are crimes - and thus which events cause victims - is subject to the influence of society's elite and powerful (Quinney, 1972). Critical victimologists point out that people can become victims as a result of natural disaster, war, and institutional oppression (Holstein \& Miller, 1990; Walklate, 1989). Social psychology recognises that people themselves negotiate who is a victim. Social cognitive approaches examine how members of different groups compete for victimhood status to present themselves more favourably than others (Young \& Sullivan, 2016). Discursive psychology, the approach I adopt in this thesis, demonstrates that claims of victimhood are deployed rhetorically in social interaction to account for certain stances and actions (McNeill, Pehrson, \& Stevenson, 2017).

Theorising about who victims are, how they behave, and what they deserve is not limited to academia. 'Lay' or 'folk' reasoning about victims draws on common-sense knowledge and cultural assumptions. Just like academics, everyday people do not always agree on what makes someone a victim or how victims behave. Common-sense knowledge is made up of opposing pieces of folk wisdom which make it contradictory and inconsistent (Billig et al., 1988). Using discursive psychology, I examine how people use common-sense reasoning to determine who is a victim in social interaction. Describing or inferring someone as a victim does not 
assert a simple fact about the world. Instead, such descriptions produce and constitute reality and someone's identity in it (Potter, Edwards, \& Wetherell, 1993). Like all descriptions, victim descriptions are indexical, taking meaning from occasions of their use and rhetorical, used for strategic ends, such as asking for help (Holstein \& Miller, 1990; McNeill et al., 2017). Thus, establishing a victim identity is not a straightforward or automatic process, but an interactional accomplishment that can be assembled from strategically invoked common-sense for practical ends in the moment of interaction.

Victim support services contribute to, and construct, a "normative hierarchy of victims" (Fattah, 2010, p. 75). Most support services for victims are voluntary organisations, including Victim Support New Zealand. While Victim Support receives some government funding, it relies on volunteers to provide support to victims. Limited resources and close ties to government mean support services are restricted in who they can support and what kind of victims they recognise (Corbett \& Maguire, 1988). A practical problem for support services is establishing who is a victim, an interactional process I examine in detail in this thesis.

Support services are often based on cultural assumptions about victims and their needs. One common-sense assumption is that victimisation causes psychological trauma and talking to someone is helpful (Gavey \& Shmidt, 2011). A consequence of this assumption is that support workers treat clients who resist talking about their experiences as emotionally-repressed (Löfstrand, 2009a), which in the case of young victims can be linked to the possibility becoming perpetrators (Löfstrand, 2009b). Cultural conceptions of age and gender also shape support workers' expectations of victims. Support workers expect women and elderly people to need support more than men or young people, and expect men to face difficulty talking about their feelings (Jägervi \& Svensson, 2015). The provision of emotional support is based on white middle-class assumptions that crime 
shatters individuals' sense of a safe world (Dunn, 2007). But the world is not initially safe for everyone. For example, as Muslims and indigenous people have repeatedly pointed out, the impact of white supremacy has been felt long before the terror attacks brought it into the national spotlight (see Rahman, 2019). The limitations of cultural expectations about victims mean that the people most likely to be victimised (such as members of marginalised groups) often receive the least benefit from support services (Dunn, 2007; Fattah, 2010).

When identifying as a victim and asking for help, people can face a dilemma of stake (see Potter et al., 1993). The common-sense benefits associated with victimhood (i.e. public sympathy, access to support services, recourse to the criminal justice system) mean that claims to a victim identity can be dismissed as self-interested (McNeill et al., 2017). Conversely, a victim identity is associated with shame and suffering (Lamb, 1999a), but necessary to access victim support services. Young men navigate this dilemma by balancing victimhood and masculinity to highlight their agency rather than passivity when describing victimisation (Åkerström, Burcar, \& Wästerfors, 2011). Likewise, clients of Victim Support present themselves as competent and self-sufficient, rather than weak and in need of help (Jägervi, 2014). People may reject a victim identity in favour of alternative categories like survivor to emphasise their agency (Jordan, 2013; Lamb, 1999a). Yet, attributions of agency can undermine a victim identity and the associated entitlement to help (Lindholm, Börjesson, \& Cederborg, 2014). Thus, negotiating identity and help for victim support can be a fraught undertaking. 


\subsection{HOW SHOULD VICTIMS BE HELPED?}

Who victims are understood to be is consequential for the provision of help. Contradictory though it may be, common-sense knowledge has demonstrable impacts on the delivery of justice and support. For example, the cultural conception of the 'ideal victim' someone who is weak, defenceless, and engaged in a respectable action when set upon by a dangerous stranger (Christie, 1986) - has pernicious effects on whether or how victims are helped. In the case of violence against women, taken-for-granted expectations about victims shapes how women understand their experiences, for example as 'rape' or 'just sex' (Gavey, 2013), whether they deserve help or whether they 'asked for it' (MacLeod, 2016), and whether they should disclose domestic violence or stay silent (Towns \& Adams, 2009). The same expectations shape police's disbelief of women's reports (Jordan, 2004), lawyers' cross-examination of women's actions (Powell, Henry, Flynn, \& Henderson, 2013), and judges' sentencing decisions that minimise perpetrators' responsibility (Coates \& Wade, 2004). Cultural common-sense remains pervasive because it is protected against induction (Schegloff, 2007a). People whose experiences differ from the ideal victim - a relationship with the perpetrator, for example - are judged against common-sense knowledge and frequently found wanting.

Categorising people (e.g. as real victims or not) is part of the "micro-politics of everyday and institutional life" (Baker, 2000, p. 99). Using categories reproduces social understandings of what is moral or normal (Stokoe, 2003). Nevertheless, categorical commonsense can be undermined or revolutionised (see Sacks, 1979). Social change can be observed when common-sense category knowledge shifts (Clifton, 2009; Stokoe, 2004). Much feminist activism challenges the links between victim identities and actions. For example, the idea that women are unharmed by rape has shifted significantly to new common-sense knowledge that rape causes psychological trauma (Gavey \& Shmidt, 2011). However, social 
change is slow. Alongside feminist attempts to highlight perpetrators' culpability, the common-sense idea that women are responsible for sexual violence remains pervasive (Jordan, 2011).

The discursive approach I adopt in this thesis analyses how victim categories are used in interaction. In doing so, I shed light on the ways ordinary meanings about victims "become sedimented, and everyday relations of power are produced and become taken for granted" (LeCouteur \& Oxlad, 2011, p. 6). Feminist activism played an integral role in victims' rights movements which centred victims within the political agenda, established support services, and spurred a research tradition which continues to this day (Jordan, 2008; Lamb, 1999b; Walklate, 1990). My work contributes to the feminist project of interrogating common-sense understandings of victimhood by documenting how those understandings shape the delivery of social support.

Victimhood is marked by contradictory and politicallycharged common-sense. For support services, victims may at once be seen as traumatised people who lack agency and deserve help (Lamb, 1999b; Wroe, 2018), and consumers of a service who should take responsibility for their emotional recovery (Löfstrand, 2009a; Svensson, 2007). Thus, determining who is a victim and how they should be helped is a contentious undertaking. As a routine part of their workday, call-takers on the Victim Support helpline are engaged in determining if callers are victims and whether they are eligible for support. Calls to the helpline thus provide a perspicuous setting (Garfinkel, 2002) to examine the relationship between victimhood and help because participants themselves are involved in determining who is a victim and what a victim identity means for help. 


\subsection{NAVIGATING THE THESIS}

The thesis is divided into eight chapters. This prefatory chapter has broadly established why victim is a consequential identity to analyse and demonstrated how victim is a contested and political identity.

The Introduction which follows establishes the theoretical framework for the thesis by charting the different ways identity and help have been conceptualised in social psychology. I discuss developments in discursive psychology and how the methods of conversation analysis and membership categorisation analysis provide tools for analysing identity and help in social interaction. The second half of the Introduction examines how self-other relations and moral accountability can be observed in the social organisation of help.

The third chapter focuses on the empirical literature on identity and help in social interaction. I discuss how help configures social relations and contexts, explaining the grounded approach I adopt to analyse context. To the best of my knowledge, there are no interactional studies of the kind of victim support service I examine, so this study builds on the interactional literature on institutional help, particularly emergency calls and helpline interactions.

In a chapter on data and method, I describe Victim Support in more detail. I overview the process of data collection and data management, with a focus on ethics and confidentiality. The most substantive section of the chapter details my analytic process. I explain why social interaction in situ is important to study, how recordings are used for conversation analysis, how transcripts were produced, and how I identified and analysed the phenomenon in the chapters that follow.

The three analytic chapters are designed as stand-alone investigations. Together, they build an evidence base to support the 
conclusions reached in the final chapter. Chapter 5 documents how a victim identity is part and parcel of asking for help. I show how asking for different kinds of help constituted callers' identities in different ways. Chapter 6 analyses how call-takers invoked the relationship between identity and help when denying or offering help to callers. Chapter 7 examines how participants managed the rights and obligations associated with victims when seeking help on behalf of others.

The final discussion chapter draws together the analytic findings to propose a mutually constitutive link between identity and help. I consider what a grounded analysis of identity and action can provide for social psychology and sketch some practical applications for improving delivery of services. 


\section{INTRODUCTION}

"Identity is the pivotal concept linking social structure with individual action.” (Hogg, Terry, \& White, 1995, p. 257).

The above quote illustrates a social psychological understanding of the fundamental link between identity and action. There is widespread agreement that identity shapes how people see themselves, relate to others, and engage with the social world (Benwell \& Stokoe, 2006). In this thesis, I examine the relationship between identity and action by analysing recorded calls to a victim support helpline. The findings provide evidence for the mutually constitutive relationship between identity and action. The very name of the service - Victim Support - links a victim identity with accessing support. Even in this setting, a relevant question is how a victim identity matters for seeking or providing support. With detailed examination of the turn-by-turn unfolding of calls to the helpline, I show how callers and call-takers invoke links between a victim identity and the action of help.

In this introductory chapter, I discuss how social psychology has approached the relationship between identity and help. I first briefly discuss social psychology in the cognitivist paradigm, before introducing discursive psychology, the theoretical framework I adopt in this thesis. In the second half of the chapter, I discuss how selfother relations and moral accountability are configured when people ask for help in social interaction.

\subsection{IDENTITY AND HELP IN COGNITIVE SOCIAL PSYCHOLOGY}

A social psychology of helping was spearheaded by Darley and Latané (1968) in response to public outcry surrounding the now infamous Kitty Genovese murder. The question of how ordinary people could stand by while a neighbour was murdered motivated anxious newspaper columns and psychologists alike. In experiments, 
Darley and Latané documented a 'bystander effect' where individuals were more likely to help when alone than in the presence of others. Earlier social psychological theory predicted that people would help in emergencies, which made the bystander effect an anomaly in need of scientific explanation (see Latané \& Darley, 1970). From their work, Darley and Latané proposed a decision-making model to explain whether a bystander would help or not. The stages of the model involve cognitive processes such as perceptions, beliefs, and intentions. If bystanders did not perceive the situation to be an emergency, believe they had a personal responsibility to intervene, or know what to do, they would be less likely to provide help. Like much of cognitive psychology, this model attempts to predict behaviour (whether someone will intervene) by determining the cognitive causes of their actions.

Darley and Latané (1968) were not directly concerned with identity, but subsequent research using social identity theory highlighted the role group membership played in helping behaviour. Social Identity Theory and Self-Categorisation Theory suggest that group membership prescribes how members should think, feel, and act, which shapes how people see themselves and others (Tajfel, 1974; Tajfel \& Turner, 1986). These theories conceptualise identity as an internal self-concept driven by cognitive processes (Hogg et al., 1995). Social identity theory predicts that bystanders are more likely offer help when they share group membership with victims (Levine, Prosser, Evans, \& Reicher, 2005). Conversely, seeking or accepting help from others can threaten social identity when it compromises individuals' ability to evaluate their group positively against others (Farmer, Farrand, \& O'Mahen, 2012; Täuber \& van Zomeren, 2012). Thus, Social Identity Theory claims that group membership can affect individuals' decisions to offer, seek, or reject help.

For social psychology within the cognitivist paradigm then, identity is conceptualised as an inner mental state and help as a behaviour influenced by underlying cognitive processes. The 
relationship between identity and help can be analysed by examining how social identity influences individuals' decisions to offer or accept help from others.

\subsection{DISCURSIVE PSYCHOLOGY}

Discursive psychology developed as a critique of the cognitivist assumptions within social psychology (see Potter \& Wetherell, 1987). Potter et al. (1993) pointed out that psychologists attempt to identify characteristics within individuals or cognitive processes within the mind, while treating reality as something unproblematic against which to measure the behaviour of experimental subjects. For discursive psychology, however, reality is neither neutral nor pre-determined, but a focus for analysis. Discursive psychologists ask how certain versions of reality are constructed through language and deployed for rhetorical ends (Wiggins, 2016). For example, the story of 38 witnesses who did nothing while Kitty Genovese was murdered has since been revealed as a myth (Levine \& Cassidy, 2009). Although details of the story have been debunked, the case remains a staple of psychological textbooks as a parable which sets powerful parameters on the psychological topics of investigation (Manning, Levine, \& Collins, 2007). Different descriptions of the Kitty Genovese case - in news reports, witness testimony, psychological models, or textbooks show how different versions of reality are constructed through language and how these versions can account for different actions such as intervening to help, or blaming those who did not (Edwards, 1997).

Influenced by post-structuralism, discursive psychology recognises that there are no objective or value-free descriptions of the social world. Poststructural theorists like Foucault argued that knowledge and identity are not objective phenomena stored in individuals' minds, but fragmentary constructions maintained through processes such as social interaction and language (Benwell 
\& Stokoe, 2006). Descriptions of people and events (such as describing someone as a victim) constitute the reality of identities, events, and social relations (Potter et al., 1993). In Taylor's (2010, p. 29) words, "talk does not describe something which already exists," rather, "talking is part of the process through which mental states and identities are being made." Discursive psychology treats both reality and identity as social constructs that are built through language and social interaction.

Discursive psychology's focus on language and interaction is deeply influenced by Sacks (1995), who argued for the primacy of social interaction in understanding social life (see Schegloff, 1989). Although Sacks was primarily concerned with his home discipline of sociology, the study of social interaction is inherently psychological (Edwards, 1995). The way people categorise themselves and others is a prime concern for psychology (Edwards, 1995). However, Sacks criticised social scientists for using categories such as sex, race, and age to divide up populations of people and make claims about their behaviour, arguing they "lack a warrant for the unanalysed use of membership categories in the conduct of their research activities" (Sacks, 1966, p. 34). The problem overlooked in such research is that every person can be categorised in a near-infinite range of ways. On what grounds can a researcher legitimately pick one category from this infinite line-up and ignore the rest? Sacks (1972a, 1972b, 1979) argued that researchers should not use pre-determined categories to make sense of people's conduct, but analyse the categories people themselves use in interaction.

Studying social interaction allows discursive psychologists to examine the categories people use in everyday life to make sense of their social worlds (Edwards, 1995). Categorising people in different ways is a resource to construct different versions of reality (Edwards \& Potter, 1992; Potter \& Wetherell, 1987). For example, determining whether someone should be helped depends on who they are understood to be. Categorising someone (e.g. as a victim) is 
always a choice from among alternatives (e.g. an attention-seeker or irresponsible person) which construct certain versions of reality in which helping or harming are rendered accountable (see Lamb, 1999b; Lindholm et al., 2014; Wroe, 2018). Categorisation practices are culture in action, where members of a culture constitute shared common-sense knowledge about who people are, how they behave, and what they deserve (Hester \& Eglin, 1997).

In police interrogations, applying the categories victim and offender to people can carry heavy social, legal, and moral consequences. Shared cultural knowledge about what people are like and how they behave means categorising a victim (e.g. with a racial slur) can provide a motive for murder by trading on a suspect's paired identity (e.g. as a white supremacist) (Watson, 1983). Describing a victim's actions can also make relevant their categorical identity. For example, a man charged with murder described how his victim propositioned him for sex, categorising her as a 'certain kind of girl' to shift blame from his actions to hers (Wowk, 1984). Men convicted of domestic violence use the same kind of gendered moral reasoning, describing their partners in ways that implicitly justify their violence - even when they explicitly admit wrongdoing (LeCouteur \& Oxlad, 2011). Thus, the link between categories, actions, and moral attributions of blame and responsibility can constitute common-sense knowledge in consequential ways.

\subsubsection{Interpretative repertories and common-sense knowledge}

The analytic tools of practical ideologies and interpretative repertories provide ways to examine common-sense meanings (or discourses) about the relationship between victims and help. Practical ideologies are "often contradictory and fragmentary complexes of notions, norms and models, which guide conduct and allow for its justification and rationalisation" (Wetherell, Stiven, \& Potter, 1987, p. 60). For example, a practical ideology of victimhood is made up of competing common-sense notions about victims, which are 
practically used to make certain actions, like seeking help, accountable in certain situations. The related concept of interpretative repertoires (Potter \& Wetherell, 1987), likewise examines how social objects, like victims, can be constructed in talk and text in different ways to manage accountability and personal stake. Interpretative repertoires are both practical and ideological. Descriptions are deployed for practical ends, while also constructed as part of a socialmoral order tied to historical and cultural context (Weatherall, 2016).

Interpretative repertoires can demonstrate how commonsense knowledge poses dilemmas for victims seeking help (cf. Billig et al., 1988). For example, women experiencing violence from male partners use contradictory common-sense maxims to reason about seeking help. Should they stay in violent relationships to protect their children and their family's reputation; or should they leave to protect themselves and their autonomy? Common-sense maxims like 'airing dirty laundry' or 'facing the music' provide contradictory answers to that question; as do competing ideologies of patriarchy, equality, individualism, and collectivism (Towns \& Adams, 2009). Similarly, women reporting rape to police use rape myths as a practical ideology to make sense of what happened to them. MacLeod (2016) showed that women displayed an understanding that their actions (such as where they were or how much they drank) could be understood as contributing to their victimisation, and so accounted to pre-empt blame from police officers.

The use of interpretative repertoires as analytic tools was a source of debate in the development of discursive psychology. This debate was particularly contentious for studies of gender and language (La, 2018; Weatherall \& Stubbe, 2015; Wilkinson \& Kitzinger, 2006). Rearticulating Sacks' (1972a, 1972b) position, Schegloff (1997, p. 167) argued that analysts engage in "theoretical imperialism" when they treat their concerns as more relevant than participants. Just because participants can be categorised as men or women doesn't mean these are legitimate analytic categories to make 
sense of how they act. Analysts' claims about identity are only justifiable, he argued, when identity is demonstrably relevant for participants and procedurally consequential for the interaction. However, Wetherell (1998) argued that interpretative repertories and ideological dilemmas provide a richer account of psychology in action than simply focusing on participants' orientations. The things people do and say make sense - not only at the level of the interaction - but in terms of normative conceptions about the social world.

Although I adopt the methodology of conversation analysis to examine participants' orientations to identity and help, the analytic concepts of interpretative repertoires and ideological dilemmas inform my analysis. These concepts have been largely overlooked by discursive psychologists who use conversation analysis, but I suggest they may be usefully deployed to analyse how politically charged common-sense about victims can pose dilemmas for those seeking help. Following Schegloff (1997), I undertake to demonstrate how participants treat victim (or other) identities as relevant and show how these identities are consequential for accomplishing help. Nevertheless, I am sensitive to the ideological contradictions that shape the relationships between victimhood and help (see Billig et al., 1988).

\subsubsection{Ethnomethodology, practical reasoning, and social action}

Alongside poststructuralism, the development of discursive psychology was influenced by ethnomethodology, a distinct sociological approach to the study of social life. Ethnomethodology recognises that members of society are engaged in figuring out who they are to each other and what they are doing as they go about their everyday lives (Garfinkel \& Sacks, 1970). Social actions, like asking for help, are built to be recognisable to other people - who have no access to each other's inner cognitive processes, but nonetheless manage to make themselves understood and accomplish coordinated activities (Edwards, 1997; Garfinkel, 1967). The relationship between 
identity and help is something members of society have orderly methods for understanding. In other words, people have means to determine who is a victim and how they should be helped. The related tools of conversation analysis and membership categorisation analysis provide systematic methods to document how participants use and understand the relationship between identity and action.

Conversation analysis and membership categorisation analysis were developed by Sacks (1995) as an ethnomethodological study of social interaction. Sacks argued that social interaction was a key site where members of society made sense of social life, themselves, and others. In contrast to assumptions within sociology, linguistics, and psychology that real talk is too messy for systematic study, Sacks demonstrated the possibilities for rigorous empirical observation of talk. The subsequent development of conversation analysis and membership categorisation analysis have demonstrated the importance of social interaction as a "primordial site of human sociality and social life” (Schegloff, 1987, p. 101).

Early work in discursive psychology - and continuing in critical discursive psychology - analysed how people constructed versions of the world in interviews (Potter \& Wetherell, 1987), or textual materials like news articles (Venäläinen, 2016). However, the widespread adoption of conversation analytic methods means discursive psychology has largely moved away from the use of interview data (Kent, 2016). Interviews are a situated context where participants' investment in what they do and say differs from ordinary talk (Wiggins, 2016). In naturally occurring social interaction, participants have a genuine stake in the outcome of talk in a way that interviews, surveys, or re-enactments simply cannot replicate (Potter, 2012; Stokoe, 2013b). The way people use the link between identity and help is likely quite different when talking to a researcher about accessing Victim Support (Åkerström et al., 2011; Jägervi, 2014) than when asking for help from a call-taker on the Victim Support helpline. 
Because identity is conceptualised in terms of action, conversation analysis offers a unique way to analyse the relationship between identity and action that fits well with discursive psychology. Likewise, membership categorisation analysis offers a way to explore members of society's practical reasoning about the link between categorical identities and associated actions. I draw on both analytic approaches when analysing participants' orientations to the relationship between a victim identity and help in calls to Victim Support.

Following the analytic mandate of the primacy of participants' orientations (Schegloff, 1997), conversation analysis approaches identity as participants' displayed understandings of who they are to each other (Stevanovic \& Peräkylä, 2014). As part of the ethnomethodological approach, conversation analysis re-specifies identity from a one-person problem to a two-person problem (Sacks, 1995). In other words, individuals' identities cannot be analysed in isolation. Identity in context shows that how one person identifies themselves is inexorably tied to who they understand their recipient to be.

Identity can be a resource to accomplish help in interaction. Conversation analysis examines how participants use different resources to build and interpret actions. Participants' sense of who they are to each other is one resource for action. For example, requesting help inevitably displays a speaker's understanding of their entitlement to help, their identity vis à vis their recipient, and the basis of the relationship between them (Levinson, 2013). Take for example, someone calling emergency services. By calling and requesting help, they show their entitlement to help as a citizen in an emergency (Drew $\&$ Walker, 2010). The call taker who dispatches emergency services ratifies this entitlement, treating the caller as legitimately in need of help (Larsen, 2013). Examining how participants use identity to accomplish action demonstrates how they understand the relationship between identity and help. 
In the analyses below, I also draw on the tools of membership categorisation analysis to examine participants' orientations to identity and help. Membership categories (e.g. victim) are stores of common-sense knowledge about what people are like and how they behave (Sacks, 1979; Schegloff, 2007a). Certain actions are category-bound activities which members treat as expectable and proper for incumbents of certain categories (Sacks, 1972a). For example, seeking help from Victim Support is a proper activity for victims, but not for members of other categories. Membership categorisation devices (collections of categories and rules of application) provide analytic tools to examine how participants build the link between identity and action. For example, the categories victim and offender are part of a collection of categories 'parties to a crime.' Rules of category-application mean categorising one person (e.g. as a victim) can infer the category membership of another. In police interrogations, categorising victims makes suspects' own categorical membership relevant (Watson, 1983; Wowk, 1984). These categories are consequential for the allocation of blame, or the provision of support, by constructing different versions of reality in which these actions are accountable.

\subsection{SELF-OTHER RELATIONS AND MORAL ACCOUNTABILITY}

The relationship between the 'self' and an 'other' is a basic unit of sociality fundamental to much psychological research (e.g. Hoorens, 1995; Perloff \& Fetzer, 1986). Interaction requires at least two people so is a key site where self-other relations are displayed, leading Edwards (1995) to argue that analysing conversation is social psychology. Conversation analysis and membership categorisation analysis provide grounded empirical methods to examine self-other relations in social interaction. Self-other relations are inexorably tied to building joint understanding and accomplishing coordinated actions such as help. Conversation analytic research has used the terminology of 'self' and 'other' to document the methods

participants use to resolve troubles of speaking, hearing, and 
understanding in the social organisation of repair (Schegloff, Jefferson, \& Sacks, 1977), and the methods participants use to seek and offer help in the social organisation of recruitment (Kendrick \& Drew, 2016).

Seeking or giving help are actions which configure selfother relations. Participants in interaction treat the self-other relations of help as accountable in two different ways. First, self-other relations are a resource to make help intelligible. Participants design their actions to be recognisable to others. Garfinkel (1967) called this accountability in the sense of intelligibility of action. Participants can use their sense of who they are to each other to determine if someone is asking for help, or to understand certain actions as help. Second, help configures self-other relations in morally accountable ways. Participants orient to certain ways, times, and people to properly ask for help, with the possibility of improper help being called to account (cf. Robinson, 2016). In the section below, I first discuss the social organisation of self-other relations in terms of knowledge, power, and

emotion. Next, I discuss how participants' orientations to accountability can be observed in both the sequential and categorical organisation of help.

\subsubsection{Social organisation of knowledge, power, and emotion}

Participants' sense of who they are to each other (their identities and self-other relations) are a central resource for building and interpreting actions. Stevanovic and Peräkylä (2014) posited that self-other relations are anchored in three orders: knowledge, power, and emotion. Briefly, the epistemic order refers to the connections between people based on knowledge. Participants negotiate who they are and what they are doing by managing their rights to own and express knowledge (Heritage, 2012; Heritage \& Raymond, 2005; Mondada, 2013a). The deontic order refers to the social organisation of power or authority. Deontics refers to the relations between people in terms of "rights and obligations in requesting for, deciding about, 
and performing actions in the world" (Stevanovic \& Peräkylä, 2014, p. 190). The emotional order refers to participants' rights to own certain emotions and express them to others. This theoretical framework conceptualises the basis of self-other relations and links self-other relations directly to action.

The management of knowledge, or epistemics, has received the greatest analytic attention of the three orders. Participants negotiate who they are to each other through rights to knowledge, in what Raymond and Heritage (2006) called the epistemics of social relations. Participants reflexively constitute links between identities, rights, and responsibilities when they negotiate who can accountably know what, and their rights to articulate this knowledge. People are ordinarily understood to have privileged access to their own experiences, and the accompanying right to define their identities and experiences (Sacks, 1984). However, institutional representatives have category-bound knowledge and expertise which exerts rights to determine who others are and what help they need. Many institutional encounters are characterised by tensions between participants' respective rights to knowledge. For example, in medical interaction, patients know more about their personal experiences, but medical professionals may know more about why patients feel the way they do and what is wrong with them (Heritage \& Robinson, 2006). I explore a similar tension in calls to Victim Support, where what participants know and who they are carries consequences for access to help.

Knowledge is often closely related to power, and a burgeoning field of research investigates links between epistemics and deontics. Research has examined how deontic rights are negotiated when parents direct their children (Antaki \& Kent, 2015; Craven \& Potter, 2010), when patients and doctors decide how treatment should be carried out (Lindström \& Weatherall, 2015), and when colleagues jointly determine upcoming work tasks (Stevanovic \& Peräkylä, 2012). In institutional contexts, such as helpline calls, 
institutional representatives routinely claim deontic rights to determine whether and how help will be provided (Butler, Danby, Emmison, \& Thorpe, 2009a; Potter \& Hepburn, 2003). Participants' respective rights to determine what will happen are particularly salient in gate-keeping encounters, where institutional representatives enact authority to determine help-seekers' eligibility (Heritage \& Clayman, 2010a). These negotiations are a key focus of my analyses and are discussed further in the following chapter.

The role emotion plays in configuring self-other relations and accomplishing action is less understood than knowledge or power. However, there is a long history of discursive psychological research on emotion as a psychological state built through talk (Edwards, 1999). Discursive psychology has demonstrated how emotions like pain, upset, or surprise are interactional achievements rather than purely physiological responses (La, 2018; Weatherall \& Stubbe, 2015; Wilkinson \& Kitzinger, 2006). Documenting where and how emotions are displayed - such as how crying occurs relative to talk (Hepburn \& Potter, 2017) - has demonstrated the way emotions are organised in interaction (see also Ruusuvuori, 2013). However, the nature of the links between social relations, emotion, and action are ripe for further exploration.

My analyses explore how participants negotiate their rights to own different emotions and display them to different recipients. Events in certain domains of experience are culturally expected to have certain emotional valences for people based on their social positions (Stevanovic \& Peräkylä, 2014). For an event like victimisation, victims, witnesses, and news-readers have different emotional rights by virtue of their identities or social positions relative to the event. Victims' rights to express emotions or receive emotional help likewise depend on who they are relative to their recipient. For example, Lamb (1999a) pointed out that victims of sexual violence are expected to display emotions of distress and trauma, while the expression of anger can impede victims' access to 
public sympathy and help. Conversely, victims who do not express emotions in the context of Victim Support can be seen as emotionally repressed and potentially at risk of becoming perpetrators (Löfstrand, 2009b). I further these lines of enquiry by examining how participants negotiate emotions when the help available is emotional support.

Negotiating the boundaries of knowledge, power, and emotion is an intrinsically normative and moral enterprise. When asking for help, participants negotiate who they are to each other, and the associated moral matters of need, imposition, obligation, and entitlement. Below, I discuss participants' orientations to the accountability of how, when, and who to ask for help.

\subsubsection{Sequential organisation of help}

Sequential organisation displays participants' orientations to the moral accountability of seeking and providing help to others. How participants ask for help, and when they do so demonstrate their understandings that help configures social relations in morally accountable ways.

A basic way help can be accomplished in interaction is through the social actions of requesting and offering. Conversation analysis has documented how help is sequentially organised in interaction through the mechanism of adjacency pairs (Schegloff, 2007b). For example, a request is a first pair part produced by one participant. This action makes relevant a second pair part from a recipient which can either grant or deny the request. The sequence of first and second actions can occur with or without verbal conduct (Clark, 2006; Drew \& Kendrick, 2018; Mondada, 2014a) and appears to be a primordial form of social interaction shared with our ape relatives (Rossano \& Liebal, 2014).

All first pair parts constrain recipients' actions by making a second pair part conditionally relevant (Schegloff, 2007b). However, requests impose on recipients by constraining future actions beyond 
the next turn of talk. Making a request thus claims deontic rights to direct another's actions (Stevanovic, 2011). In some cases, the imposition posed by a request may be small, as a recipient can respond by simply handing over an object (Zinken \& Ogiermann, 2013). In other cases, requests may involve elaborate future plans that involve substantial effort (Stevanovic \& Peräkylä, 2012). Research has shown that requests vary systematically based on the kind of help sought (Drew \& Couper-Kuhlen, 2014). In my data, callers request help in the form of emotional support or practical advice that will be provided later, by a different participant. Thus, the moral matters of constraint, obligation, or imposition vary depending on what is being asked for.

The preference organisation of adjacency pairs (Schegloff, 2007b) demonstrates participants' orientations to the moral accountability of seeking and providing help. Different kinds of second pair parts (e.g. granting vs. denying a request) are asymmetrically structured. Responses which advance the action (i.e. granting a request) are preferred second pair parts. This preference is not a matter of participants' motives or desires (in the vernacular sense of preference), but the structural relationship of different parts of the sequence. Structurally preferred responses tend to come without delay, while dispreferred responses like denial or rejection are typically delayed and mitigated. For example, granting a request can occur with a simple agreement token ("yes") or by handing over an object (see Drew \& Couper-Kuhlen, 2014). By contrast, denying a request is usually delayed, mitigated, and accounted for (see Schegloff, 2007b, pp. 64-65). The normative interactional preference is thus organised to promote social cohesion by making actions that further help structurally preferred and providing systematic ways for participants to minimise the social threat of denying another's request.

Schegloff (2007b, p. 82) noted that, when "accomplishing the transfer of something of value - whether object, service, or 
information - from one person to another, there appears to be a preference for offer sequences over request sequences." He suggested that requests are dispreferred first pair parts that are regularly delayed, mitigated, or disguised as other actions entirely. In some cases, participants may 'fish' for an offer rather than making a direct request (cf. Pomerantz, 1980), or requests may be disguised as other actions entirely, such as offers or proposals for joint action (Levinson, 2013). Yet Kendrick and Drew (2014) challenged the evidence supporting Schegloff's claims. Although Schegloff suggested requests are regularly delayed and mitigated in conversation, Kendrick and Drew showed that requests can frequently come in first position, such as the reason for a call. Likewise, in Chapter 5, I analyse callers' requests for help that occur in their first turn of talk.

Instead of a straightforward preference, Kendrick and Drew (2014) argued that requests and offers have a symbiotic relationship. Requests index a problem facing the speaker and present the recipient with a solution to carry out. The conditional relevance of adjacency pairs means recipients face a normative obligation to grant or deny the request (and the solution to the problem contained within). Alternatively, speakers can report or display a problem, and recipients may offer possible solutions. Recipients thus have an opportunity rather than an obligation to help and can determine a possible solution to the problem themselves.

In subsequent work, Kendrick and Drew (2016, p. 2) proposed the concept of recruitment to analyse help in the form of "actions by one person that may resolve troubles or difficulties in the progressive realization of a practical course of action by another." Verbal requests are the most explicit method of recruiting assistance. Requests are instances of self-initiated recruitment where the speaker identifies the solution and recruits a recipient to do it. Other recruitment methods, such as embodied displays of trouble, indicate a need for help without asking for it directly (Drew \& Kendrick, 2018). These methods provide an opportunity for other-initiated 
recruitment where recipients identify a need for help, determine a solution, and then provide it. Thus, different ways of recruiting help organise different relationships and obligations between participants.

Participants' orientation to different times, or sequential positions in interaction, to properly seek help also displays their orientation to moral accountability. When others are present, participants regularly engage in self-help (such as looking for items) before asking for help (Kendrick \& Drew, 2016). Publicly displayed attempts at self-help provide an opportunity for others to provide help, but if this does not occur, participants can accountably ask for help. Asking others without attempting self-help can be sanctioned (cf. Heritage, 1990; Robinson, 2016). The normative expectation for self-help is particularly salient in institutional contexts (discussed in more detail in the following chapter). When calling institutions for help, callers regularly describe their attempts at self-help to account for why they are calling (Edwards \& Stokoe, 2007). These descriptions can be pursued by institutional call-takers who treat them as a necessary precondition before help can be given (Edwards \& Stokoe, 2007). Thus, participants treat seeking help as morally accountable only after attempting to resolve the problem alone.

\subsubsection{Categorical organisation of help}

The moral accountability of help is grounded in rights and obligations associated with different membership categories. Sacks' (1967, 1972a) seminal analysis of a suicide helpline showed that categories provide an organised system of moral accountability for help-seeking. In contrast to the immediate helping that takes place in co-present interaction, like passing an object or lending a hand (Kendrick \& Drew, 2016), deciding who to turn to for problems like feeling suicidal involves consideration of categorical rights and obligations. The categorical organisation of help is key to my analyses, particularly in Chapter 7, and so here I detail Sacks' categorical framework. 
In a series of analyses, Sacks $(1967,1972 a)$ examined how callers to a suicide helpline could claim they had 'no one to turn to' even while talking to the call-taker. Callers' claims indicated they had conducted a search for help, which Sacks argued, is normatively and morally organised through membership categories. The search for help is organised by a collection of relationship categories (R). This collection is made up of paired relational categories (e.g. husbandwife, friend-friend, stranger-stranger) which are standardised as "a locus of rights and obligations concerning the activity of giving help" (Sacks, 1967, p. 203). Some pair members have a proper obligation to provide help (denoted as $\mathrm{Rp}$ ) and the right to be turned to by a pair member in need. Members of other relational categories lack these rights and obligations and are thus improper to turn to (Ri). By claiming they had 'no one' - no present or available members of Rp categories - callers accounted for seeking help from the call-taker, a stranger who would be normatively improper to turn to.

The rights and obligations regarding different kinds of help are organised with reference to different categories. Services such as helplines operate on the assumption that certain kinds of problems (such as suicide or victimisation) require professional help. Yet even though helpline counsellors may see themselves as professionals with proper knowledge and expertise about problems like suicide, callers can categorise them as strangers whom it is improper to turn to (Sacks, 1972b). The same dilemma is apparent in the case of caregiving. In some cases, caring for patients is an activity bound to professional membership, while in others, participants treat caring as a right and obligation of family members (Hunt, 1991; Izumi, 2017). Likewise, the kind of help Victim Support offers - emotional support and practical advice - can be bound to professionals who have the necessary expertise to deal with victimisation; or bound to friends and family members who have the rights and obligations to support someone after a traumatic experience. In the analytic chapters, I explore how participants orient to and manage this ideological 
dilemma (Billig et al., 1988), particularly when seeking help on behalf of others.

\subsection{SUMMARY}

This introductory chapter has charted some of the different ways social psychology has conceptualised the relationship between identity and action. In this thesis, I adopt the theoretical framework of discursive psychology, using the tools of conversation analysis and membership categorisation analysis to analyse how participants understand and use the link between a victim identity and help in social interaction.

Social psychology largely investigates the link between identity and help using Social Identity Theory and Social Categorisation Theory. These cognitivist theories explain how individuals' membership in different groups influences how they understand themselves and perceive others when making decisions whether to help. Identities are internal states and cognitive processes (such as perceptions, beliefs, or categorisation schema) that have a determining influence on behaviours like help. In contrast, discursive psychology examines the relationship between identity and help by analysing how people display who they are to each other when building of intersubjectivity and accomplishing of action. Through talk in interaction, people construct psychological phenomenon like identities and use them to accomplish action. Rather than conceptualising help as intended or motivated behaviour, discursive psychology approaches help as action, and analyses how different constructions of identity are used to accomplish help in different ways.

Drawing on conversation analysis and membership categorisation analysis, I examine how participants accomplish the link between identity and help in social interaction. Conversation analysis provides a rigorous empirical method to examine the 
relationship between identity and help in interaction. Participants' orientation to who they are to each other is a resource to build and interpret actions. Thus, identity - for participants - is inexorably bound to action. The action of help has been conceptualised in terms of requests and offers, and the organisation of recruitment in interaction. Membership categorisation analysis likewise provides a systematic way to observe how participants invoke the relationship between identity and action. Identity is conceptualised in terms of membership categories, which are linked to actions through category-bound activities, and the ways that participants use identity categories to accomplish and account for different actions.

The relationship between identity and help is inherently a moral one, and particularly so when the salient identity is victim. When participants invoke the link between identity and help in interaction, they orient to the moral accountability of help and the way that help constitutes self-other relations. Negotiating social relations in interaction is a fundamentally psychological enterprise, bound up with considerations of need, imposition, obligation, relationships, and so on. In the analytic chapters, I use the tools of conversation analysis and membership categorisation analysis to examine how participants constitute self-other relations in terms of the epistemic, deontic, and emotional orders, and use these self-other relations to render seeking, giving, or denying help as morally accountable actions. 


\section{LITERATURE REVIEW}

In the previous chapter, I discussed how help configures self-other relations in morally accountable ways. Here, I extend that discussion to show how help can "constitute social relationships and social contexts" (Lindström, 2005, p. 213).

The ways help is accomplished and treated as morally accountable varies based on participants' understanding of who they are to each other, what they are doing, and the social context of their interaction. Below, I first briefly discuss the relationship between help and identity in everyday, or mundane, contexts. Everyday encounters demonstrate that help is a basic part of social life (Kendrick \& Drew, 2016). However, the data I analyse in this thesis are calls to Victim Support. These data are instances of institutional interaction, where participants orient to identity and help in different ways. In this chapter, I discuss how a grounded approach to context can demonstrate how participants use the relationship between identity and help to constitute social contexts such as the Victim Support helpline.

Although there are no interactional studies of victim support services to date, interactional research from a range of different institutional settings has demonstrated some of the fundamental challenges for accomplishing help. My analyses draw heavily upon insights from research on emergency dispatch and helpline calls. In the second half of the chapter, I discuss how participants' orientations to knowledge, power, and emotion provide ways to examine the moral accountability of institutional help.

\subsection{EVERYDAY HELP AND SOCIAL RELATIONS}

Through everyday methods for accomplishing help, participants negotiate self-other relations and moral accountability. Different ways of seeking and providing help are resources for 
participants to configure social relations between themselves and others. Research within the field of interactional linguistics has identified recurrent linguistic forms, or social action formats, for the actions of requesting and offering help (Drew \& Couper-Kuhlen, 2014).

Even from a young age, participants are sensitive to the ways that self-other relations can be managed through different request forms. For example, Wootton (1981) demonstrated that fouryear-olds distinguished between question request forms (e.g. "can I have that?") and declarative statements (e.g. "I want it!"). After having an initial request turned down by their parents, children chose between alternatives in strategic ways. Using a question request form orients the recipient's authority to grant or deny the request, while using a declarative denies the rejection and the recipient's rights to make it. Likewise, different request forms can highlight a speaker's entitlement to help, or the contingencies associated with granting it (Curl \& Drew, 2008). Asking for help can be accomplished in different ways, and participants choose between alternatives to manage their identities, their relationship with their recipient, and their expectations about how help can be given.

When offering help, participants use different social action formats to foreground themselves as help-givers or recipients as help-receivers. Participants use different offer formats in different sequential positions to constitute self-other relations. Curl (2006) found that participants used conditional if-then formats to present offers as the reason for the call, interrogative formats when they determined a problem from prior talk, and offers matched to recipients' needs if their recipients made this explicit. Designing offers in different ways displays participants' orientations to their own and others' needs, desires, willingness, and ability (see also Clayman \& Heritage, 2014). 
Through offers and requests, participants constitute who they are to each other. Likewise, different methods of recruiting assistance configure different self-other relations (Kendrick \& Drew, 2016). Although participants demonstrably orient to the moral accountability of help in everyday interaction, these considerations are particularly salient (and consequential) in different social contexts.

\subsection{CONSTITUTING SOCIAL CONTEXTS}

Just like identity, I conceptualise context as a participants' phenomenon. Rather than treating context as a fixed property that shapes interaction, in this thesis, I treat context and action as interdependent. The ethnomethodological stance on context holds that context is both the project and product of participants' actions (Heritage \& Clayman, 2010c). In other words, participants orient to and constitute context through interaction. In this section, I discuss the mutually constitutive relationships between identity, help, and social context. I begin with research that highlights the link between identity and help in online support forums, before turning to institutional contexts with similarities to Victim Support.

\subsubsection{Identity and help online}

A growing body of discursive work has adapted the tools of conversation analysis and membership categorisation analysis to examine how participants orient to the link between identity and help online. In online forums, participants use identity claims to seek membership in support groups, account for seeking help, and to provide support to others (Giles, 2006; Lamerichs \& te Molder, 2003; Smithson et al., 2011a).

Specialised support groups define themselves by the kinds of people and problems that can be helped. Thus, for many online support groups, identity claims function as tickets to entry. For example, on a bipolar support forum, newcomers use their recent 
diagnosis to account for seeking help (Vayreda \& Antaki, 2009). On eating disorder recovery sites, users must accept their condition as an illness to get help (Riley, Rodham, \& Gavin, 2009). Identifying in different ways, such as glamorising eating disorders or claiming not to have a problem, are treated as problematic for access to group membership (Stommel \& Koole, 2010).

The ways forum members ask for help constitutes both their own and others' identities. On suicide support forums, members face the challenge of presenting themselves as authentically suicidal to establish their legitimacy to belong. Claiming to be suicidal can be dismissed as a cry for help (see Sacks, 1972b), in much the same way that claiming a victim identity may be dismissed as a self-interested way to seek help (see McNeill et al., 2017). To manage this dilemma of stake (Potter et al., 1993), posts on a suicide support forum regularly avoided asking for help directly, and instead worked up a suicidal identity by demonstrating being psychologically 'on the edge' (Horne \& Wiggins, 2009). Not asking for help lowered the obligation for others to respond, constructing their identities as potentially also 'on the edge' and possibly incapable of offering help. However, as is the case in many support forums, simply identifying in a relevant way was treated as seeking help, with other members responding with empathy, advice, and pleas to 'hang on' (see also Smithson et al., 2011b; Vayreda \& Antaki, 2009). Negotiating moments of crisis by ignoring or acknowledging others' responses allowed forum members to seek support while maintaining their own and others' identities as authentically suicidal (Wiggins, McQuade, \& Rasmussen, 2016).

Online communities construct identities for members through the collective maintenance of group norms and shared understandings (Giles, 2006). For example, Giles and Newbold (2013) found many posts on a peer mental health forum were concerned with what predicates could be associated with the category depression. By enquiring whether activities or experiences were 
normal, members jointly constituted shared community knowledge about what it means to be depressed. My analyses likewise examine what predicates and activities participants build as normal for victims.

\subsubsection{Institutional help}

Identity categories - and their associated rights, obligations, activities and attributes - are a key resource for participants to accomplish help in institutional settings (Psathas, 1999), where "considerations of roles, responsibilities and entitlements are foregrounded" (Evans \& Fitzgerald, 2016, p. 209). Below, I discuss how the relationship between identity and help is a key way institutional contexts are "talked into being" (Heritage, 1984b, p. 290).

Participants constitute institutional contexts through their understanding of the relationship between identity and help. For example, in the social context of caregiving, senior citizens and home-help providers jointly negotiate entitlement. Senior citizens make imperative requests to claim entitlement to help for some tasks, and question requests when the task may fall outside the remit of home-help's role (Lindström, 2005). Negative interrogatives (e.g. "can't you turn on the light?") display an expectation the home-help can help and ought to have done so, while positive interrogatives (e.g. "may I ask to get a bit further into the chair?") suggest the request is beyond the home-help's domain (Heinemann, 2006). Thus, the format of requests displays participants' understandings of who they are to each other in relation to the social context.

Participants' orientation to institutional context is a resource to build and interpret requests. In some cases, people can be understood as requesting help even before they begin speaking. The inferential framework of emergency calls means that calling is treated as a request for help (Wakin \& Zimmerman, 1999). Call-takers 
display a default presumption that each call is a virtual emergency and may call-back or even dispatch units before hearing a caller's request (Zimmerman, 1992). Because there is only one form of help available, and shared common-sense knowledge about when to call, emergency call-takers can determine what help callers need and how to provide it from a call alone. In other contexts, call-takers need more details to determine what kind of help callers are seeking. For example, helpline call-takers display an understanding that callers are seeking help even before a request is formulated. However, callers can resist this link between identity and action, such as by categorising themselves as ordinary people with everyday needs rather than seekers of institutional services (te Molder, 2005). Thus, the link between identity, help, and social context is an interactional accomplishment.

Participants can determine who they are to each other vis à vis the institutional context they are operating in. In emergency calls, call-takers typically ask questions and callers answer them (Zimmerman, 1992). Sometimes, however, such as the case of an ongoing forest fire, the flow of information between participants can be altered. Raymond and Zimmerman (2007) found that callers sought information and advice from call-takers regarding if they knew about the fire, where it was heading, and whether they should evacuate. Even though these requests reconfigured the relationship between participants, participants jointly oriented to them as deviations from the norm, re-instating the normative framework of the institution. Thus, institutional contexts do not determine participants' conduct, but provide a resource to understand who they are to each other and what they are doing.

\subsection{THE MORAL ACCOUNTABILITY OF INSTITUTIONAL HELP}

As mentioned in the previous chapter, participants orient to the moral accountability of turning to strangers for help (Sacks, 1967). In this section, I first discuss how prior research has examined 
the accountability of institutional help. Then I review how self-other relations can used to accountably seek and offer help in terms of knowledge, power, and emotion.

One well-documented way to accountably seek help is to present a relevant institutional problem. For example, medical helpseeking requires a 'doctorable' problem (Heritage \& Robinson, 2006), calling the police requires a 'policeable' problem (M. Whalen \& Zimmerman, 1990), seeking mediation services requires a 'mediatable' problem (Edwards \& Stokoe, 2007), and so on. Participants orient to the moral accountability of help by treating institutional help as relevant only for people with certain kinds of problems.

When callers lack familiarity with the service, they may face difficulties in presenting a relevant problem (Stokoe, 2013a). A further tension, of particular relevance to the Victim Support helpline, is that participants do not always agree on what constitutes a relevant problem (Rønneberg \& Svennevig, 2010). In calls to Victim Support, determining a joint understanding of an institutionally relevant problem can be difficult. Callers' understandings of the help they are entitled to do not always align with call-takers' understandings of the institutional limitations on the help that can be given.

Participants orient to the moral accountability of seeking different kinds of help from institutions. Problems like raising children, managing finances, or dealing with neighbours do not have the same common-sense status as medical problems or emergencies. One reason is that not everyone is encouraged to seek help in this context, with institutions instead targeted to 'at risk' individuals (Broadhurst, 2007). Another reason is that people are expected to manage their mundane problems in life, "at least before those troubles are medicalized or legalized or technicalized in some way" (Edwards $\&$ Stokoe, 2007, p. 10). Participants orient to the accountability of their problem when seeking help. For example, when asking to 
renegotiate a student loan contract, callers oriented to the moral inferences that could be drawn about them (Ekström, Lindström, \& Karlsson, 2013). Seeking help from Victim Support can pose similar dilemmas. On the one hand, feeling upset after a traumatic experience, or needing advice about what to do can be understood as mundane everyday problems that callers might be expected to solve themselves. On the other hand, victims' need for support has been formalised in Victim Support's mandate. My analyses examine how participants orient to the accountability of seeking this kind of help.

Presenting a relevant problem - particularly for an institution named Victim Support - is linked to callers' identities. To accountably seek help, callers must present themselves as the right kind of person with the right kind of problem. Negotiating callers' relevant identities and what help they need is a fraught moral enterprise when the relevant identity is victim. However, other institutions face similar challenges in establishing joint understandings of who callers are and what they need. For example, MensLine is an Australian relationship helpline that identifies clients as men and offers solution-focused counselling based on the presumption men want instrumental help rather than emotional support. Yet many callers claim they simply want to talk (Feo \& LeCouteur, 2013). Similarly, the Kids Help Line identifies clients as children and offers child-centred counselling based on the presumption children can make their own decisions. Counsellors make these philosophies manifest when they let callers decide how to present their problems and avoid giving direct advice (Butler, Potter, Danby, Emmison, \& Hepburn, 2010; Danby, Baker, \& Emmison, 2005), but not all callers are seeking to be empowered, and some ask for help directly (Butler et al., 2010; Emmison \& Danby, 2007a).

Self-other relations are a resource for participants to reason about the accountability of institutional help. Below, I overview research that has documented how participants' orientations to 
knowledge, power, and emotion shape the ways help is sought and provided.

\subsubsection{Knowledge and rights to help}

The epistemic order is a resource for participants to understand callers and their requests for help. For example, when seeking emergency assistance, callers regularly establish the basis of their knowledge (e.g. being within eye- or ear-shot) and their social relationship to the problem (M. Whalen \& Zimmerman, 1990). Claiming different social identities makes relevant different motives and entitlement for seeking help. For example, a shop-keeper whose store has been vandalised, a resident who heard shouting from a nextdoor apartment, or a passer-by who noticed something suspicious are treated as having different motives for calling. Call-takers question callers about what they know and how, and may deny requests if callers cannot sufficiently account for their knowledge (Cromdal, Osvaldsson, \& Persson-Thunqvist, 2008; Fele, 2014; Heritage \& Clayman, 2010a).

Likewise, on a child protection helpline, young callers claimed first-hand knowledge to present claims of abuse as factual and accounted for seeking help by categorising themselves as friends (Hepburn, 2005). In contrast, adult callers claimed to be concerned third parties, disavowing first-hand knowledge of abuse that would potentially incriminate them (Potter \& Hepburn, 2003). Call-takers use the social organisation of knowledge to reason about identity and accountability, such as whether a call is genuine or a prank (Emmison \& Danby, 2007b; Hepburn, 2005). In the analytic chapters which follow, I likewise analyse how participants orient to their respective rights to knowledge when building and interpreting requests for help.

Common-sense knowledge is another resource to build understandable requests for help. The shared nature of common-sense means both callers and call-takers can reason about who callers are 
and why they are seeking help. For example, on a radio counselling line, participants used normative meanings associated with age to jointly reason about callers' problems and possible solutions (Thell \& Jacobsson, 2016). Likewise, stage-of-life and family categories are resources for callers on the Kids Help Line to present activities like caring for other children or worrying about money as non-normative and burdensome when accounting for calling (Danby et al., 2015). Because expectations about normative activities for children are culturally shared, counsellors can use the same categorical reasoning to validate callers' experiences and propose solutions (Cromdal, Danby, Emmison, Osvaldsson, \& Cobb-Moore, 2018). Thus, common-sense knowledge about the link between identity and help is a way for call-takers to identify who callers are and the kind of help they need. However, common-sense is contradictory (Billig et al., 1988), meaning participants can draw different common-sense conclusions about victims and their needs for help.

In seeking and providing help, participants jointly negotiate their respective knowledge and expertise. Participants invoke their relative territories of expertise (and thus participants' social relations) through the words they choose to describe problems. For example, callers to a software helpline presented themselves as competent technical users by recounting how they noticed the problem and what they attempted to do, while orienting to call-takers' expertise to recognise anomalies and determine the cause of the problem (Baker, Emmison, \& Firth, 2001). On a birth crisis helpline, a call-taker's choice between technical or vernacular vocabulary likewise displayed expectations of what her recipient would know (Kitzinger \& Mandelbaum, 2013). Using technical terminology constructed a shared social identity for caller and call-taker as experts, while vernacular descriptions displayed the call-taker's expectation the caller would not understand, constituting her identity as a comparative novice (Celia Kitzinger \& Mandelbaum, 2013). Thus, 
different rights to knowledge can constitute participants' identities and the social context of institutional help.

\subsubsection{Determining how help will be given}

Determining if or how help will be given involves deontic considerations of who participants are to each other. Participants' deontic rights to determine interactional outcomes are often closely linked to epistemic considerations of who callers are and what they need.

Advice is one form of help which has received sustained analytic attention for the way it invokes self-other relations. In institutional contexts, deontic asymmetries between participants can be observed in the ways advice is sought, provided, or avoided. When callers tell their troubles, they invoke the reciprocal categories of troubles-teller and troubles-recipient (Jefferson, 1988). These categories provide rights, obligations, and relevant actions which are quite different from those associated with the categories of adviceseeker and advice-provider that often structure service encounters (Jefferson \& Lee, 1992). Thus, when callers tell troubles, institutional representatives can be faced with a dilemma: focus on the problem and its properties by giving advice; or attend to the person and their experience by affiliating as a troubles-recipient. Call-takers handle this dilemma differently in different contexts. For example, calltakers on a peer mental health line respond to callers as troublesrecipients to present themselves on an equal footing (Pudlinksi, 2005). Likewise, counsellors on the Kids Help Line avoid giving advice to defer to callers' authority to solve their own problems (Butler et al., 2010; Emmison, Butler, \& Danby, 2011). Conversely, MensLine's philosophy of solution-focused counselling means calltakers orient to their relevant identities as advice-givers rather than troubles-recipients (Feo \& LeCouteur, 2013). 
One recurrent dilemma for institutional representatives is managing requests that cannot be granted. The ways this dilemma is managed constitutes different institutional contexts and social relations. In commercial service encounters, call-takers specify or alter callers' requests in ways that allow them to be granted (S. Lee, 2011), orienting to callers' entitlements as customers. In calls to police or emergency services, call-takers deny requests if callers cannot sufficiently account for their need, orienting to their deontic authority to determine whether and how help is given (Heritage \& Clayman, 2010a; Rønneberg \& Svennevig, 2010). On helplines where call-takers are barred from giving advice, call-takers can invoke their categorical membership to account for the limits of their knowledge when callers ask for advice directly (Butler et al., 2009a), present courses of action as already known to callers (Moore, 2016), or suggest advice in mitigated ways, such as script proposals or advice-implicative interrogatives (Butler et al., 2010; Emmison et al., 2011). These responses allow call-takers to maintain their identities as supportive listeners and callers' identities as autonomous individuals with the rights to decide what to do. Thus, in commercial, emergency, or helpline interaction, call-takers invoke relevant institutional self-other relations by responding to requests in ways that invoke the kind of help available in context.

When participants have different understandings of the nature of the help available and how it can be asked for, fateful consequences can arise. For example, in the infamous 'Dallas call,' a caller requested an ambulance, but did not describe the problem, displaying an expectation that his request alone was sufficient to demonstrate his need for help (J. Whalen, Zimmerman, \& Whalen, 1988). The call-taker, however, treated a description as necessary before the caller's request could be granted. The subsequent disagreement between caller and call-taker fatally delayed the provision of help, showing the life-and-death consequences of participants' negotiation of the nature of help in institutional calls. 


\subsubsection{Displaying and responding to emotion}

Institutional interaction is characterised by emotional asymmetry. Callers may be seeking help for a rare or urgent lifeevent, while call-takers are carrying out the routine tasks of their workday (Zimmerman, 1992). Displays of emotion show callers' stance on the problem they are seeking help for and can account for why they are seeking help (Weatherall \& Stubbe, 2015). However, displays of emotion regularly pose interactional difficulties for institutional representatives.

In institutional calls, participants display different understandings of the relevance of emotion. For example, in emergency calls, callers' displays of emotion (such as swearing, shouting, or pleading) demonstrate their assessment of the seriousness of events and their need for help (Heritage \& Clayman, 2010c). Yet callers' emotional displays can impede their ability to talk - stalling the progress of the interaction and the call-takers' ability to provide help. Call-takers treat emotion as a barrier to institutional tasks when they label callers 'hysterical' to account for their inability to record the necessary details (J. Whalen \& Zimmerman, 1998).

Research has demonstrated the different strategies institutional representatives use to respond to callers' displays of emotion. On a child protection helpline, call-takers use 'take your time' responses to encourage callers to return to description after they are overwhelmed by crying (Hepburn \& Potter, 2007). Call-takers' displays of empathy or sympathy accounted for callers' rights to their emotions, while nonetheless orienting to the relevance of ongoing institutional business (Hepburn \& Potter, 2017). Yet in other institutional contexts, such as a dispute resolution service, call-takers avoid responding to callers' emotional displays. Callers use emotion to legitimise their complaints, but call-takers edit out emotion when reformulating callers' problems (Weatherall \& Stubbe, 2015). Call- 
takers' orientation to their (lack of) emotional rights is a key way the neutrality of the institution was talked into being (Weatherall, 2015).

Interactional research has largely examined the difficulties emotional displays can pose for accomplishing institutional help. However, in my analyses, I examine how emotional displays - and participants' orientation to emotional rights - constitutes identities and self-other relations that make help accountable.

\subsection{SUMMARY}

Interactional research has documented how help is accomplished in different settings. In this chapter, I have reviewed some of the ways help can constitute participants' sense of who they are to each other and the context they are interacting in. In my analyses, I adopt a grounded approach to context to analyse how participants orient to the institutional character of their interaction. In line with interactional research, I aim to show how participants' orientation to identity and help is central to their understanding of the institutional context.

Determining who participants are and their relative entitlement and obligation to help is crucial to the interactional work of institutions. Although some research has addressed how participants' sense of who they are to each other shapes their understandings of what they are doing, rarely is the link between identity and help explicitly treated as a fundamental part of the work of institutional helplines. In this thesis, I aim to demonstrate how participants orient to the link between identity and help. I focus on how a victim identity is invoked and used in consequential ways to seek, provide, or withhold help. In doing so, I shed light on an underexamined activity that is essential to the work of all institutional helplines. 


\section{DATA AND METHOD}

In this chapter, I provide a background to the setting of Victim Support and the organisation of the Contact Service from which data were drawn. I overview the data collection process, how ethical issues were managed, and the way I managed the data. Discursive psychology has a distinctive analytic mentality, and in the last section I detail the analytic process, including why and how social interaction is studied, the analytic status of recordings and transcripts, and the way I identified and analysed phenomenon in interaction.

\subsection{BACKGROUND TO THE SETTING}

Victim Support is a New Zealand community organisation that provides free services including emotional support, practical advice, and advocacy to victims of crime and trauma. The organisation aims to restore victims' wellbeing and aid their journey to recovery, treating victimisation as an abnormal event that shatters victims' expectations about the world (Dunn, 2007).

The organisation is made up of paid and voluntary staff. Volunteer support workers provide services throughout the country, including at the scenes of crimes and in victims' homes. Paid staff members include contact service workers who answer calls to the helpline. Like other victim support services around the world, the distinction between paid technical work (managing incoming calls) and voluntary emotional work (providing support) obscures the way these forms of work are regularly combined (Roose, Verschelden, Vettenburg, \& Vanthuyne, 2012). As my analyses show, the work accomplished during a call is more complex than what is usually glossed as 'technical.' Although the organisation formally recognises call-takers' roles in technical terms only, empirical analysis of their work in action demonstrates a range of activities, supposedly straightforward technical tasks, and other actions that might not be expected. 
Although the organisation's definition of victim is not limited to crime, Victim Support is closely aligned to the criminal justice system. The organisation developed out of police recognition that criminal justice services overlook victims (see Taylor, 2006), a trajectory quite different from other support services with more explicitly political agenda, such as Women's Refuge (Walklate, 1989). Victim Support has close organisational links with Police. Support workers have office space in police stations and the national Contact Service is located in the Police Headquarters building. Nearly $80 \%$ of referrals for support are made by police officers, and the organisation uses police reference codes to classify incidents. Thus, even though the organisation nominally recognises victims of trauma, trauma is codified as incidents such as witnessing a traffic accident, experiencing a natural disaster, or losing a loved one to suicide. People with experiences that cannot be neatly categorised as incidents (particularly salient in the case of domestic violence or other ongoing patterns of behaviour) face difficulty accessing support, as my analyses later in this thesis show (see also Tennent \& Weatherall, 2019).

The data site for my research is the Victim Support Contact Service, a comparatively recent development in the organisation's provision of support. Volunteers have been providing support to victims since 1986, with the service nationalised in 2004. The Contact Service was opened in 2010 to manage increasing demand. The Contact Service was designed to reduce the burden on volunteers with a paid team of trained call-takers to manage incoming calls. The Contact Service operates 24 hours a day, seven days a week and manages phone lines for police, staff, and members of the public.

The two public phone lines managed by the Contact Service are the Victims of Crime Information line and 0800 Victim. Victim Support manages the first of these two lines under contract for the Ministry of Justice. The Ministry provides court victim advisors to victims whose cases are progressing through the criminal justice 
system, and the information line is a way for callers to contact their court victim advisors to receive information about their cases. Victim Support call-takers answer the phone and transfer callers to their court victim advisors. The second phone line is Victim Support's own phone-line, with the '0800' number designating a free phone line. Although advertised as a helpline, call-takers are not trained to provide support during calls. Instead, call-takers connect callers to support workers, transfer callers to other agencies, or allocate new clients a support worker who will contact them later.

The Contact Service is receiving an increasing number of calls. When my research began, the Contact Service manager reported over 77,000 calls were managed in 2014 with call volume increasing by $2 \%$ each month. In the most recent Annual Report, the organisation reported 128, 807 calls answered in 2018, with demand continuing to grow (Victim Support, 2018). During my meetings and observation of the Contact Service, I noticed that management and staff expressed concern at the large number of calls that were being transferred to other services. Once I began analysing data, I noticed a paradox. Although most calls are transferred, call-takers do not treat this as the proper work of the organisation. In the extract below - even while offering to transfer the caller - the call-taker (CLTKR) treats her action as accountable.

\subsubsection{Molly 2}

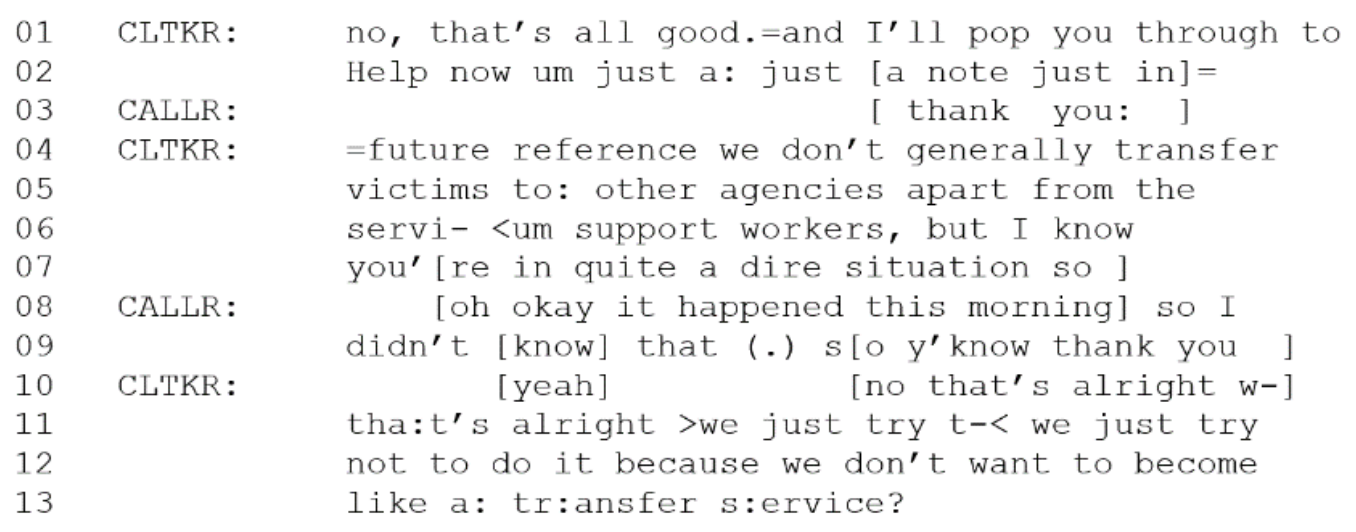


The Contact Service was designed to reduce administrative burden on volunteer support workers. Rather than contacting volunteers directly, clients call 0800 Victim, are screened by contact service workers, and then transferred to support workers. In 4.1.1, the call-taker treats this as the proper business of the phone line. Although she is about to enact a transfer to Help, a specialist sexual violence support agency, she orients to this activity as beyond the normative framework of help in this setting.

\subsection{DATA COLLECTION}

The Contact Service routinely record calls for training purposes, while volunteers' calls are not recorded. After amending their privacy agreement to allow recordings to be used for research, the Contact Service manager provided call recordings for the research. Data were collected in three samples. In total, the data set consists of 396 calls to the victim helpline, answered by 14 different call-takers. The data comprise 23 hours and 34 minutes of recording.

The first sample was collected in late 2015 as part of a summer research project. The aim of the project was to document how organisational work was accomplished during calls and some of the barriers to successful delivery of service. The Contact Service manager provided 36 recordings of calls answered by three different call-takers. The sample consisted of incoming calls to two different phone lines: 17 calls to the Victims of Crime Information Line and 17 calls to the 0800 Victim line.

After completing the summer research project and embarking on doctoral research, I collected a broader sample of call recordings. The initial sample was dominated by two call-takers and my aim was to collect more data to allow more credible claims about participants' practices and possible implications for practice. The variability of calls to the victim helpline, coupled with the fact it is the organisation's dedicated phone-line meant I decided to focus 
exclusively on calls to 0800 Victim in the second sample. The Contact Service manager provided another 23 call recordings, from eight different call-takers. With an eye to balancing a representative sample with a manageable amount of data for detailed analysis, the second data collection brought the sample of 0800 Victim calls to 40, totalling nearly three hours of recording.

The third data collection phase was a purposeful sample which I organised in consultation with the Contact Service manager. Rather than allowing the Contact Service discretion to decide which calls would be interesting for research (as the manager had admitted to doing), I decided to collect all incoming calls across a week. The Quality Assurance manager identified all recordings of incoming calls to the 0800 Victim line from Monday to Sunday. I visited the Contact Service three times during the week to collect data on an encrypted USB drive. This third data collection yielded 356 calls, handled by 14 call-takers. Calls range in length from 15 seconds to up to 20 minutes, although over half of the total sample are less than two minutes long.

\subsection{ETHICS AND CONFIDENTIALITY}

The research was granted ethical approval by the School of Psychology Human Ethics Committee under delegated authority of Victoria University of Wellington. The Contact Service amended their pre-recorded message and online privacy statement to inform callers that recordings could also be used for university research. Before their call was answered, callers heard a message informing them their call would be recorded. Callers could request recording be halted at any point. Only in three cases in the data did callers refer to the recording, and despite two offers by call-takers, they consented to the recording continuing. Call-takers provided written consent to have their call recordings included in the research sample. I informed call-takers that the research would focus on patterns across interactions rather than individual behaviour, and that data would not 
be used for performance evaluation. Call-takers were given the option to remove call recordings they did not wish to be included in the samples.

After collection, data were subject to two-fold anonymisation. First, I edited identifying information like names, addresses, and contact information from the sound-files. Rather than replacing the identifying talk with white noise, I reversed selected aspects of the sound-file. This has the same effect of de-identifying the data, while maintaining temporal aspects of speech (i.e. length of time; number of syllables spoken). Second, I anonymised transcripts by replacing identifying information with pseudonyms. I choose pseudonyms with the same number of syllables as the edited talk. Numbers were rearranged (e.g. seven becomes zero as they are both two syllables). I used invented names for most place names. In doing so, I maintained a distinction between English and Māori names (e.g. Westlake street might become Highland road while Hawera becomes Menara) to retain details of potential relevance to participants.

\subsection{DATA MANAGEMENT}

Each call was listened to, logged, and assigned a unique identifier. Unique identifiers consist of call-takers' pseudonym and the number of the call (e.g. Samuel 1; Claire 12). These appear in the extract names in the analytic chapters that follow. After listening to each call, I logged details in a catalogue, such as the key content of the call and a break-down of the overall structure of the call. I also listed call details in an index file. In the index, I recorded the length of each call, glossed the reason for the call, noted the incident type if mentioned (e.g. burglary, assault, arson, etc.), the outcome of the call (transfer, referral, other), and where the call was transferred to, if so (volunteer support worker, police, court victim advisor, so on).

Conversation analysis treats demographic information as irrelevant unless discussed by participants themselves. However, I 
noted the apparent gender break-down of callers in the index so as to identify phenomenon of interest (such as female callers experiencing violence, see Tennent \& Weatherall, 2019). Determining callers' gender from their voices alone is not infallible (see Wilkinson, 2011), yet is the same amount of information available to call-takers who can and do attribute gender to callers. Excluding some unclear cases, 284 callers were recorded as 'female voice' and 108 as 'male voice'. Even though the service is not gendered (in contrast to other services like Women's Refuge), female callers appear to make up nearly three quarters of the research sample.

Using the call $\log$ and index file, I identified calls of interest to transcribe. For example, I was interested in which calls were transferred to external agencies, and which calls resulted in referral. In total, 200 calls have been transcribed, totalling 11 hours and 21 minutes of recording. The average length of each call is three and a half minutes, although the longest lasts over 20 minutes.

\subsection{ANALYTIC PROCESS}

\subsubsection{Analysing social interaction}

For discursive psychology, social interaction is the object of analysis. Sacks' (1995) work challenged widely-held assumptions that real talk is too messy for systematic study and provided a rigorous empirical method for analysing talk as it occurs. Not only is it possible to study social interaction in a systematic way, social interaction is a fundamental site where psychological matters like identity, help, and social relations are built and managed (Edwards, 1995; Edwards, 2012).

In this thesis, I analysed recorded interactions between callers and call-takers on the Victim Support helpline. These calls allowed me to analyse the relationship between the psychological phenomenon of identity and help in "their home environment of live unconstrainted interaction where the parties have a genuine and 
practical stake in outcomes" (Potter, 2012, pg. 447). Calls to Victim Support are instances of naturalistic data. The calls are naturallyoccurring interactions, although the term naturalistic recognises that recorded interactions are as close as possible to interactions as they would occur. My data pass the "dead social scientists' test" (Potter, 2002, p. 541), because the interactions between caller and call-taker were not shaped by my research agenda and occurred without my intervention.

Recordings are used for conversation analysis because they ideally capture what occurred in the same amount of detail as participants themselves experienced in the moment of interaction. Rather than relying on a researcher's recollections or field notes, recordings preserve a representation of an interaction as it occurred that can be paused, repeated, and shared with others. Recordings can be repeatedly examined without changing and are thus integral to conversation analysis' observational method (Sidnell, 2013). Recordings allow analysts to produce an endogenous account of participants' displayed orientations by preserving the temporal dimensions of interaction and the level of detail participants had access to (Mondada, 2013b). Recordings are the primary data, while transcripts represent on the page the details of a recorded interaction.

Sound files for the extracts presented are available on request. Please contact either emma.tennent@vuw.ac.nz or ann.weatherall@vuw.ac.nz.

\subsubsection{Transcription}

Standard orthographic transcription (the 'verbatim' kind used in much social science research) misses many of the basic features that research has demonstrated are central to understanding activities in interaction (Hepburn \& Bolden, 2017). The way talk is delivered - faster than usual, louder, drawn out, high-pitched, and so on - is fundamental to how participants build and interpret actions 
(Levinson, 2013). Slight changes to these features can make the difference in what an utterance is taken to do or mean. Because these features are relevant for participants to determine what an action is action and how they should respond, analysts must also treat them as relevant and important if they are to produce an account of action (Hepburn \& Bolden, 2017).

The study of action requires transcripts that represent the sequential unfolding of talk. Transcription in conversation analysis is an iterative process which is also the first phase of analysis. Conversation analytic transcripts aim to capture as much detail as participants had access to in the moment of interaction. The transcription notation developed by Jefferson (2004) includes temporal and sequential aspects of talk; features of speech delivery and intonation; and features which accompany talk. Temporal and sequential aspects of talk include moments when people talk at the same time as each other (overlap), when turns are delivered without discernible silence between them (latching) or when silences occur within or between turns of talk (gaps and pauses respectively). Silences are precisely timed - not by absolute measurement, but relative to the participants' own tempo of talk. Features of speech delivery include volume, speed, pitch, and voice-quality, as well as the intonation of words and turns. Transcription is not limited to verbal conduct, but also includes non-verbal features such as breathing (in-breaths and out-breaths), laughing, and crying (Hepburn, 2004). A list of transcription conventions used in the analysis is included in the Appendix.

\subsubsection{Analysing phenomenon}

Conversation analysis is an observational science. I began by repeatedly listening to the call recordings and reading (and refining) transcripts in a process called unmotivated looking. Rather than beginning with a hypothesis, or searching for a specific phenomenon (such as participants' gender identities; see Schegloff, 
1997), unmotivated looking enjoins analysts to approach the data with an open mind and "pose those problems that the data bears" (Sacks, 1995, p. 471). Although I was interested in how a victim identity might be relevant for callers seeking help, I did not presuppose where or how this would occur (cf. Speer, 2002). Instead, I set out to examine how callers asked for help and whether identity was a relevant for doing so. As the analysis shows, victimhood is not the only identity participants treat as relevant for helping and identities can be invoked in quite different ways.

Once I noticed a phenomenon (such as callers referring to themselves as victims, call-takers offering transfer, or callers describing where they were), I looked for other instances of it. The process of collection-building allowed me to refine my understanding of the phenomenon by examining variation across different instances in interaction (Hoey \& Kendrick, 2017). Just as biologists collect different specimens of butterfly, conversation analysts collect different cases of 'requests', 'offers', 'reasons for calling', 'identifications', and so on (Hutchby \& Wooffitt, 1999). Starting with a broad and generic description, I collected multiple instances of similar or slightly different phenomenon (Sidnell, 2013). As I decided whether each new case was a candidate for inclusion or exclusion, I revised my preliminary description of the phenomena.

Participants are constantly engaged in making sense of each other, and so there is an orderliness to talk available for analysis (Sacks, 1984). Resources such as composition (how the turn is built) and position (where the phenomenon occurs within the turn and sequence), allowed me to build an analytic description of the practices in question (Sidnell, 2013). The aim of my analysis is to show how participants used and oriented to phenomenon such as identity and help.

Participants display their understanding of what an action is through the way that they respond to it. In analytic terms this is 
referred to as the next turn proof where the next turn displays how a participant has understood the prior action (Sidnell, 2013). For example, when someone says my house was burgled, are they providing information, telling a story, making a complaint, asking for help, telling a joke? The list is potentially endless. Rather than pondering the possibilities in the abstract, conversation analysts examine how participants there-and-then made sense of such an utterance (Schegloff, 1986). By saying oh dear, someone can show they have understood the talk as an unfortunate story; while responding with an offer of service treats the talk as a request for help. Thus, participants display their understanding of actions, in the first instance to each other, and to the overhearing analyst.

The analyses presented in Chapter 5 are drawn from a collection of 104 cases where callers presented their reason for calling. I limited cases to those where callers were seeking help for themselves, with 'seeking help' conceptualised in the broadest terms. In the analysis, I document how callers' requests for help invoke their identities in different ways. In Chapter 6, I analyse how call-takers invoked the link between identity and help when denying or offering help to callers. I analysed the different ways call-takers responded to callers' reasons for calling in the 104 cases and documented the sequential position of subsequent offers call-takers made. Chapter 7 examines the phenomenon of help-seeking on behalf of others, and the different ways participants orient to identity for this kind of help. The analysis is based on a smaller collection of 32 calls in which callers identified as seeking help on behalf of others. For each case, I analysed how callers referred to themselves and the person they were calling for, and how they accounted for calling. The analysis demonstrates participants' orientations to categorically organised rights and obligations for help. 


\section{ASKING FOR HELP}

The central argument of this thesis is that identity and help are inextricably linked. In this first analytic chapter, I show how asking for help makes relevant participants' social identities. Below I analyse four different kinds of help to demonstrate how the nature of the help sought is part and parcel of participants' identities. When asking to speak to a support worker, seeking emotional support, requesting practical advice or requesting information, callers configured identities and self-other relations in different ways. In the four sections below, I analyse how callers sought these four kinds of help. For each case, I analyse how identity (participants' shared sense of who they are to each other) was a resource to build and interpret actions as requests for help. Self-other relations can change from moment-to-moment, but are characterised by participants' relative rights to knowledge, power, and emotion (Stevanovic \& Peräkylä, 2014). In the analyses below, I examine how participants' identities and self-other relations are constituted through their orientation to epistemics, deontics, and affect when asking for help. I also use the relationship between help, identity and self-other relations to examine how participants orient to and constitute the social context of the call (Lindström, 2005). Asking for help displays callers' understanding of the kind of help available, and the way rights and obligations to help are distributed between themselves and their recipient.

\subsection{SEEKING A SUPPORT WORKER}

In this first section, I present three cases where callers requested transfer to a support worker. Callers who ask for help in this way invoke the social context of the Contact Service, constituting social relations between themselves and call-takers (Lindström, 2005). I analyse how callers' requests are intelligible through their identities as clients (whose legitimate victimhood is already established) and morally accountable through their knowledge of 
institutional processes and entitlement to access support. Callers who present transfer requests as their reasons for calling display their understanding of the call-taker's identity as a contact service worker who can connect them to their support workers. Institutional policy mandates that volunteer support workers are not to give their contact details to clients directly. Instead, to access their support workers, clients call 0800 Victim, are verified by contact service workers, and then transferred. In the cases below, I analyse how callers' requests display their understanding of the relationship between identity and help and configure self-other relations.

In 5.1.1, both participants orient to the way the caller's request invokes identities for herself and the call-taker. The call opens with the standard institutional greeting, including the Māori greeting "kia ora" (line 1).

\subsubsection{Samuel 52}

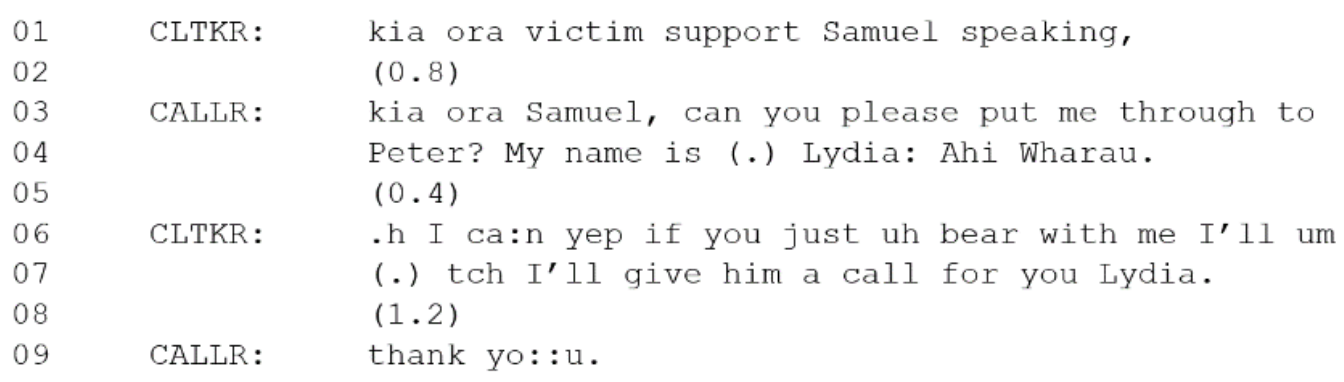

The caller's first turn of talk displays her understanding of where she has called, who her recipient is, what his institutional role entails, and her own entitlement to help. The caller's request displays her understanding of who she is to her recipient and who he is to her (Stevanovic \& Peräkylä, 2014). She displays her entitlement to help by designing her request with the modal verb "can" (line 3 ) in an interrogative question (Curl \& Drew, 2008). She also displays an expectation that her request alone is sufficient to provide a warrant for help (cf. J. Whalen et al., 1988). Asking to be transferred displays 
her knowledge about the kind of help available, and the call-taker's role in providing it.

The caller's references to herself and others display her understanding of the relevant social relations. She refers to the person she wishes to speak to by first name, while identifying herself with first and surname (line 4). First name references are a way to display someone known in common between speaker and recipient, while full names do not convey the same expectation of recognition (Schegloff, 1996). Thus, the caller displays that Peter is someone she knows and expects the call-taker to know, while she does not expect him to recognise her by her first name alone. The caller thus orients to - and constitutes - the institutional context of the call (Heritage \& Clayman, 2010d). She displays an understanding that her full name is relevant to progress the institutional business (call-takers access clients' files by searching their name in the database), while treating Samuel and Peter as members of the same collection 'named employees of the organisation' (Psathas, 1999).

Although first name reference invokes Samuel and Peter's joint membership in the category 'Victim Support', the caller distinguishes between them. As someone the caller knows and has a relationship with, Peter can be inferred as her support worker. By asking the call-taker to "please put me through" (line 3), the caller invokes Samuel's identity as a contact service worker. She treats transfer as a kind of help he can provide, displaying her knowledge of institutional procedures and the nature of the help available. Displaying this knowledge is one way the caller identifies herself as a client. As a client, the caller has already accessed support where presumably, she first had to establish her legitimacy as a victim. As a legitimate victim, she is entitled to speak to her allocated support worker. This entitlement is coupled with knowledge about how to access support by calling the helpline and requesting transfer. Thus, the caller's epistemic rights to know how to ask for help display her identity as a client. 
The call-taker's identity as a contact service worker - which the caller orients to in the design of her request - is associated with an obligation to grant the caller's request and connect her with support. His response (lines 6-7) ratifies the caller's claimed entitlement to help and confirms transfer is something he can do. Both participants thus orient to transfer as the relevant help in this case (cf. Watson, 1986). By doing so, they jointly constitute the social context of the helpline as a conduit to service.

Requesting transfer to a support worker is enough to constitute callers' identities as clients and established victims. However, in 5.1.2, caller and call-taker display different understandings of the relationship between identity and help. The caller displays an expectation that her request is sufficient to demonstrate her entitlement, and orients to her relationship with the support worker as the relevant basis for identification. The call-taker however, displays that the caller's request is contingent. To resolve the misunderstanding, participants make explicit reference to the caller's identity as a victim. 


\subsubsection{Molly 49}

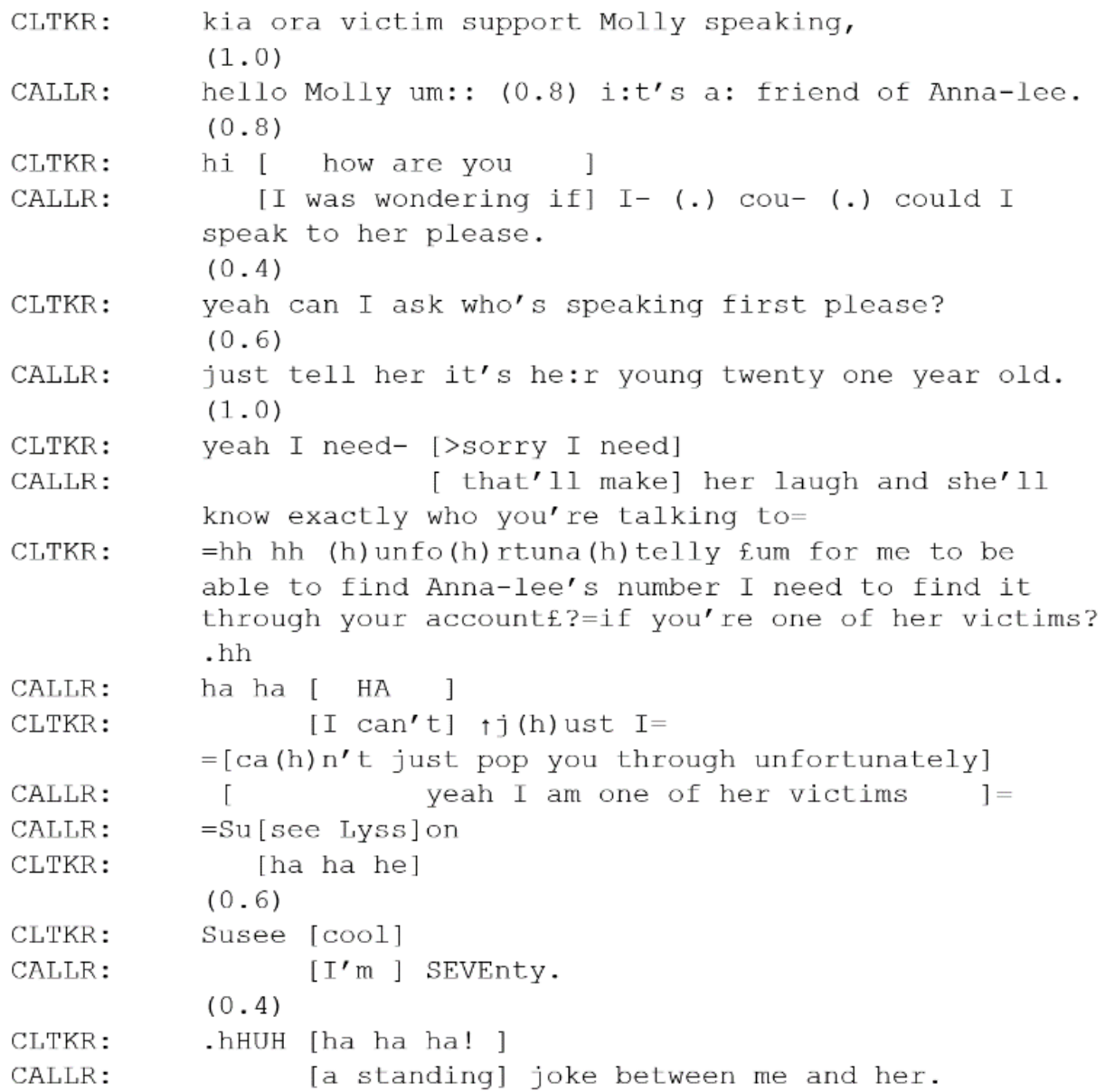

Caller and call-taker display different understandings of the link between identity and help. The caller treats transfer as the kind of service for which her request alone is sufficient to warrant help (cf. J. Whalen et al., 1988). The caller begins by categorising herself as "a: friend of Anna-lee" (line 3), displaying an expectation that this turn is sufficient as a reason for the call. The call-taker however treats this turn as an identification, initiating a how-are-you sequence in overlap with the caller's explicit request (lines 5-7). The request is projectable as I was wondering if I could speak to her, a declarative format that orients to the contingencies associated with granting (Curl \& Drew, 2008). However, after overlap is resolved, the caller reorders her talk to "could I speak to her please" (lines 6-7). Modifying 
the request from a declarative to an interrogative format presents the request as if it came in the 'first slot' despite its sequential position as her second turn of talk (Fox \& Heinemann, 2017). Likewise, the subsequent reference "her" (line 7) displays that the caller's project has, from the outset, been to speak with Anna-lee (Schegloff, 1996).

Calling to be transferred displays the caller's understandings of her own and others' identities. As in 5.1.1, requesting transfer displays the caller's understanding she has called the Contact Service and that the call-taker is able to transfer the call. The design of this request displays her understanding of her recipient's identity as a contact service worker. The caller displays an expectation her request is understandable to her recipient, and sufficient to be granted based on her claimed identity as a friend. The call-taker, however, displays a different understanding of the relationship between the caller's identity and her access to help.

The caller's request is a first pair part of an adjacency pair which makes relevant granting or denial (Schegloff, 2007b). The calltaker responds with "yeah" before launching a request of her own (line 9), an action which is understood differently by the participants. The caller understands the turn as granting her request and asking how to introduce her once the call is transferred. She displays this understanding in her next turn of talk, where she directs the call-taker to "just tell her it's he:r young twenty one year old" (line 11). The call-taker, however, understands the turn as an insertion sequence, which must be dealt with before she can respond to the caller's request (see Schegloff, 2007b). The participants' different understandings of the action display different understandings of social relations and social context. The caller treats the call as a straightforward conduit to service and displays the presumption that her request will be granted. The call-taker treats the call as a gatekeeping environment, where granting requests is contingent on institutional procedures (Heritage \& Clayman, 2010a). 
In the above extract, participants display different understandings of which self-other relations are relevant. The caller orients to her relationship with her support worker as relevant. In response to the call-taker's identification request, she uses an alternative recognitional reference (Stivers, 2007), "he:r young twenty one year old" (line 11) which she claims will make Anna-lee "laugh" (line 14) and be sufficient for her to "know exactly" who she is (line 15). This reference displays the caller's expectation that, by drawing on their shared relationship, the support worker will be able to identify who she is. The call-taker, however, orients to her relationship with the caller as relevant. She displays that the caller needs to identify herself to the call-taker to progress the institutional business. The caller's alternative recognitional may very well be sufficient for Anna-lee to recognise her (and laughter at line 16 displays affiliation with the caller's stance on this as a joke), but it is insufficient for the call-taker's present purposes.

The call-taker displays that (contrary to the caller's displayed understanding) the request has not yet been granted. She describes the practical process of carrying out a transfer (accessing the support worker's details through the caller's case-file) and orients to her own and the caller's identity. By describing constraints on her institutional role, the call-taker orients to her identity as a contact service worker, whose ability to carry out the request rests on the caller's compliance with institutional procedures (i.e. identifying in an institutionally recognised way). This description makes explicit the link between the provision of help and the caller's identity. The call-taker claims her ability to grant the request is conditional on the caller's identity as "one of her victims" (line 18).

The caller's entitlement to the service and her knowledge about her support worker are not enough for the call-taker to grant her request for transfer. Instead, the caller must also identify herself in institutionally relevant ways. To resolve the breakdown in intersubjectivity, both call-taker and caller use the explicit 
categorisation victim to establish the caller's entitlement to help and accomplish an institutionally relevant request. Here, both participants conflate victim and client category membership. The relevant predicates of victimhood - for these participants at this interactional moment - are having a case-file in the database and the relevant entitlement to call for a support worker. Thus, what it means to be a victim is bound up with the kind of help asked for.

In the call below, the call-taker proffers a categorisation of the caller as a victim, displaying an understanding of victimhood in terms of its institutional relevance. The caller, however, displays a different understanding of victimhood. The call opened with the caller's request for transfer and here, the call-taker is searching for her casefile.

\subsubsection{Adrian 32}

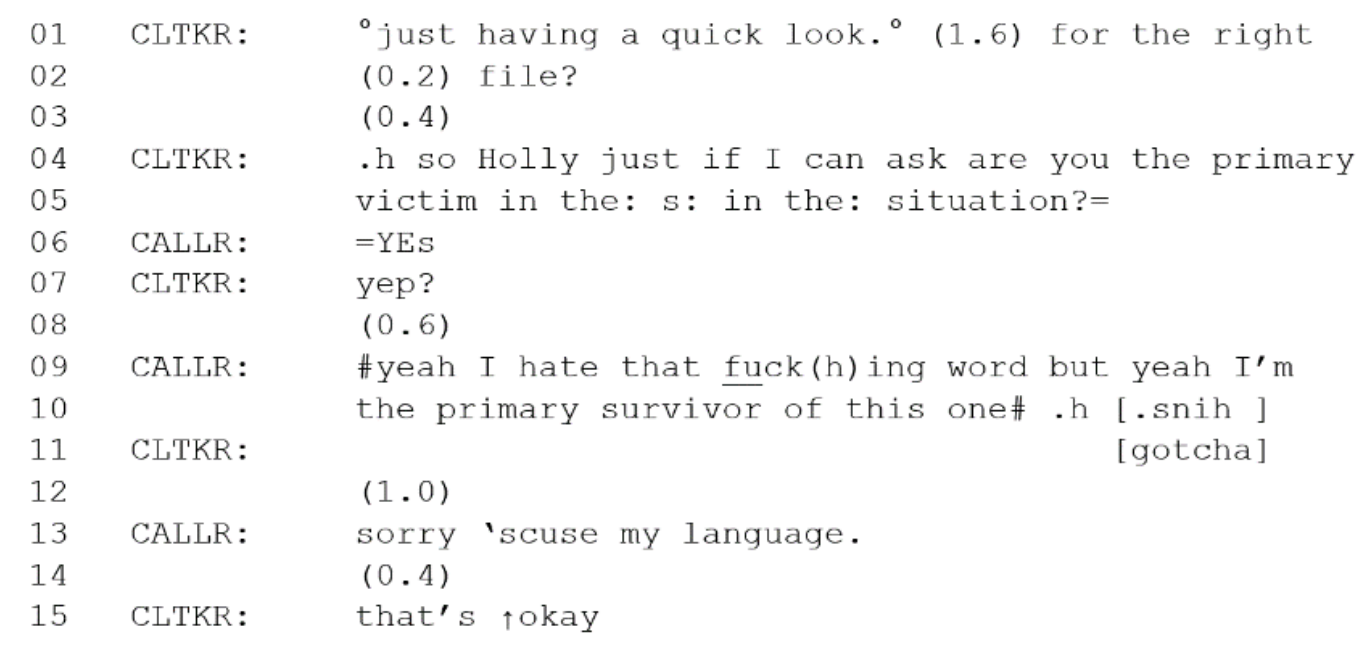

By searching for the caller's file, the call-taker treats her as a client whose details are stored on the institutional database. His quieter talk (marked by ${ }^{\circ}$ in line 1 of the transcript) is indicative of the kind of online commentary participants can use when engaging in another activity, such as interacting with the computer (Näslund, 2016). 
Much like in 5.1.2, the call-taker conflates the categories victim and client. Due to the name of the service, someone who is a client of Victim Support is, by definition, a victim. The call-taker's request for information proffers a categorisation of the caller as "the primary victim" (lines 4-5). In institutional terminology, a primary victim is the person who directly experienced victimisation, while secondary victims are those who are indirectly affected by the event (e.g. family members). On the institutional database, multiple victims can be entered on the same case file and ranked in this way. The calltaker is designedly vague about what the caller has been a victim of, referring to it as "the: situation" after some perturbations in talk (line 5). The design of his request displays he is not asking about the caller's victimisation per se but attempting to secure an institutional classification of the caller. The caller displays an understanding the call-taker is asking about her category membership relative to the incident recorded in the database. In quite pragmatic terms, will the casefile be listed under her name, or someone else's? The call-taker is involved in the practical task of finding the caller's case-file, so he can connect her to her support worker. The caller initially orients to the call-taker's project, providing confirmation in the adjacent turn (line 6).

However, the caller then displays a different understanding of her relevant category membership. After the call-taker's request for confirmation (line 7), she takes up an emotional stance towards the category she has just accepted, claiming to "hate that fuck(h)ing word" with marked emphasis on the expletive (line 9). This negative emotional stance accounts for her modified repeat of the call-takers' initial question, "yeah I'm the primary survivor of this one" (lines 910). By taking up an emotional stance towards the word victim, the caller claims the rights to identify herself with an alternative category term. The categories victim and survivor are associated with different common-sense knowledge, activities, and predicates. A victim identity is associated with weakness, passivity, and shame, while a 
survivor identity is associated with strength, agency, and resilience (Jordan, 2013; Lamb, 1999a). However, in this case, the relevant predicate for accessing help (having a case-file listed under her name) remains the same, which the caller indicates with her repetition of "primary" (line 10). Thus, although she displays an understanding that her category membership as a victim can be ascribed by others, she claims the rights to define her own categorical identity.

Even while identifying in an institutionally-relevant way to get help, this caller orients to the relevance of who she is and who can determine her identity. The call-taker displayed an understanding that the nature of the caller's victimisation was not relevant for accessing help. Although the caller does not describe her experience directly, she displays that her experience is relevant for determining who she is. The category survivor has common-sense associations with sexual violence (Lamb, 1999b). Using the indexical reference "this one" (line 10) to refer to the call-taker's description "the situation" (line 5) infers the caller has had multiple experiences of victimisation. While for the call-taker, the caller's identity as a primary victim is relevant for his practical task of locating her case-file, the caller makes inferentially available the nature of her victimisation, orienting to her entitlement and need for help.

The three cases presented above demonstrate how participants configured links between identity and help when callers requested transfer to a support worker. Requests for transfer were sufficient for callers to establish their identities as victims and clients of the service. In this institutional context, the categories victim and client are conflated, with participants orienting to clients as people whose status as legitimate victims was already established. Callers constituted their identities as clients by displaying knowledge about institutional procedures. By requesting transfer, callers claimed deontic rights to determine how help would be provided. However, call-takers oriented to their greater deontic rights to determine how or whether requests could be granted. When participants displayed 
different understandings of how help could be given, call takers made callers' categorical identities as victims explicit. Although callers understood victim categories as indexing client membership, they also claimed emotional rights to define their own identities.

In the following section, I examine how participants linked identity and help with reference to emotional support.

\subsection{SEEKING EMOTIONAL SUPPORT}

Emotional support is a key form of help offered by Victim Support. Volunteer support workers provide emotional support to victims in face to face meetings or over the phone. Contact service workers can enter new clients into the institutional database and allocate a support worker to make contact. In this section, I analyse how callers are understood to be seeking emotional support. In the first case, the link between the caller's experience, identity, and the help allows participants to establish a mutual understanding of the caller as a victim seeking emotional support, while in the second, participants are unable to establish joint understanding of the help the caller needs.

In the case that follows, caller and call-taker jointly link the caller's experience with her identity as a victim and her need for emotional support. In contrast to clients who request transfer, firsttime callers like this one do not always produce direct requests for service. Here, the caller simply describes her recent experience. Nevertheless, the call-taker understands that description as asking for help. 


\subsubsection{Tom 1}

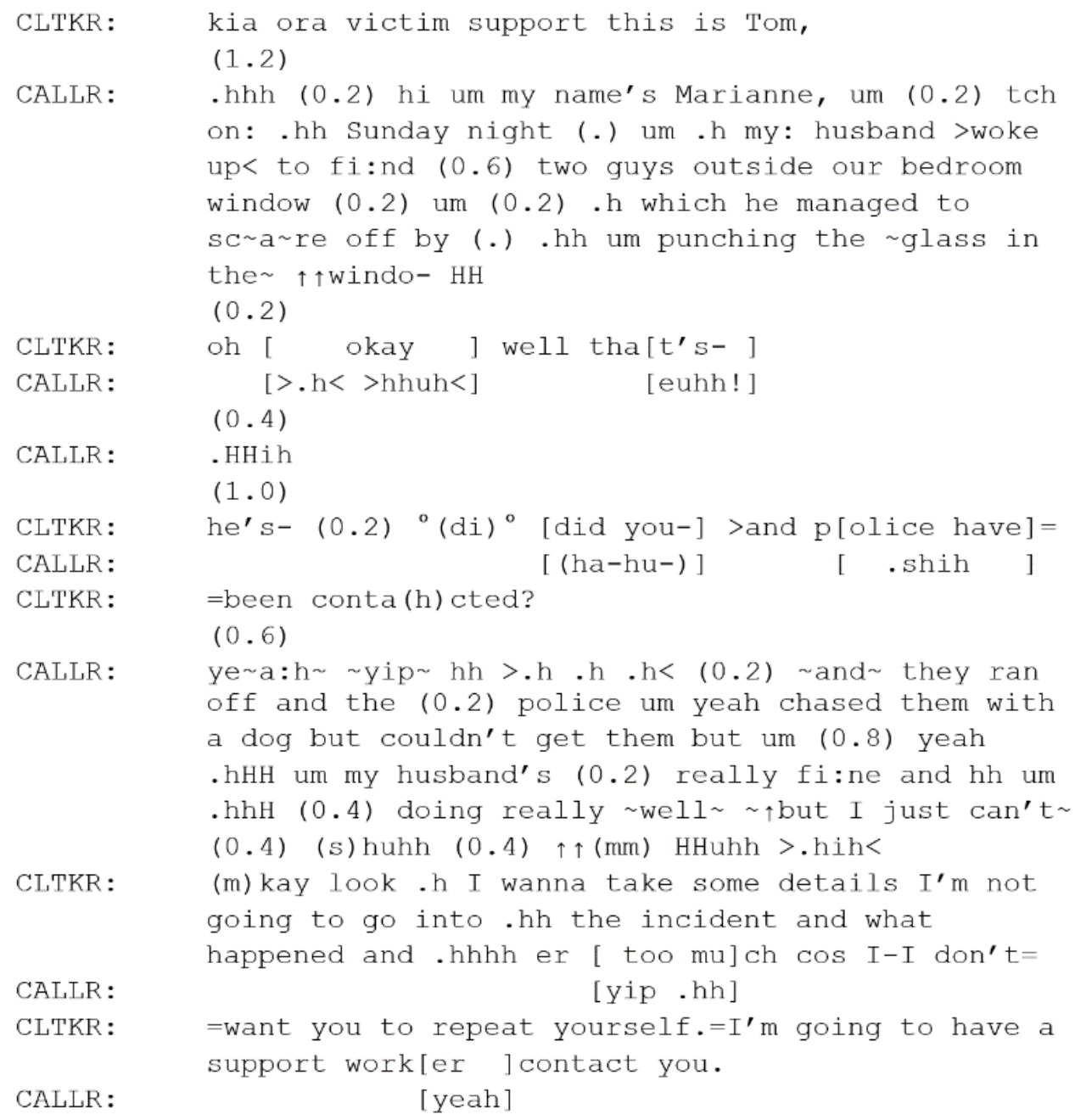

In contrast to the callers in the previous section, who treated the service as one for which requesting alone was sufficient (because their entitlement to service had been previously established), this caller treats help from Victim Support as accountable. Narrative descriptions have been documented as formats that allow callers to manage issues of motive and knowledge in emergency calls and helplines (Potter \& Hepburn, 2003; Zimmerman, 1992), and here the caller uses a narrative to account for seeking help. She begins what is recognisable as a story by recounting recent events (Mandelbaum, 2013) that took place "on: .hh Sunday night" (line 4). This call takes place at night two days later. Thus, the caller's story is a description 
of recent events, which are demonstrably still impacting her. She describes a trespassing event (lines 4-8) and demonstrates the traumatic nature of this experience when crying overwhelms her ability to speak (line 8).

The caller displays (without saying so directly) that she is seeking emotional support. Her emotional display comes as a flooding out of talk (Goffman, 1961) which displays her social position relative to the events described. The display of emotion demonstrates her identity as a victim affected by her experience. In a context where emotional support is a relevant form of help, this emotional display is a key resource for building and interpreting the request for help (see Stevanovic \& Peräkylä, 2014). The caller displays her understanding of the help available by explicitly formulating her husband's and her own emotional states. Although he is "doing really $\sim$ well $\sim$ " (line 23 ), she both claims (" $\sim$ but I just can't $\sim$ " line 23) and demonstrates (with a second flooding out at line 24) her inability to cope.

The caller's narrative description displays her understanding of the kind of people and problems Victim Support can help. Both participants orient to the criminal nature of the events described, with the call-taker's question (lines 15-17) displaying his understanding of the policeable character of the events. By describing an experience of a crime, the caller invokes her category membership as a victim, and claims the associated rights to seek help from Victim Support. Claiming the rights to own and display emotions regarding the events positions the caller as a traumatised victim entitled to receive emotional support from the service.

Although the call-taker treats the caller as a legitimate victim entitled to receive help from the service, he orients to his deontic rights to determine how help will be provided. By telling her story to the call-taker, the caller displayed an expectation he has the knowledge and competencies to meet her needs (Psathas, 1999). It is 
not unreasonable to assume that someone who identifies as a member of Victim Support (line 1) can provide support to victims. Yet rather than providing support, the call-taker uses "look" (line 25) to indicate his next action is not directly fitted to the caller's prior turn (see Sidnell, 2007). The call-taker orients to potential misalignment between participants by naming the category "a support worker" (line 30) and characterising his actions as details-gathering. In this way, he partitions the organisation into two categories: support workers and contact service workers (see Sacks, 1972a). The activity of providing emotional support is bound to the category support workers, while contact service workers only have the category-bound rights and competencies to allocate support workers. In this offer of help, the call-taker formulates the Contact Service as a conduit to help, clarifying that help in the here-and-now takes the form of arranging support rather than providing it directly (cf. Watson, 1986).

Describing an experience and displaying emotion can be sufficient to build a request for emotional support. Yet, as 5.2.2 shows the link between a victim identity and help is a negotiated accomplishment. 


\subsubsection{Sharika 2}

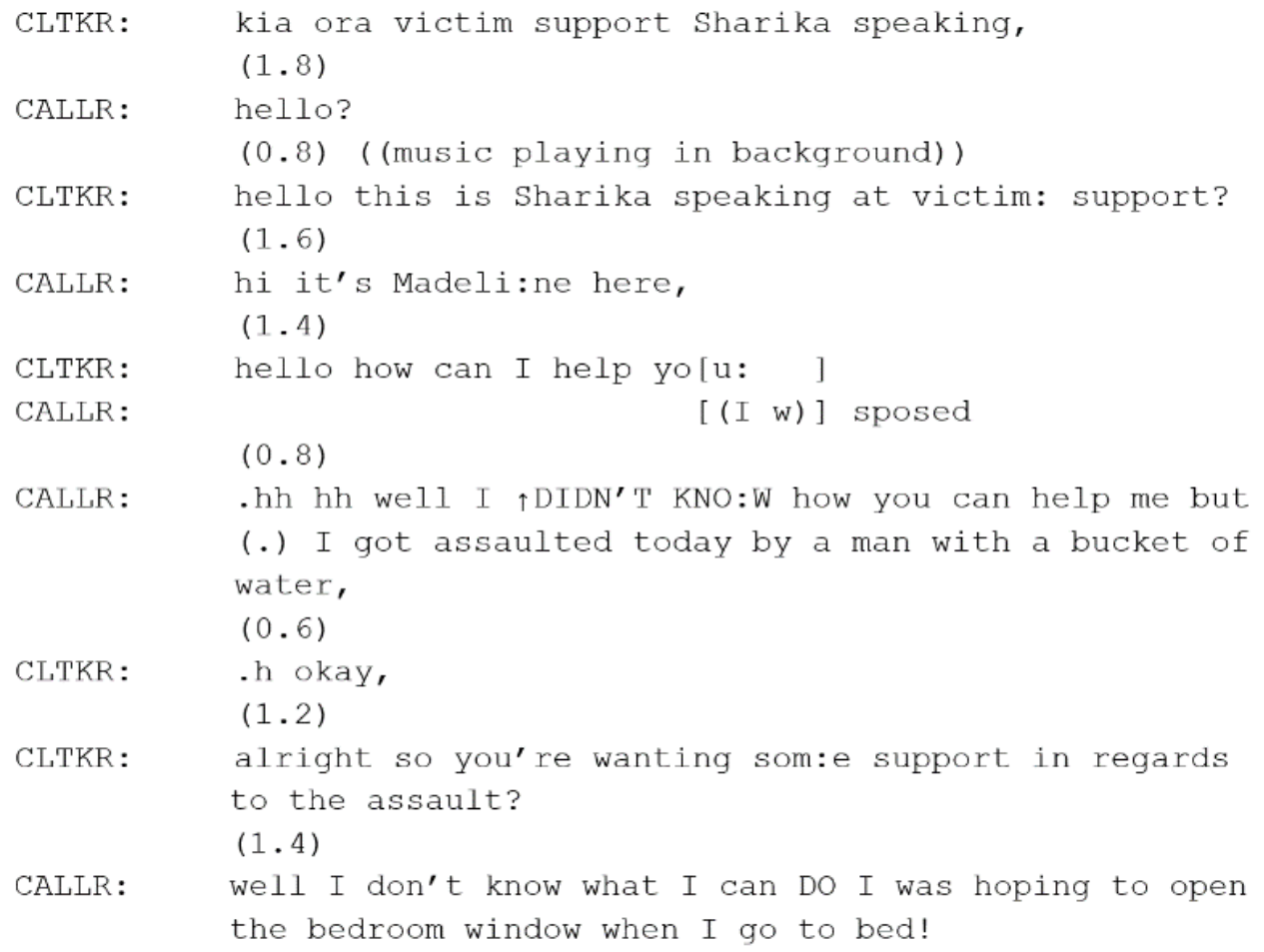

The way the call-taker responds to the non-normative opening of the call displays her understanding of her identity and the social context of the institution. The routine call opening (line 1) and the repair (line 5) identify the call-taker as a representative of Victim Support. Opening turns like this are deployed on other helplines to let callers decide how to present themselves and their reason for calling (cf. Danby et al., 2005). Yet when the call-taker pursues a reason for the call by asking "how can I help you:" (line 9), she displays that there are limitations on what callers can relevantly do. The calltaker's question displays the presumption that the caller is seeking help and implies a request is a relevant way to ask for it. The calltaker's action invokes her identity as a help-provider and projects the caller's identity as a help-seeker.

Yet the caller challenges the presumption that calling the helpline is linked to her identity as a help-seeker. Rather than producing a type-fitted response (Schegloff, 2007b) to the call-taker's 
question (such as a request for service), she claims she lacks knowledge about what help she needs or how she should ask for it. She claims the reason she is calling is because she "got assaulted today" (line 13). This description makes her categorical identity as a victim inferentially available. Yet by disavowing knowledge of how the call-taker (or organisation) can help her, the caller inverts the relationship between victims and help seen in 5.2.1. Although the caller identifies as a victim, she displays that she lacks the necessary knowledge about help available to be able to ask for it. Thus, her lack of epistemic access means she lacks the deontic rights to determine what help she needs or how it should be given.

Nevertheless, the call-taker treats the caller's description as a request for help. Her request for confirmation displays her understanding that the caller is "wanting som:e support in regards to the assault" (line 18-19). Using the definite article "the", the call-taker transforms the caller's description into categorisation (Stokoe, 2009), treating assault as a relevant institutional problem. Someone with a relevant institutional problem for victim support is, by definition, a victim. Rather than asking are you wanting some support? the declarative format "you're wanting som:e support" (line 18) displays the call-taker's understanding that this was the action of the caller's turn, which she is now merely confirming, rather than proposing for the first time. This displays the call-taker's understanding of an accountable reason for the call: having a relevant experience for the institution (victimisation) and seeking a form of help that is available (support). This request for confirmation attempts to shift the caller into a service-encounter framework (Jefferson \& Lee, 1992) by formulating the reason for the call in terms of a service that can be provided.

The caller neither confirms nor denies the call-taker's understanding that she is seeking support. Well-prefaced turns indicate that the following talk will privilege the speaker's desires, knowledge, and experience (Heritage, 2015), and are often used to 
signal an answer to a question will not be straightforward (Schegloff \& Lerner, 2009). Here, the caller's well-prefaced turn (lines 21-22) rejects the call-taker's understanding that she is seeking support, claiming the epistemic rights to formulate her reason for calling. She treats her problem (opening the window) as not straightforwardly associated with support. Presenting mundane needs is one way helpline callers can claim identities as ordinary people rather than clients in need of help (te Molder, 2005). The caller's response challenges the call-taker's displayed understanding that she (and the organisation she represents) can help the caller. Although both participants orient to the caller as a victim entitled to help, they negotiate just what form this help should take.

These two cases demonstrate the consequential link between identity and help. In 5.2.1, caller and call-taker establish a joint understanding of the caller as a victim seeking emotional support. The caller's identity as a victim renders her narrative description intelligible as a request, and accounts for her entitlement to seek and receive emotional help. In 5.2.2, the call-taker likewise treats description of victimisation as a request for help. But in this case, the caller claims a lack of knowledge about the help available. Participants do not accomplish a joint understanding of the caller or her project, demonstrating that the link between a victim identity and help is a joint accomplishment.

This section has shown that describing a recent experience can be enough for callers to be understood as victims seeking help. Why then, would callers categorise themselves as victims explicitly? The following section shows that callers use victim categories when seeking practical help. 


\subsection{SEEKING PRACTICAL HELP}

Callers seeking practical advice and advocacy explicitly categorised themselves as victims to account for seeking help from Victim Support. Self-categorisations can license blaming or complaints by presenting callers as lacking help they are entitled to (Watson, 1978).

The case below demonstrates the three-part structure callers used to identify themselves and ask for help. The caller selfcategorises as a victim (lines 4-6), describes the problem (lines 9-17), and requests help (line 20). The analysis attends to the ways that explicitly identifying as a victim displays the caller's understanding of the relationship between identity and help.

\subsubsection{Samuel 16}

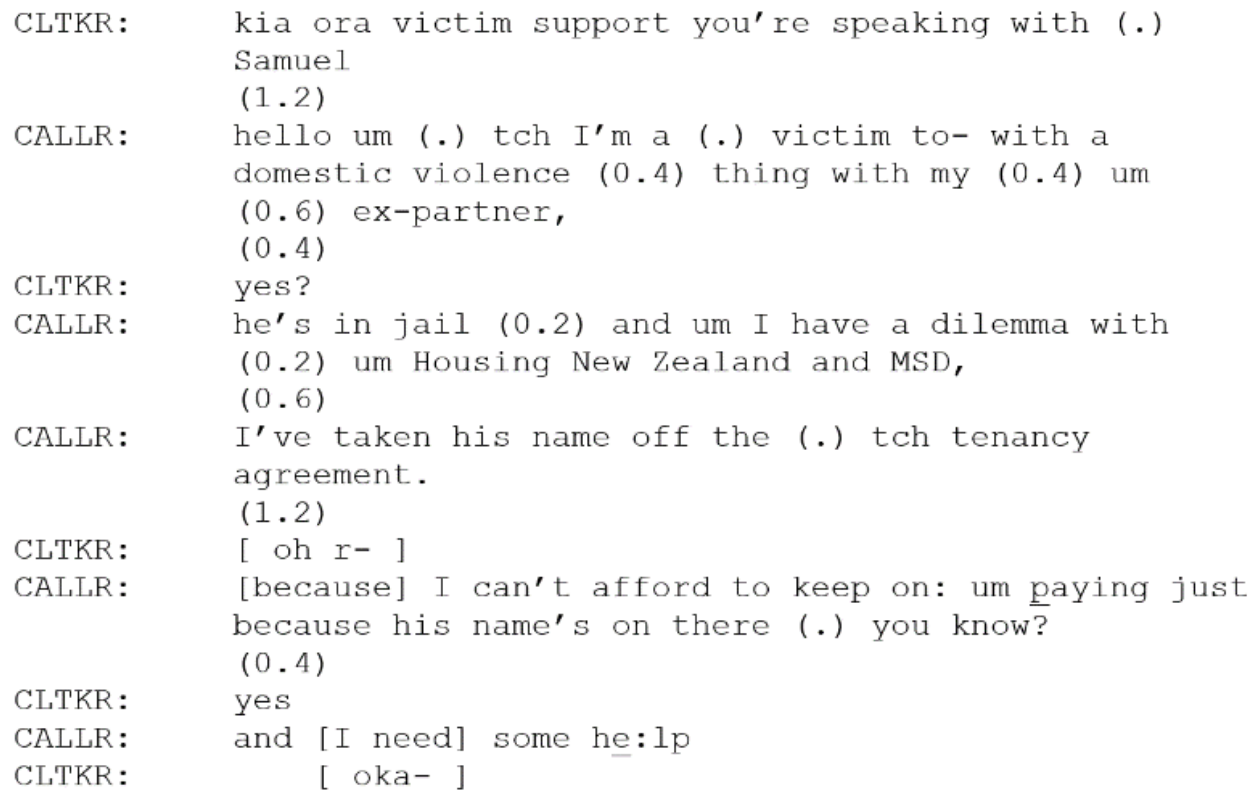

The caller explicitly identifies as a victim in her first turn of talk. The categories victim and perpetrator have common-sense links as a standardised relational pair, where mentioning one is enough to infer the other (Sacks, 1972b). When the caller refers to herself as a victim and refers to a third party as "my (0.4) um (0.6) ex-partner," 
(lines 5-6), the ex-partner can be categorised as the perpetrator. Common-sense knowledge about domestic violence is that perpetrators and victims have a 'domestic' relationship (i.e. as spouses, partners, or family members). Here, the reference term "expartner" (line 6) displays that the basis of that relationship is over. Thus, in her opening turn the caller establishes relevant self-other relations between herself as a victim and her ex-partner as a perpetrator.

Although the caller uses the category term domestic violence to present her experience in an institutionally relevant way, her formulation, "a domestic (0.4) thing" (line 5) indicates this category does not quite fit. Her problem deviates from common-sense understandings of domestic violence because the perpetrator of the violence is not the direct cause of her current problem. Her ex-partner is in jail (line 9), an outcome that can be associated with 'success' for victims of domestic violence (Newbold \& Cross, 2008; Powell \& Murray, 2008). Unlike the caller in 5.2.1, she is not seeking emotional support directly after her experience of victimisation. Instead, the causes of her "dilemma" (line 9) are the social services designed to help her (MSD is an acronym for the Ministry of Social Development). She has removed her ex-partner's name from the tenancy agreement, but state agencies are forcing her to obtain his signature and he is refusing to co-operate (not shown).

By categorising herself as a victim, the caller presents herself as "heir to the relevant category-bound entitlements" (Watson, 1978, p. 108). As a victim, the caller is entitled to receive help. Arguably state housing providers also have an obligation to help victims of domestic violence but, upon encountering trouble with those institutions, the caller has turned to Victim Support. Categorising herself in her request demonstrates the caller's understanding that her identity as a victim entitles her to help from Victim Support. 
In the case below, the caller also self-categorises as a victim in his first turn of talk. Rather than coming as part of a narrative description before the reason for the call, here, the caller's category comes in a first pair part where he explicitly enquires about the organisation's ability to help him. Both caller and call-taker draw explicit links between his identity as a victim and his rights to help.

\subsubsection{Molly 5}

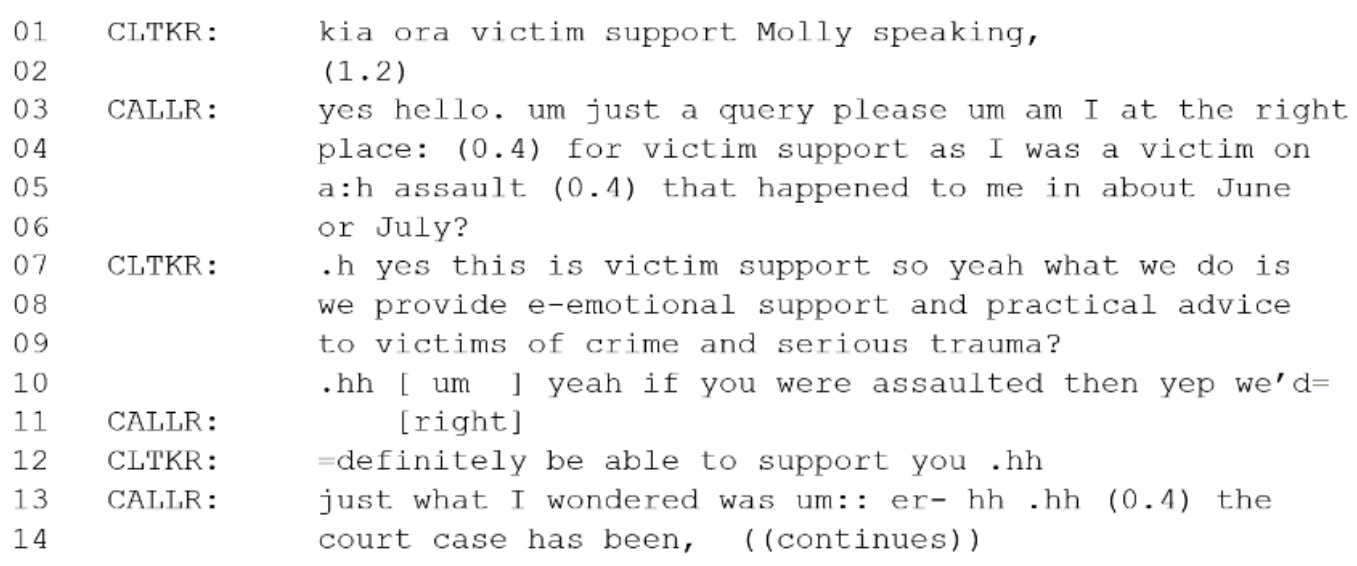

The caller categorises himself as a victim as part of his "query" about whether he has reached the right place for victim support (line 3). This first turn of talk indicates a potential misalignment between caller and called (Schegloff, 1986). Although he claims to be uncertain about whether he has reached "the right place:" (lines 3-4) for Victim Support, he identifies as a victim and claims to be seeking support. By categorising himself as "a victim" (line 4) he presents himself as the kind of person entitled to access support. By describing events that "happened to me" (line 5), he minimises his agency or intent (see Wooffitt, 1992), invoking the common-sense notion that victims are not responsible for their experiences (see Lindholm et al., 2014).The caller specifies that the assault occurred months earlier (this call takes place in November), which indicates he is not seeking help to deal with the immediate effects of victimisation (cf. 5.2.1), but a different kind of help. 
The call-taker's response explicitly links a victim identity with support. She first re-issues the institutional identification "this is victim support" (line 7), before specifying the nature of the help available. Using the plural pronoun to speak on behalf of the organisation (Heritage, 2004), the call-taker describes "what we do is we provide e-emotional support and practical advice" (lines 7-8). These two forms of help are explicitly linked to the identity category, "victims of crime and serious trauma?" (line 9). Thus, the caller unpacks both aspects of the organisation's name - who the victims are, and what the support is. The name of the organisation is, in this case, also a description of the activity. The call-taker makes explicit that the caller's experience makes him eligible for support, ratifying his claimed identity as a victim and his entitlement to the service. When she claims, "we'd definitely be able to support you" (lines 1012), she treats him as a potential client of the service, using support as a verb now that the nature of support has been specified.

The following two extracts are from the same call. They provide further evidence that callers invoke the link between a victim identity and help in strategic ways. In these cases, the caller categorises herself as a victim to display she is not receiving the help she is entitled to.

\subsubsection{Samuel 9}

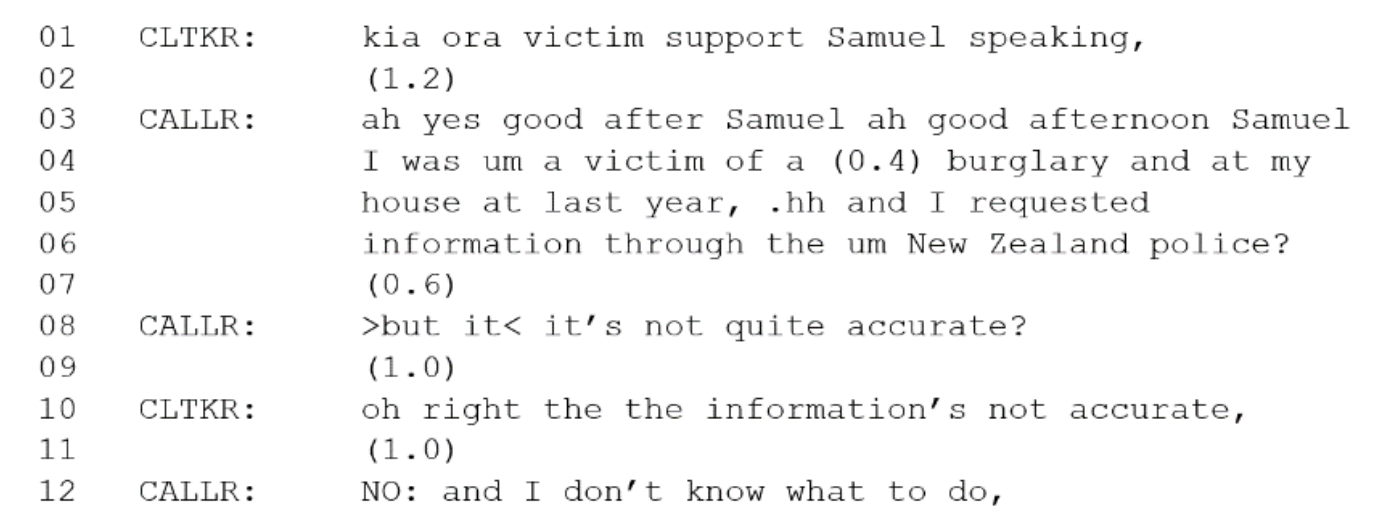


The caller's self-categorisation as "a victim of a (0.4) burglary" (line 4) accountably provides for her entitlement to receive help. Like the caller in 5.3.2, the time reference "last year" (line 5) indicates she is seeking help some time after her experience of victimisation. Rather than seeking emotional support, she is seeking practical help to deal with the institutions she has encountered since becoming a victim. The caller's social identity and relationship to the problem provides for her entitlement to help (M. Whalen \& Zimmerman, 1990). As the victim, she has 'ownership' of the burglary, and thus the associated rights to make requests of police, expect information to be stored about the event, and provided upon request. Claiming category membership can make relevant blameallocation techniques like accusations and complaints (Watson, 1978). By categorising herself as a victim, the caller treats receiving inaccurate information as potentially blame-worthy. As a victim, she is entitled to help from police. With this help noticeably absent, she can accountably turn to Victim Support.

There are two paired sets of categories which the caller treats as relevant. The relationship between the categories victim and police are a locus for rights and obligations (cf. Sacks, 1972b). Victims are entitled to receive help from police and police are obligated to provide it. The caller treats information about the burglary at her house as the kind of help she is entitled to ask for. That the information is inaccurate suggests police have failed in their category-bound obligations. The caller also orients to the relationship between incumbents of the categories victim and Victim Support. Like police, members of Victim Support have obligations to help victims. The caller displays that her rights as a victim have not been fulfilled by police, and so she is now turning to Victim Support for help, as is her right.

The caller makes her entitlement to help explicit in the following extract. In the intervening lines, the call-taker has offered to transfer the caller to police, which she rejected. Below, the call- 
taker indicates he is not sure who to transfer the caller to if not police. The caller's response explicitly invokes her rights to help as a victim.

\subsubsection{Samuel 9a}

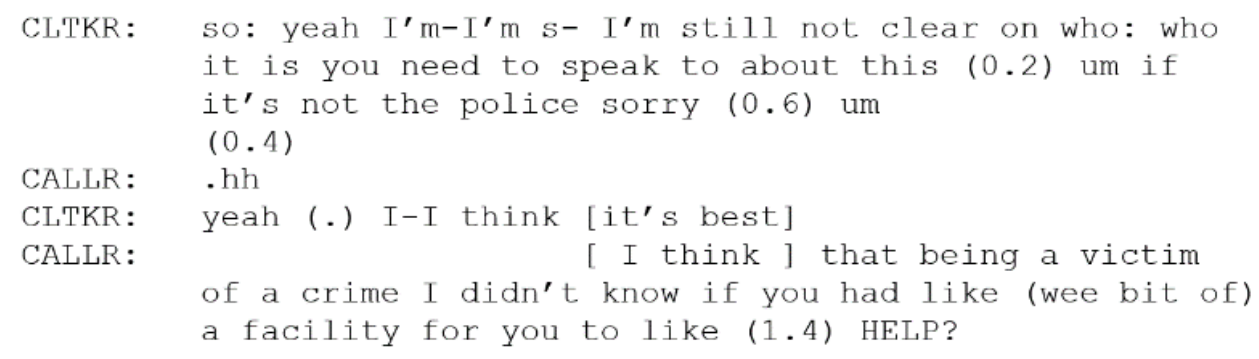

The call-taker displays his understanding that police are the relevant organisation to help the caller with her problem. He claims that, since she has rejected his earlier offer, he is unable to determine who else she would "need to speak to" (line 2). The call-taker orients to his deontic rights to determine how help will be given, treating transfer as the kind of help that can be provided. He recognises an obligation to help the caller in terms of connecting her with the relevant agencies, but as she has rejected his suggestion of police, he is left unable to help her.

The caller, however displays that transfer is not the kind of help she is seeking. As the call-taker begins what is projectable as advice (line 6), she once again categorises herself as a victim. She claims that, "being a victim of a crime" (lines 7-8), she is entitled to greater help than that she is currently receiving. She formulates her victimhood as a state of being which grants her the entitlement to help from Victim Support. The flipside of this entitlement is the calltaker's obligation to provide it. She explicitly links her victim identity with her expectation that he would (and should) help her. The caller displays her deontic rights to determine whether the services on offer are an acceptable form of help. Invoking her category-bound entitlements draws attention to the noticeable absence of the help she is entitled to which is associated with blame-allocation and complaint (Watson, 1978). The noticeably absent feature, "HELP?" comes after 
a significant intra-turn delay and is markedly louder (line 9), displaying the relevant thing the caller is seeking, but has yet to receive.

Through self-categorisation, callers claim categorical membership as victims, and the associated entitlements that accompany it. Callers oriented to help from Victim Support as a category-bound entitlement. Categorising themselves displayed their understanding of this entitlement, which could be used to accountably seek help, or comment on the noticeable absence of help they were entitled to. Below, in the final section of this chapter, I examine how seeking different kinds of information could constitute, or in fact disavow, callers' identities as victims.

\subsection{SEEKING INFORMATION}

In this section, I demonstrate participants' orientations to the relationship between identity and help when callers requested different kinds of information. In the first two cases, seeking information about a perpetrator makes a caller's victim identity relevant. The next two cases display callers' orientations to certain kinds of help which disavow a victim identity. For each case, I demonstrate how participants use the link between identity and help to make their requests intelligible and accountable.

The caller's request for information below displays her orientation to the link between identity and help. The caller uses identity (for herself and others) as a resource to accountably build her request for help. 


\subsubsection{Ellie 6}

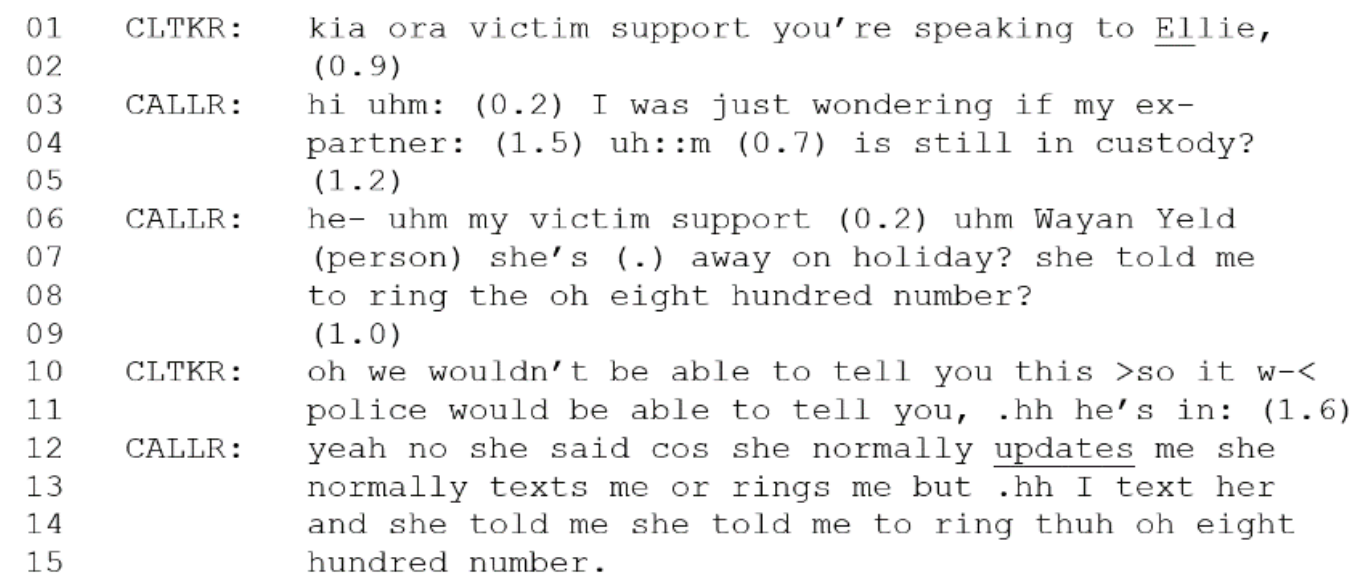

The caller presents the reason for the call as a declarative request for information. The nature of the information she seeks invokes her identity as a victim. Although she does not refer to herself or her experience directly, the caller's reference to her "ex-partner" and his possible location "in custody" (lines 3-4) invoke her identity as a victim. People held in custody have (allegedly) committed a crime, so the caller's reference to this location invokes her expartner's identity as a perpetrator. Perpetrator and victim are categories organised in a standardised relational pair. Following the rules of consistency and economy, if one member is categorised in one way, others should be too (Sacks, 1972a). If one (ex-)partner is the perpetrator, then the other (the caller) can be categorised as the victim. When the same people can be categorised as ex-partners and victim and perpetrator, common-sense inferences mean the crime can be understood as domestic or intimate partner violence (see Tennent \& Weatherall, 2019).

By directing her request to the call-taker, the caller displays her understanding that, as a victim, she is entitled to seek this kind of information from Victim Support. When no response from the calltaker is forthcoming (line 5), she explicitly accounts for calling. Her account displays that her request has been licensed by a third party 
who directed her to call (lines 6-8). The call-taker, however, claims that Victim Support are unable to provide the information the caller seeks (lines 10-11). The extract below picks up a few turns later, when the participants establish that the person the caller is seeking is not a Victim Support worker, but a court victim advisor. Here, the caller explicitly invokes her experience to account for her request.

\subsubsection{Ellie 6a}

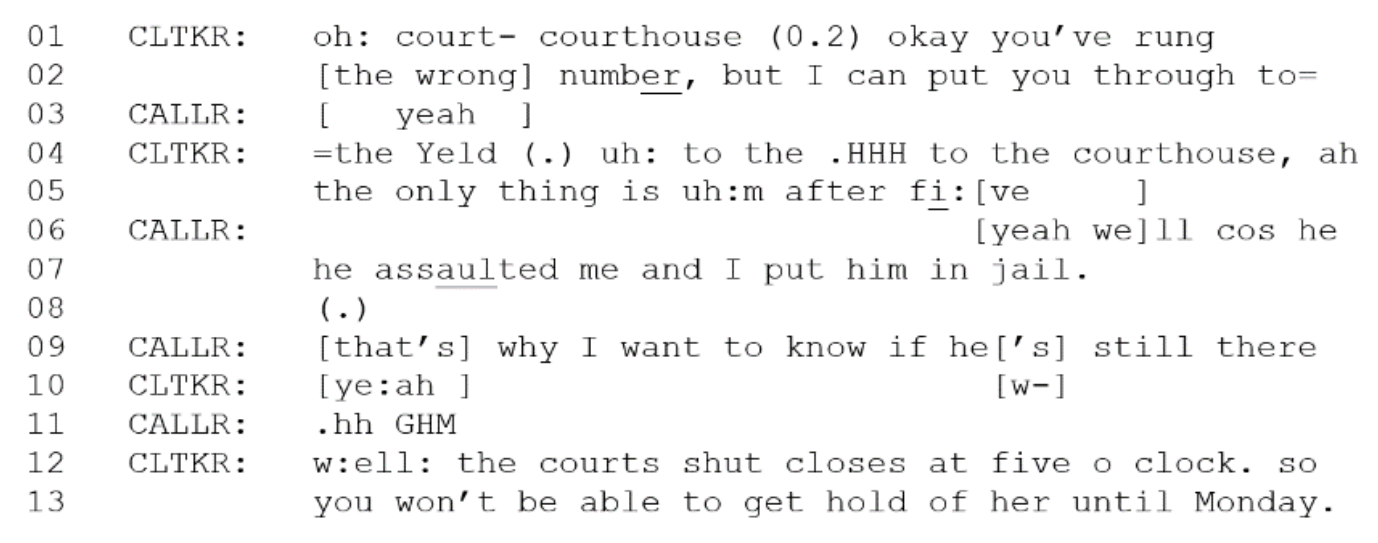

The inferences available from the caller's initial description (5.4.1) are now explicitly referenced. The description "he assaulted me" (line 7) categorises the caller as the victim of her ex-partner's violence, while the claim "I put him in jail" (line 7) makes clear the ex-partner is imprisoned because of his violence against her. The caller presents this as an explicit reason "why" (line 9) she is seeking information about his location. If the caller is understood merely as an ex-partner, she lacks the category-bound entitlement to know the whereabouts of someone she is no longer in a relationship with. Yet, if the caller is understood as a victim, she does have category-bound rights to know whether the perpetrator is still in custody. After all, this information can have life or death consequences (see Jordan, 2008).

Just as the caller in 5.3.4 explicitly categorised herself as a victim, the caller here uses a category-implicative description to invoke her identity as a victim and her entitlement to help precisely when help is not being offered. Despite the caller's claimed 
entitlement to help from Victim Support - licensed by her directions from an institutional third party - the call-taker claims the deontic rights to determine whether and how help will be given. She orients to transfer as the only available form of help and informs the caller it is too late to transfer her call. The call-taker displays an understanding that the caller is seeking to speak to her court victim advisor. The caller, however, displays an understanding that she can access the information she needs by calling Victim Support. This misunderstanding of the help the caller is seeking leads to the call ending without the caller accessing help in the form of transfer or information. I pick up the implications for service-provision and victim wellbeing in the Discussion chapter.

In 5.4.1 and 5.4.2, the caller's identity as a victim is bound up with her request for information about the perpetrator. In the two cases below, callers seek information that disavows their identities as victims. I analyse how callers orient to the dilemma of seeking help from Victim Support while disavowing a victim identity.

\subsubsection{Marianne 3}

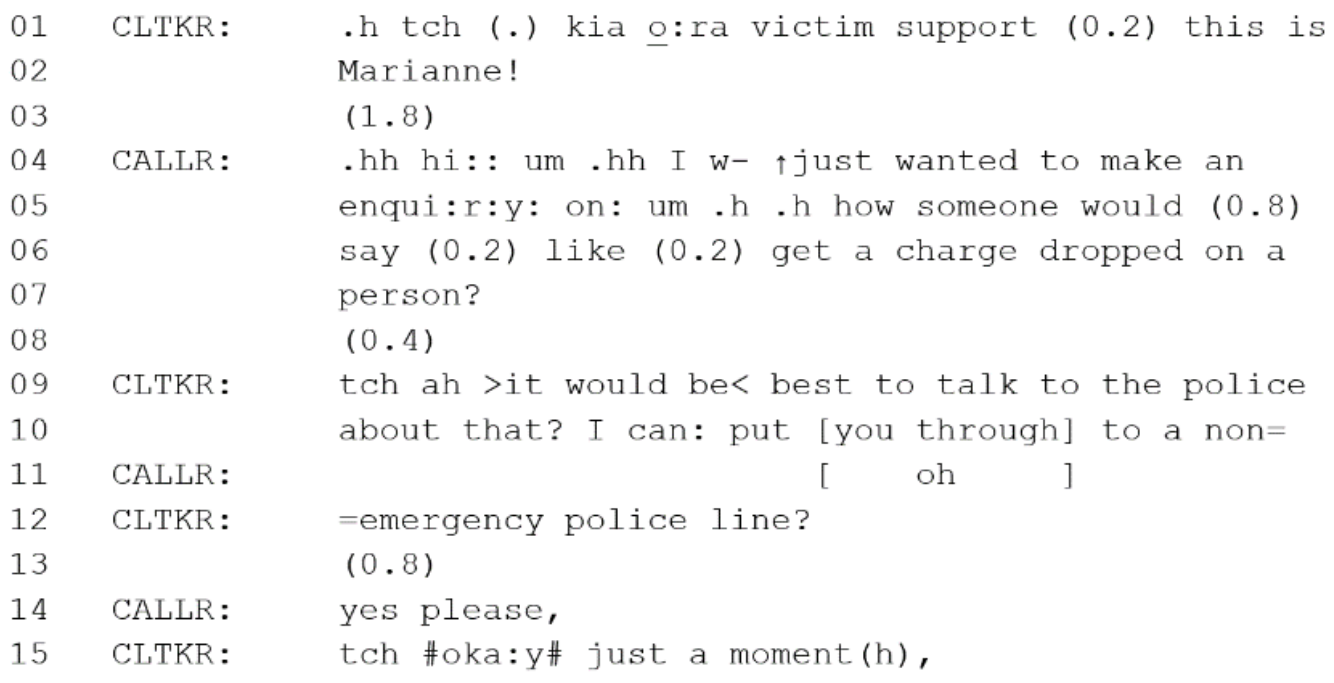

The kind of help the caller is seeking, and the way she asks for it, disavow her identity as a victim. The caller is seeking advice 
about how to "get a charge dropped" (line 6). Laying charges against someone is a method by which institutions (such as police and courts) formally recognise (alleged) victims and perpetrators. By seeking help to drop charges, the caller seeks to revoke a prior claim to victimhood.

The design of the caller's request also inverts the link between help and victim identity. Her use of reference forms manages the inferences that can be drawn about her from her request for help. The non-recognitional reference "someone" (line 5) is regularly used when speakers presume their recipients do not know (or need to know) the person referred to (Schegloff, 1996). By deviating from the unmarked reference "I" (line 3), the caller displays that she is not necessarily seeking help for herself, thus pushing back on the inference that seeking help from Victim Support makes her a victim. Likewise, using the indefinite article to refer both to "a charge" and "a person" (line 6) neutralises inferences that would otherwise be available about the problem and the people involved (cf. 5.4.1).

Even though the caller disavows a victim identity, she displays an expectation that her problem is a relevant one for institutional help. Directing her enquiry to the call-taker - and the institution she represents - displays the caller's expectation that Victim Support can provide help for these kinds of problems. However, the call-taker displays a different understanding of how the caller can be helped. Rather than answering the caller's enquiry, the call-taker provides advice. The design of the advice, " $>$ it would be $<$ best to talk to the police" (line 8), matches the caller's design of her request, presenting the advice as general course of action rather than something the caller specifically should do (see Emmison \& Firth, 2012; Vayreda \& Antaki, 2009). The call-taker moves from advice to offer in the same turn of talk, presenting transfer as a relevant form of help in the here and now. For the caller, advice about dropping charges is a form of help Victim Support could provide; but for the call-taker this help lies in the deontic realm of police. Thus, 
participants negotiate which institutions can provide different kinds of help.

In 5.4.4, the caller likewise manages the link between a victim identity and help, and the moral inferences that can be drawn based on this relationship.

\subsubsection{Jenny 2}

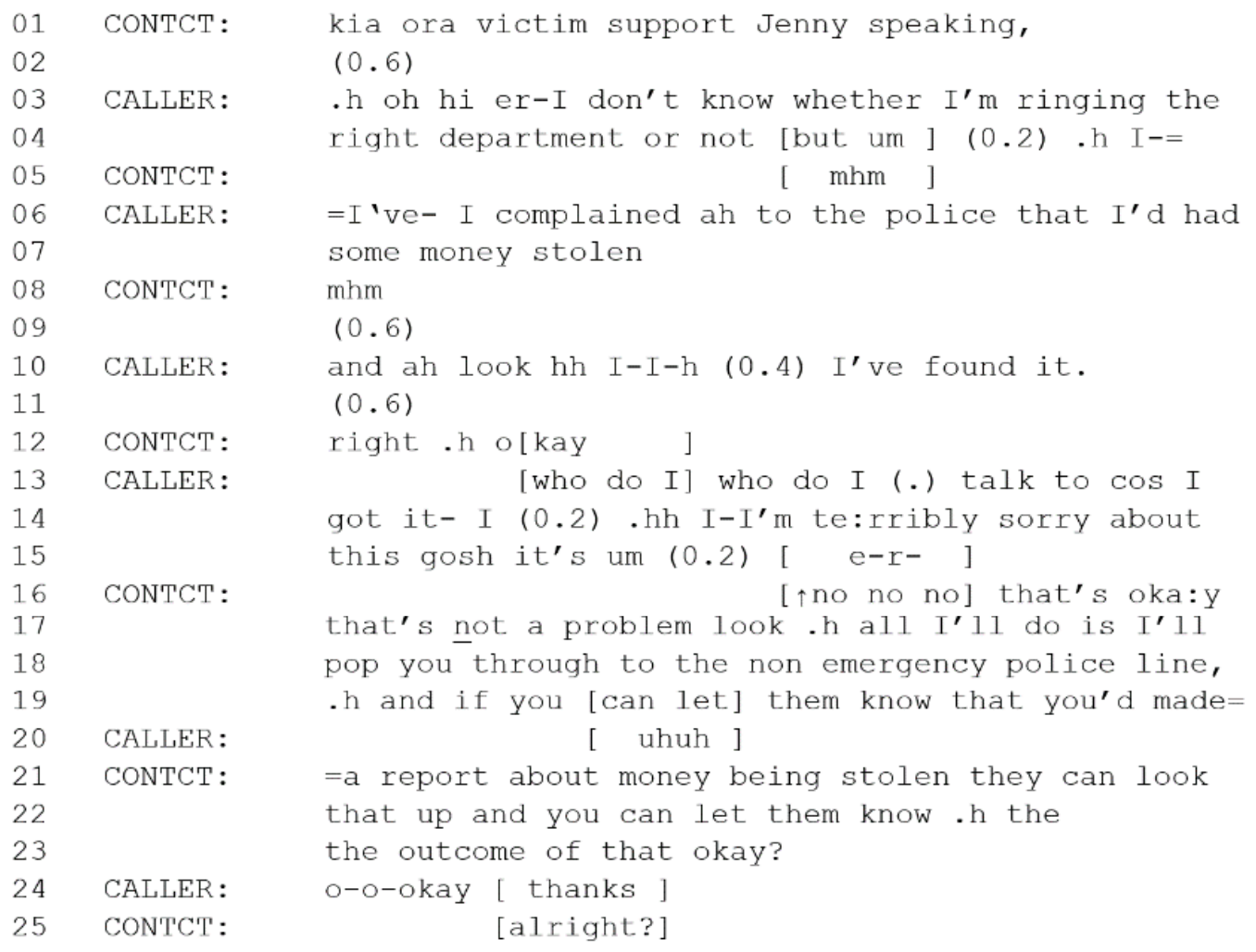

The caller begins by indicating a potential misalignment between caller and called, displaying her understanding that Victim Support may not be the "right department" (line 4) to provide the kind of help she seeks. Before she even presents her problem or asks for help, the caller suggests that the nature of her problem (and identity) are not straightforwardly fitted to the kind of people and problems the organisation can support.

The caller's description of different versions her problem (lines 4-10) demonstrates the consequential ways identity and action 
can be linked (see Cuff, 1993). The caller first describes complaining about stolen money (lines 6-7), an activity which makes her identity as a victim relevant. This identity is associated with entitlement to seek help from police. However, the caller's second description, of having "found" the money (line 10) re-categorises both herself and her problem. If the money was not stolen, but lost, her problem is not a crime. And if the caller has not experienced a crime, she is not a victim. Furthermore, if she is not a victim, she is not entitled to police help. Complaining to police about stolen money is a victim's right. Complaining to police about lost money makes different inferences available about her identity and motives (see Jayyusi, 1984). Thus, different versions of reality make different inferences available regarding the caller's identity and her rights to help.

Caller and call-taker display different stances on the accountability of the caller's action. The caller treats her actions as morally accountable through an incomplete account (line 13), explicit apology (line 14), stance marker "gosh", and perturbations in talk (line 15), which display her emotional stance of upset. The call-taker, however, uses the multiple saying "no no no" (line 17) to cut short the progression of the caller's apologies (Stivers, 2004) and explicitly claims "that's not a problem" (line 18). The call-taker treats the caller as entitled to ask for help and offers to transfer the call (lines 17-23). The design of the call-taker's request presents transfer as a form of help the caller is entitled to. She minimises the costs of her action with the preface "all I'll do" and the description "pop you through" (line 18) to display that granting the caller's request is no imposition, but a form of help she can readily provide (Clayman \& Heritage, 2014). In this way, she invokes her identity as a service provider, and establishes the caller's reciprocal entitlement to request and receive services from the organisation (although ultimately the resolution of her problem lies with police). 


\subsection{SUMMARY}

Participants invoke and negotiate the link between identity and help in different ways when callers seek different kinds of help. Different ways of building a request for help display callers' understandings of who they are to their recipient, and participants' relative entitlement and obligation to help.

Requesting transfer to a support worker is a kind of help that invokes callers' identities as clients. After all, having a support worker is a predicate of being a client of the service. In these calls, callers do not need to claim or demonstrate their identities as victims, because as clients they are already established as legitimate victims who have been recognised by the service. Although transfer requests can be sufficient to identify callers as clients and victims, when trouble arises, call-takers make explicit reference to victim categories to establish a joint understanding of who callers are and the kind of help they can be given. Callers display their understanding of the institutional relevance of a victim identity in this context, but display that other identities are relevant for how they understand themselves and their relations to others. Thus, whether identifying as a friend of a support worker, or as a survivor, callers display different stances towards a victim identity. This demonstrates some of the practical trouble callers face in managing their identity when seeking help from Victim Support, a theme I will return to in the Discussion.

Participants oriented to the link between help in the form of emotional support and callers' identities as victims of recent experiences. This link is one way that the common-sense assumption victimisation causes emotional trauma (see Gavey \& Shmidt, 2011) is made manifest in interaction as a practical resource for participants to build and interpret requests for help. As other work has shown, requests are not delimited by linguistic forms like questions (Fox \& Heinemann, 2016; Lindström, 2005; Stevanovic, 2011). In certain contexts - and based on certain relationships between participants - 
statements, descriptions, or displays of emotion can be understood as seeking help. After all, what counts as a request is, in the first instance, a matter for participants to determine. On the Victim Support helpline, participants treat descriptions of victimisation as requests for emotional help. Although in some cases, this link is treated as taken-for-granted, callers can challenge the assumption that their identity as victims means they are seeking help. In fact, the link between a victim identity and help is a negotiated accomplishment that can be invoked and used by participants strategically.

When seeking practical advice or advocacy for problems resulting from victimisation, callers invoked their identities as victims explicitly to establish their entitlement to help. Self-categorisations present callers as the kind of people whom the organisation claims to support - even if they may not have an institutionally relevant problem. Furthermore, categorisation invokes callers' rights and entitlements as victims, and Victim Support's comparative obligations to help. Categorisation is a resource for callers to advance complaints that the help they are entitled to receive has not been provided.

Seeking information also invoked callers' identities. The kind of information sought, and how it was asked for, made commonsense inferences available about who callers were and what they had experienced. Asking for certain kinds of information (such as someone's potential release from prison) invoked callers' identities as victims. Conversely, other kinds of information (such as how to drop charges) disavowed caller's identities as victims. Even while seeking help from Victim Support, callers can challenge or undermine the link between identity and action.

For an institution named Victim Support, one resource for callers seeking help is to categorise themselves as victims to establish their entitlement to support. In the cases above, callers' claimed victim identities were also ratified by other institutions such as police 
and courts. Thus call-takers do not contest their identities as victims, but when the help requested falls beyond their institutional remit - as is often the case - they may reformulate the kind of help callers need and which institutions are obligated (and able) to provide it. I examine this dilemma for call-takers in more detail in the chapter which follows. 


\section{OFFERING AND DENYING HELP}

This chapter further explores the relationship between identity and help by examining how call-takers make relevant callers' identities when offering or denying help. Call-takers are institutional gatekeepers who have the deontic authority to determine if callers are eligible for service (Heritage \& Clayman, 2010a). In this context, eligibility is predicated upon a victim identity and a relevant institutional problem fitted to the kind of help available.

I examine how call-takers constitute callers' identities when responding to their requests for help. I begin with cases that show two different ways call-takers denied callers' requests for help. Then, I analyse how identity is a resource for call-takers to make offers. I discuss two kinds of help: enlisting callers as clients to receive support and transferring callers to other services. Transfer is by far the most common form of help provided on the helpline, with $80 \%$ of the calls in the sample transferred. Yet callers do not always orient to transfer as an acceptable form of help. I examine how callers and calltakers negotiate what callers need and how it can be provided. These negotiations rest upon understanding who the caller is relative to different institutions. In the analysis, I attend to participants' orientations to their relative epistemic and deontic rights to determine who they are and how help can be given.

\subsection{DENYING HELP}

Just as callers orient to the link between victim identity and help when making requests, call-takers orient to this link when denying them. For a service entitled Victim Support, denying a request for help implies the caller is not a victim who can be supported. Call-takers use two different resources to render denials accountable. First, I show how call-takers can formulate callers' problems as beyond the institutional remit. Denying callers have a relevant problem for Victim Support denies that they are the kind of 
people who can be supported. This claim inevitably counters the position callers have taken by calling the helpline (namely that they are victims entitled to support). Second, I show how the link between identity and access to support is made explicit when callers categorise people to deny requests for service.

In the case below, the caller's request for police help displays her understanding of her problem as criminal victimisation. The call-taker's denial of this request reformulates the caller's problem as one which neither police nor victim support can help with. This formulation of the caller's problem has implications for her identity as a victim.

\subsubsection{Samuel 89}

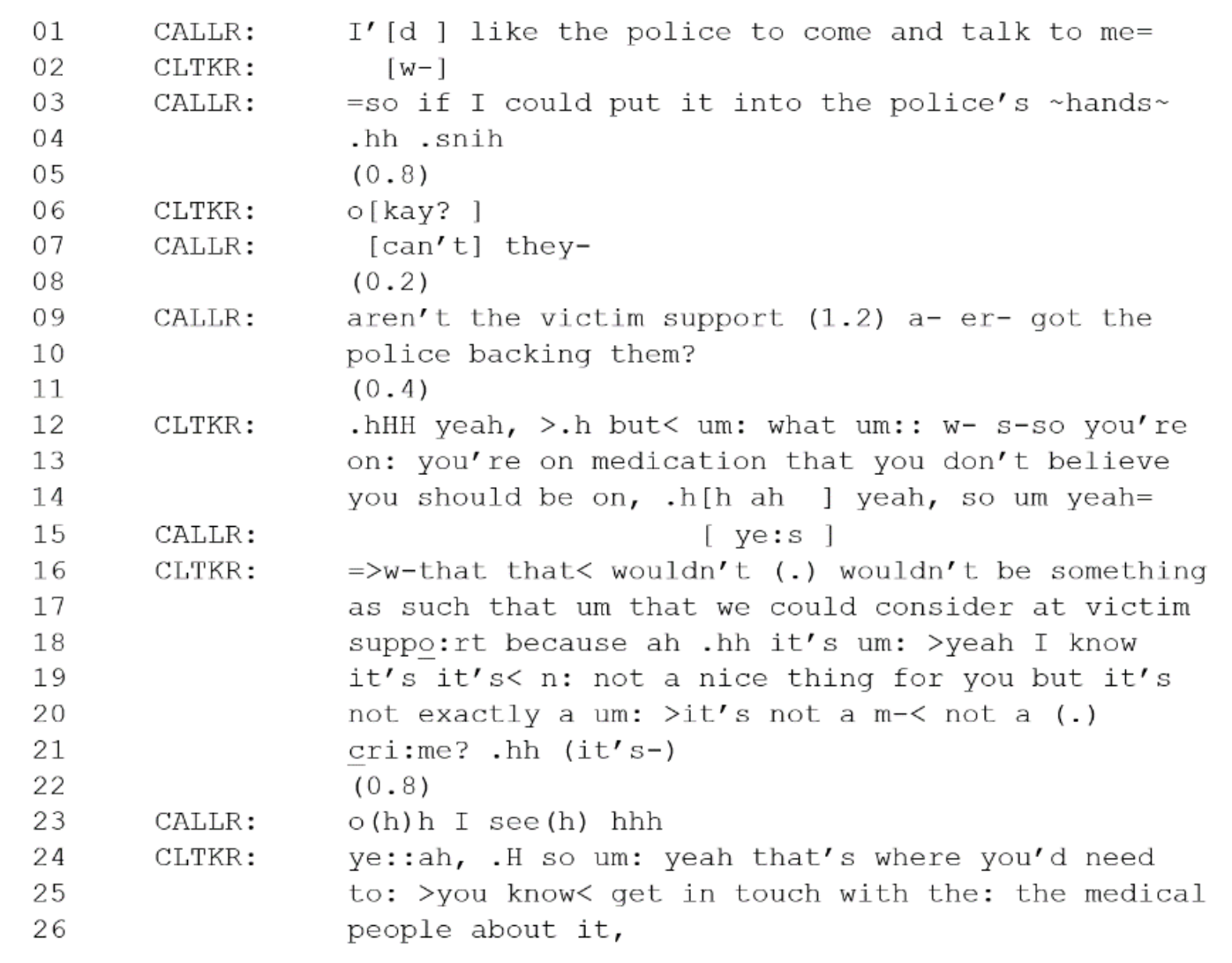

The caller displays an understanding that she is entitled to help from Victim Support and police. Declarative requests display 
speakers' understanding of their entitlement to help (Fox \& Heinemann, 2016). Here, the caller's request, "I'd like the police to come and talk to me" (line 1) formulates her desires and displays her expectation of the request being granted. Even when a response is not forthcoming, she orients to the relationship between service-providers as a relevant contingency (lines 9-10), rather than her entitlement to ask for help. One basis for the caller's entitlement is her identity as a victim.

The call-taker, however, orients to the caller's categorybound entitlements to make requests of the service. After marked perturbations which display a difficulty in responding (line 12), he formulates her problem to account for denying her request. He describes the problem as one that the caller believes she has (lines 1214), rather than an objective state of affairs (e.g. you've been burgled). The caller agrees (line 15), asserting primary epistemic rights to her own experience (see Heritage \& Raymond, 2005). However, the calltaker then assesses the caller's problem in terms of institutional considerations, claiming her problem is not "something" (line 16) Victim Support can help with. The plural pronoun "we" (line 17) identifies the call-taker as a member of the organisation and claims the deontic rights to determine what problems can be addressed (see Heritage, 2004).

The link between the caller's problem and the organisation's ability to help her is spelt out with a lexically-marked account (line 18) where the call-taker draws on two competing descriptions. The first, "it's $<$ n: not a nice thing for you" (line 19) describes the caller's negative stance towards her problem. The second, which parses as it's not a crime (lines 20-21), describes the absence of an institutionally relevant category (crime) which would make the caller a victim entitled to help from Victim Support and Police. People are generally understood to have the epistemic rights to formulate their experiences (Heritage \& Raymond, 2005). The perturbations in the call-taker's talk (lines 19-21) orient to the delicacies of formulating the caller's 
experience, while nevertheless asserting epistemic rights to assess and categorise her problem. By deleting the mitigating claim "exactly" (line 20), the call-taker's repaired talk directly disavows the problem is a crime. The category term "cri:me?" (line 21) comes after a micro-pause and is intonationally marked as the institutionallyrelevant criteria missing from the caller's problem. The commonsense link between victims and crimes makes inferentially available that if she has not experienced a crime, she is not a victim.

The call-taker claims that the caller does not have an institutionally relevant problem and that, by extension, she is not the kind of person Victim Support or police can help. Instead, he suggests "the medical people" (lines 25-26) as alternative help-providers. Rather than formulating a specific occupation (such as nurse, general practitioner, etc.), this category refers to relevant people who can help with problems like the caller's. If she is a victim of crime, the caller may be entitled to help from Victim Support and police, but as someone who believes she is on the wrong medication, she is in fact entitled to help from members of the medical profession.

The participants here orient to competing versions of reality, or different interpretative repertoires. The caller's request constructs her as a victim who is entitled to seek help. In this version of reality, the action of seeking help from Victim Support and police is accountable and they are obligated to provide it. Yet in the version of reality described by the call-taker, the caller's identity and entitlement is constructed differently, and a different action - denying her request for help - is rendered accountable. If she is not a victim with a relevant institutional problem, she is not entitled to help from the service and he is not obligated to provide it. Thus, different versions of reality - what has happened to the caller, who she is relative to her problem and who is obligated to help her - are consequential for access to support. 
In 6.2.2, the call-taker likewise orients to the link between a victim identity and a relevant problem to accountably seek help. The caller's partner has been temporarily removed from the property by police and she is seeking a mediator to be present when he returns. The call-taker orients to the caller and her partner as having different entitlement to support by virtue of their actions and identities.

\subsubsection{Monica 16}

\begin{tabular}{|c|c|c|}
\hline 01 & CALLR: & um: (0.6) tch .hhhhh I just want to know if \\
\hline ? & & there's anybody I can contact that could \\
\hline & & $\sim$ come around here? \\
\hline & & $(0.4)$ \\
\hline & CALLR: & I'm in nortonburt in moorland, um could come \\
\hline & & round here (0.2) 'bout nine thirty in the \\
\hline & & mo:rning to- just be here when he comes and \\
\hline & & $(0.4)$ talk to him. \\
\hline & & $(0.4)$ \\
\hline & CALLR: & .Shih (1.0) HHuh \\
\hline & & $(1.8)$ \\
\hline & CLTKR: & okay $\underline{u}: m$ so victim support [only ] supports= \\
\hline & CALLR: & [.snih] \\
\hline & CLTKR: & $=$ victims of cri:me so: um our support workers \\
\hline & & wouldn't be able to: provide support fo: $r$ \\
\hline & & your partner? \\
\hline & & $(0.8)$ \\
\hline & CLTKR: & um: but what I could [do is ] have them to= \\
\hline t & CALLR: & [ (br) $\mathrm{HH}]$ \\
\hline & CLTKR: & =provide support for you:, =but I'm just trying \\
\hline & & to $\uparrow$ che:ck.h I'm just trying to: work how-how \\
\hline & & I'd put you into our system, \\
\hline & CALLR: & .sniHh \\
\hline & CLTKR: & so um (.) has he committed an offence? of any \\
\hline & & sort! \\
\hline & CALLR: & .hhhhhh $\sim$ um not that I'm aware of. \\
\hline
\end{tabular}

The caller's request for "anybody I can contact" (line 2) displays her understanding that the call-taker may be able to refer her to other services. The help she requests is a visit from someone who can "just be here" (line 7) and "talk to him" (line 8). The call-taker treats this request as ambiguous regarding whether the caller is seeking help for herself or her partner. Her response distinguishes 
between the caller's and her partner's different identities and associated rights to receive help from the service.

The call-taker makes explicit the limits of service, claiming that "victim support only supports victims of cri:me" (line 12-14). This explicitly links access to help with an identity (victim) and a relevant problem (crime). The upshot, marked by "so:" (line 14) is that the caller's partner is not eligible for support. The call-taker thus displays her understanding that the partner is not a victim of crime. Call-takers can use plural pronouns to identify they are speaking as members of the institution (Heritage, 2004). Here, the call-taker uses the plural pronoun "our" (line 14) to present the denial of help as an institutional constraint on entitlement. The call-taker thus displays to the caller that if she was seeking help on behalf of her partner, her request cannot be granted.

As a counterpoint, marked with "but" (line 18), the call-taker suggests the caller may be eligible for support. The call-taker's offer, "what I could do is have them to provide support for you:," (lines 1820) uses the personal pronoun "I" to refer to the call-taker's actions directly, while the modal verb "could" marks this offer of help as contingent. This offer suggests that the caller, unlike her partner, is the kind of person the organisation can support, namely a victim of crime. However, in a latched turn constructional unit (line 20), the call-taker displays trouble entering the caller into the system (lines 21-22), treating the caller's identity as non-straightforward.

Despite the caller's earlier description of police removing her partner from the property (not shown), the call-taker displays that she has not understood that description as referring to a crime, which is made explicit with her interrogative (line 24). The caller's negative response (line 26) likewise displays her understanding that the events she has previously described do not constitute "an offence" (line 24). The participants here jointly orient to the activity of committing an offence as bound to the category crime. Based on the call-taker's 
earlier definition of the limits of service (lines 12-14), if the caller has not experienced a crime, she is not a victim, and thus ineligible for Victim Support.

Thus, when denying requests for service, call-takers disavow that callers are victims with relevant problems for Victim Support. These denials are instances of gate-keeping (Heritage \& Clayman, 2010a) where call-takers reinforce the boundaries of the appropriate relationship between a victim identity and entitlement to help. In contrast, the cases analysed in the following section demonstrate how call-takers can ascribe callers' identities as victims to offer them help.

\subsection{OfFERING REFERRAL}

The first case below demonstrates the straightforward way call-takers link callers' identities and experiences when offering to take a referral and enlist them as clients. The second case shows how the link between identity and help is procedurally consequential for offering referral and demonstrates some of the difficulties in ascribing the caller as a victim with a relevant problem.

In 6.2.1 which follows, the call-taker reformulates the caller's experience to account for offering referral. 


\subsubsection{Samuel 61}

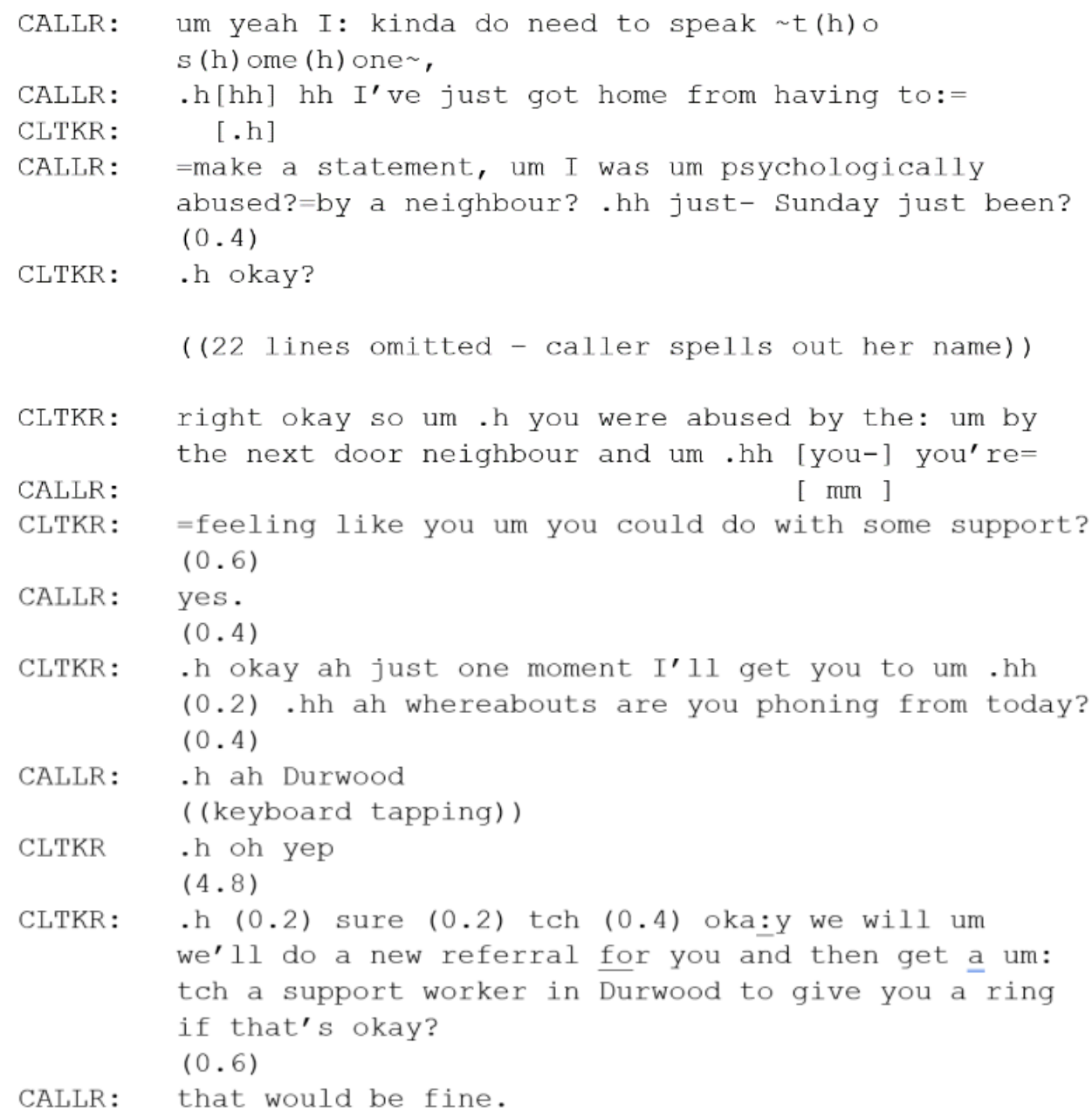

Like the caller in 5.2.1, the caller is seeking emotional support after a recent experience of victimisation. She produces a declarative request (lines 1-2) and describes her experience to account for seeking help (lines 5-6). The call-taker's request for confirmation links the caller's experience of being "abused" with her request for support (lines 9-12). The call-taker's turn displays his understanding of who the caller is and why she is calling. Requests for confirmation like the call-taker's display an orientation to recipient's primary epistemic rights to describe their experiences (Heritage \& Raymond, 2005).

After the caller's confirmation (line 14) and the insertion sequence to record the caller's location (lines 17-22), the call-taker 
produces the referral offer. He uses the plural pronoun "we" to propose a joint activity, "do a new referral" (line 24) which will require the collaboration of both participants as the call-taker asks questions and records the caller's answers on the database. He indicates the distribution of benefits in the upcoming action (Clayman $\&$ Heritage, 2014), by designing the offer to include "for you" (line 24) and explaining that the referral process will result in a local support worker contacting the caller (line 25-26). Thus, his offer is designed to facilitate the kind of help the caller requested by arranging someone for her to talk to (lines 1-2). Notably, the specification of the category term "support worker" (line 25) indicates that the calltaker's role is to arrange support, rather than provide it during the call itself (cf. 5.2.1).

In the following case, the call-taker likewise links the caller's experience with her access to support. However, in this case (which is a continuation of the call presented in 6.1.2), formulating the caller's experience in an institutionally relevant way requires some interactional effort. Although caller and call-taker earlier established that the caller's experience was not a crime, the call-taker has undertaken to enlist her as a client. Two minutes after the previous extract, the call-taker directly links a formulation of the caller's problem with the organisation's ability to help her. 


\subsubsection{Monica 16}

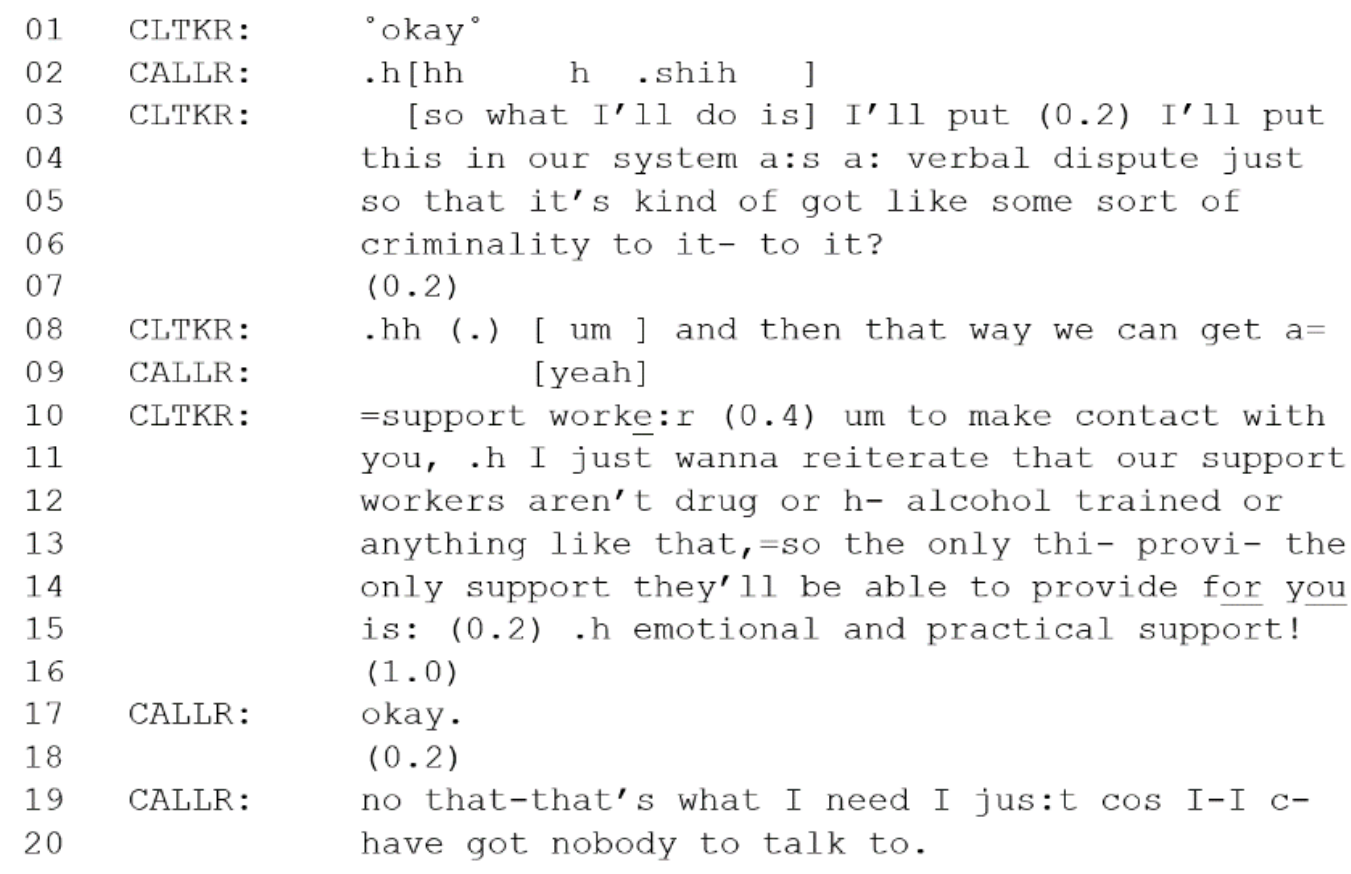

The call-taker ascribes a category for the caller's experience to accountably render her as the kind of person the organisation can support. She announces that she will enter the caller's problem "a:s a: verbal dispute" (line 4). This category is one of many police codes that call-takers can select when enlisting clients for support. The calltaker links the predicate of "criminality" (line 6) with this category, which is tied to the institution's ability to allocate support workers (lines 8-11).

By categorising the caller's experience as a crime, the calltaker constructs the caller's identity as a victim. This version of reality allows the call-taker to manage accountability and personal stake (Potter \& Wetherell, 1987). The call-taker renders her action of offering referral accountable by ascribing the caller's identity as a victim of crime. If the caller is a victim of crime, she is entitled to support, and the call-taker can accountably enlist her for support. Alternative descriptions of who the caller is and what she is doing (i.e. someone seeking help for troubled partner) render other actions 
(such as denying the request) accountable and reconfigure the rights and obligations between participants (see 6.1.2).

Having rendered the caller's problem as an institutionally relevant one (and by extension, her identity as a victim), the call-taker attends to the nature of the help available. She disavows that support workers can provide help related to drug and alcohol problems, referring to the caller's earlier categorisation of her partner as a drinker (not shown). Instead, the call-taker asserts that institutionally relevant help is "emotional and practical support" (line 15) for the caller. After accepting this restriction (line 17), the caller accounts for why she needs this kind of help (rather than the specialist alcohol and drug counselling) by claiming that she has "nobody to talk to" (line 20). She thus treats emotional and practical support as accountable kinds of help to seek from an institution, warranted only when other help-providers are unavailable (Sacks, 1972b). The ways callers account for seeking institutional help will be picked up in the following chapter.

Call-takers oriented to their personal stake when offering referral. As gatekeepers to the service, call-takers' decisions to offer or deny the service are available to scrutiny from other institutional representatives. To justify referral offers, call-takers draw on interpretative repertoires that construct callers as legitimate victims and themselves as institutional representatives obligated to help. These descriptions are at once practical - accounting for the local course of action - and ideological, constructing a version of reality in which certain people are recognised as legitimate victims within a broader social-moral order. Thus, call-takers demonstrate that the link between experience, identity, and help is procedurally consequential for access to Victim Support services. In the section below, I analyse call-takers' offers for a different kind of help. 


\subsection{OFFERING TRANSFER}

Offers of transfer recognise callers' entitlement to help, but deny that Victim Support can help them. In many cases, these offers counter a position that callers have taken by calling the helpline, namely that they have a problem relevant for Victim Support. Below, I analyse how participants negotiate the formulation of callers' experiences and identities to determine what they need and how they can be helped. In the following three cases, call-takers offer help in the form of transfer to police. These offers display call-takers' understandings of callers as people with what Whalen and Zimmerman (1990) called a 'policeable' problem. In other words, offers to transfer to police treat callers as entitled to police help. Callers negotiate both how to understand their identities relative to their problems and the nature of the help they need.

In the following case, participants negotiate the kind of help the caller needs, displaying different understandings of the caller's rights to help from different service-providers. 


\subsubsection{Molly 60}

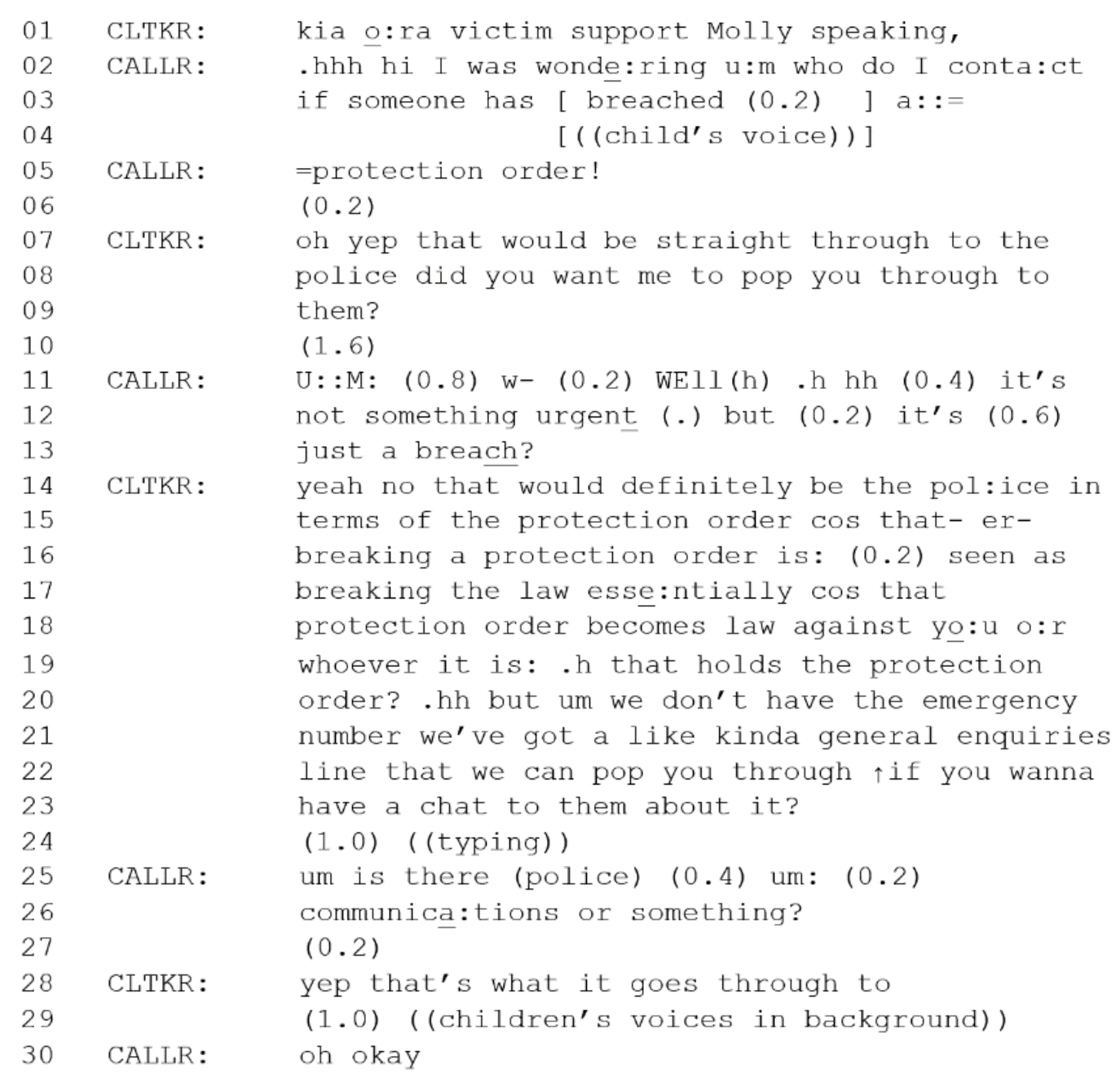

The design of the caller's request displays her understanding that her problem may not be one that Victim Support can help her with, but that the call-taker can inform her of "who" she needs to contact (line 2). In a similar way to transfer requests (analysed in 5.1), this request constitutes the social context of the call as a conduit to service. The call-taker responds by providing advice and then offering transfer. The advice, "that would be straight through to the police" (lines 7-8), treats the caller's problem as a straightforward and relevant policeable matter (see M. Whalen \& Zimmerman, 1990). The nature of the caller's problem infers her identity as a victim. Protection orders are granted by New Zealand family courts in cases 
of domestic or family violence. Having a protection order is a predicate of being a victim, granting the caller entitlement to seek police help. Offers designed as interrogatives display that speakers have educed a problem from prior talk (Curl, 2006). Here, the calltaker begins her offer with "did you want" (line 8), indicating that she has determined the problem (needing to talk to police) and is offering transfer as a solution.

Yet the caller does not display the same understanding of her problem as a policeable matter. Rather than accepting or rejecting the transfer offer, she describes her problem. She first disavows that it is "something urgent" (line 11), displaying an understanding that transfer to the police is inapposite for non-urgent problems. As a counterpoint, she transforms her initial description (lines 1-4) into categorisation, "it's (0.6) just a breach?" (lines 11-12) including the minimising token "just" to disavow that her problem is serious. Thus, caller and call-taker draw on two different interpretative repertoires. The call-taker's offer displays her understanding that a breached protection order is a relevant matter for police intervention. By contrast, the caller described her problem differently to account for why she has called Victim Support rather than police.

The call-taker disagrees with the caller's stance on her problem, upgrading her claim that the problem is a policeable matter. She reformulates the caller's description ("just a breach") as "breaking the law" (line 17). This description invokes the category crime, a kind of problem with common-sense links to police. If a law has been broken, and a crime committed, the caller can be understood as a victim. However, the call-taker refers to "yo:u o:r whoever it is: .h that holds the protection order?" (lines 18-20), using an or-prefaced repair to suggest that both reference terms (the caller or anyone in her situation) are technically correct (see Lerner \& Kitzinger, 2015). Nonetheless, she agrees that the caller's problem is not an urgent police matter, specifying that the offered transfer is to the general police line. Neither caller nor call-taker treat the breach as an 
emergency. Her subsequent offer suggests the caller can "have a chat to them about it?" (line 23), characterising the caller's actions in a mundane way (rather than alternative like report it, or make a complaint) to pursue acceptance (Davidson, 1985), which the caller later provides (line 30).

In the following case, participants likewise negotiate how to understand the caller, her problem, and her accompanying rights to help.

\subsubsection{Samuel 83}

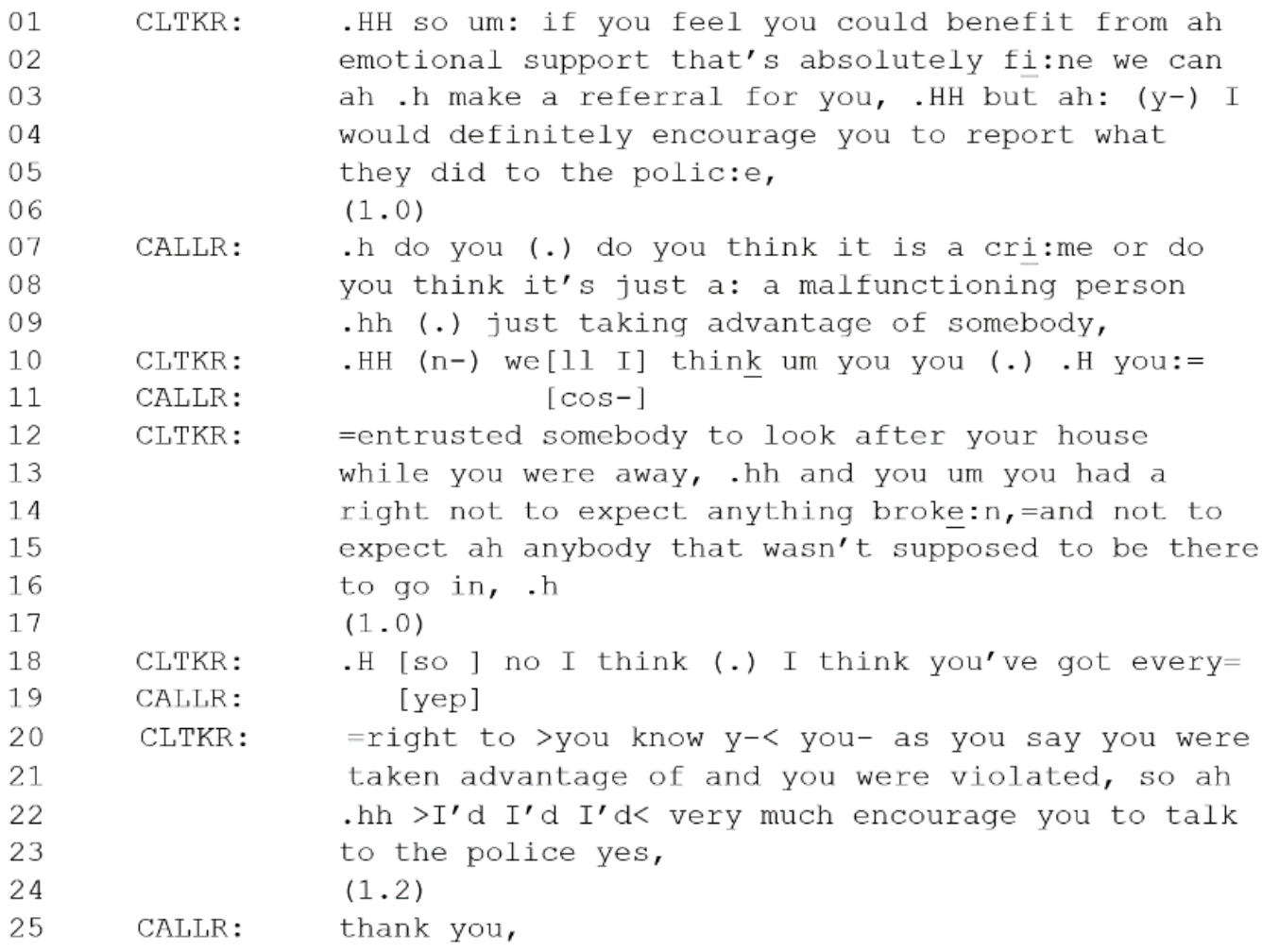

Caller and call-taker displays different understandings of the caller's identity and her associated rights to help from different institutions. The call-taker's offer to make a referral (lines 1-3) displays his understanding that the caller is a victim entitled to emotional support from Victim Support. His advice that she contact police (lines 3-5) displays his understanding that, as a victim, she is also entitled to report her experience to police. The caller, however, 
treats the status of her problem and identity as a victim as yet to be determined, asking the call-taker for his opinion.

Rather than accepting or rejecting the advice, the caller provides the call-taker with two versions of her problem formulated as yes/no interrogatives. The first, "do you think it is a cri:me" (line 7) displays her understanding of a relevant problem for police help. The second, "do you think it's just a: a malfunctioning person .hh (.) just taking advantage of somebody," (line 7-9) displays her understanding of a problem that does not warrant police help. The principle of contiguity (Schegloff, 2007b) suggests the second option is designed for agreement, and is the caller's understanding of her problem. If the caller's experience is a crime, the person responsible is a perpetrator and she is a victim. Within this interpretative repertoire, reporting to the police is accountable. However, if the caller's experience is simply unfortunate, the person responsible is "malfunctioning" and she is merely "somebody", she is not entitled to report what happened to police. People who seek police help without a relevant policeable problem can be morally (or even legally) sanctioned (M. Whalen \& Zimmerman, 1990) and the caller displays that she cannot accountably accept the call-taker's offer of transfer.

Rather than selecting either of the caller's options, the calltaker formulates the caller's experience and identity in a different way to invoke her moral rights to seek help. He describes how she "entrusted" her home to someone (line 12), invoking a trust-based relationship between the caller and house-sitter. That relationship is a locus of rights and obligations, whereby the caller (as homeowner) has the rights to expect her property unharmed and her rules upheld (lines 14-16). The fact the house-sitter broke this agreement amounts to the caller being "violated" (line 21). This description accounts for his renewed recommendation - although notably he advises she "talk to" police (lines 22-23) rather than report the crime. This allows him 
to defer to the police's rights to judge events as crimes, while nevertheless arguing the caller is entitled to turn to them for help.

In this case then, participants display that different ways to understand the caller and her problem provide for different rights and entitlements. Although the call-taker does not make the caller's identity as a victim explicit, he uses her relationship with the housesitter to invoke her rights to seek help. In the following chapter, I further explore how participants orient to relationship-based rights and obligations when understanding victimhood and how to respond. First however, I present one final case where the call-taker's offer is not accepted. Despite the call-taker's displayed stance on the caller's identity and entitlement to help, she treats other aspects of her identity as relevant for understanding her problem and seeking help. This case demonstrates how the link between identity and help is procedurally consequential. 


\subsubsection{Adrian 10}

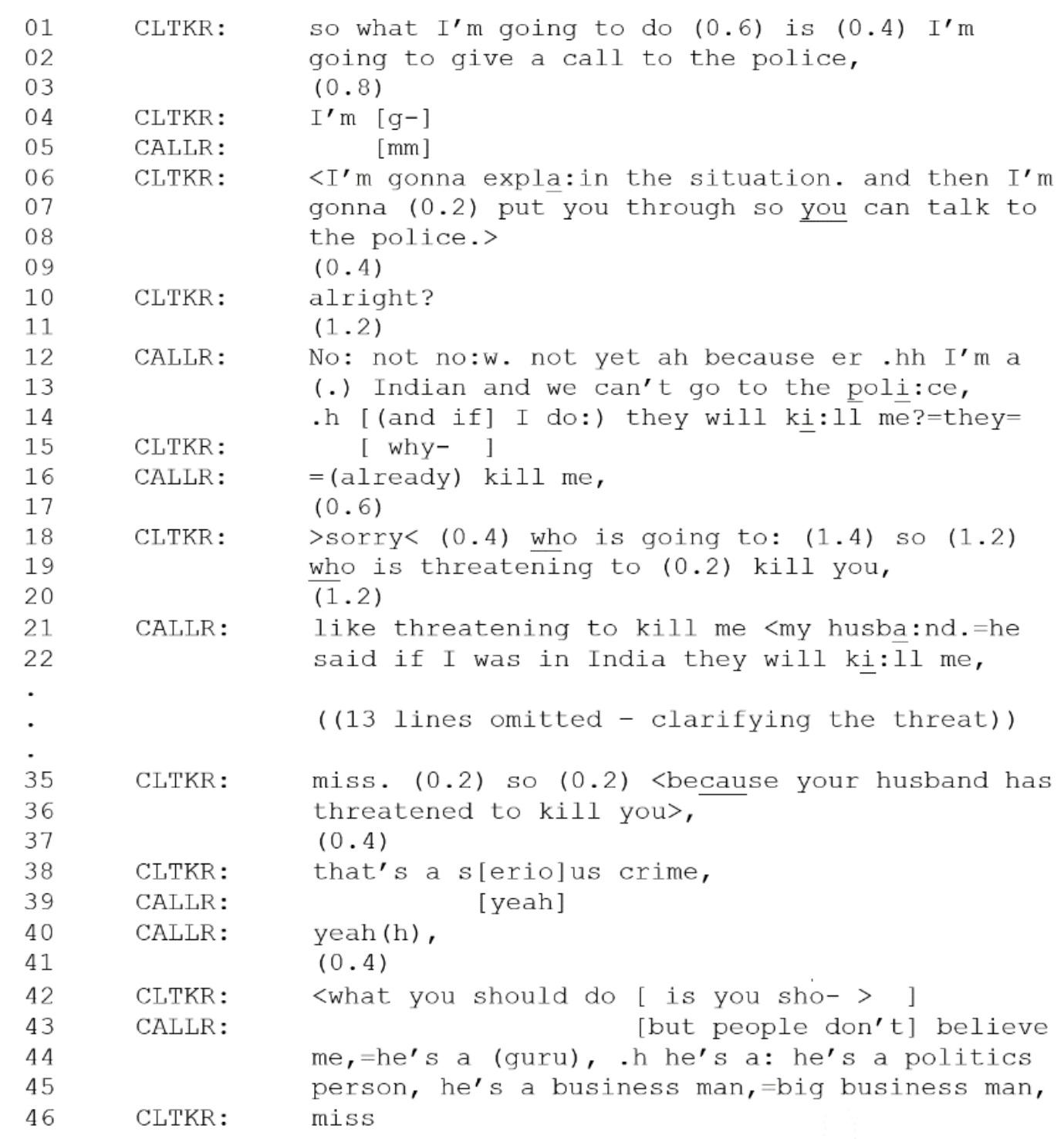

The call-taker's transfer offer displays his understanding of the caller's identity as a victim of crime who is entitled to police help, but in her rejection, she orients to a different identity as relevant. She invokes her racial identity with the self-categorisation "I'm a (.) Indian" (lines 12-13). Using the plural pronoun "we" to speak as a category member, she specifies the relevant predicate, "we can't go to the poli:ce" (line 13). The caller suggests that if she were to violate this category-restriction by taking up the call-taker's offer to talk to police, she could be killed for doing so (lines 14-16). That these 
threats come from the caller's husband (whose shared racial membership can be inferred) demonstrates Sacks' (1979, p. 13) argument that "systems of social control [are] built up around these categories which are internally enforced by the members."

The call-taker's request for confirmation (lines 18-19) display his orientation to the relevance of the caller's victim identity rather than her identity as an Indian. Instead of accepting her rejection of his offer, he uses her disclosure of threats as a resource to begin a modified offer for the same kind of help (Davidson, 1990). After clarifying the threat (not shown), he formulates the caller's problem, "your husband has threatened to kill you" (lines 35-36), and categorises it as "a serious crime," (line 38). This shift from description to categorisation displays his understanding of what activities constitute serious crimes (see Stokoe, 2009). By formulating the caller's experience as a serious crime, the call-taker invokes her identity as a victim and reasserts her entitlement to seek police help. His advice about what she "should do" (line 42) is based on his categorisation of her experience, making it projectable as a subsequent offer of transfer to police. The caller displays her understanding of this projected action, producing another rejection before he has finished speaking (lines 42-43).

Rather than offering an alternative categorisation of her problem and herself (as the callers in 6.3.1 and 6.3.2 do), the caller invokes her husband's identity to provide another reason why she cannot turn to police. She claims that "people don't believe me," (lines 43-44) and ties this attribute to his membership in the categories "a politics person" and a "big business man," (lines 44-45). For the call-taker, the caller's disclosure of a serious crime justifies her seeking police help. For the caller - regardless of the criminal nature of her experiences - her husband's identity invalidates her seeking any kind of help. It is not only police, but "people" in general who doubt the caller. She attributes this doubt, not to aspects of her identity, but his - because he is a politician and businessman, people 
will not believe him capable of crimes. The link between gendered violence and disbelief has long been documented by feminists (see Jordan, 2004), and the caller's category-based account presents her fear of disbelief as culturally recognisable. The ideological dilemmas of seeking help as a victim of violence are further explored in the following chapter.

The call-taker treats the caller's problem as the institutionally relevant aspect in determining what kind of service should be provided. If she has experienced a serious crime, she is a victim, and thus entitled to seek help from police. The call-taker disregards the caller's orientation to racial and occupational identities for herself and the perpetrator._Notably, the caller does not disavow her identity as a victim nor the status of her problem as a serious crime. Yet, she indicates that the link between identity (as a victim) and action (talking to police) is not straightforward because other aspects of her identity provide conflicting norms about how to act and who to turn to.

Despite the caller's claims that her and her husband's identities are relevant for determining who to turn to, the call-taker does not treat these as institutionally relevant reasons for rejection. In the final line of this extract, he bids for the floor and offers transfer once more before the caller disconnects the call (not shown). The calltaker's disregard of the caller's reasons for rejection ultimately result in the call ending without the caller accessing help from police or Victim Support. This outcome demonstrates the consequential nature of how participants understand one another. The negotiations during the call can carry real-world implications for callers' safety, wellbeing, and access to support. 


\subsection{SUMMARY}

This chapter explored participants' orientations to the link between identity and help by examining call-takers' practices. Calltakers act as gatekeepers to determine whether callers are eligible for services. Although callers have primary rights to their experience (knowledge of what happened and how they feel), call-takers oriented to their rights to determine whether such experiences meet institutional requirements (cf. Lindström \& Weatherall, 2015). In performing the institutional task of gatekeeping, call-takers necessarily make judgements about caller's experiences, identities, and entitlements (Heritage \& Clayman, 2010a).

When denying callers' requests for help, call-takers treat callers as neither victims nor clients. In other words, they are not the kind of people with the kind of problems the organisation recognises an obligation to help. Although calling for help displays callers' understanding that they are a victim entitled to support, call-takers have the deontic rights to ultimately deny callers' requests. Thus, the link between identity and action is procedurally consequential. If participants do not establish a joint understanding of callers as victims, call-takers can accountably deny them access to the service.

Conversely, offering referral displayed call-takers' understanding of callers as eligible clients of the service. These offers treated callers as relevant people with relevant problems for the institution. Call-takers formulated caller's problems in ways that constituted their identities as victims and demonstrated the institutional relevance of their problems. Call-takers thus rendered their offers of help accountable by invoking callers' identities as relevant clients for support.

Offers of transfer likewise displayed call-takers' understandings of who callers were and what they needed. In some cases, call-takers treat callers as victims entitled to help from Victim 
Support and other services. In other cases, call-takers treat callers as victims, but deny their potential identities as clients. Although callers negotiated the nature of their problems and the kind of help needed, call-takers oriented to their greater deontic rights to determine how help was provided.

Through the different kinds of help they offer, call-takers display their understanding of who they are relative to callers. When call-takers offer to enlist callers as clients, they act as institutional representatives who are obligated to help victims in need of support. Yet by formulating callers' problems and identities in different ways, call-takers provide for the relevance of other help-providers. If callers are not victims, or their problems fall beyond Victim Support's institutional remit, then the organisation (and the call-taker) are not obligated to help them. Thus, negotiating the link between identity and help is procedurally consequential for the outcome of calls and the delivery or withholding of support.

In the following chapter, I extend my analysis of identity and help by focusing on callers who seek help on behalf of others. In this circumstance, categorising the problem and the person in need is also accompanied by categories for callers, which manage their rights and obligations to seek help on another's behalf. 


\section{SEEKING HELP ON BEHALF OF OTHERS}

This chapter explores participants' orientation to the link between identity and action when callers seek help on behalf of others. This kind of help-seeking invokes different kinds of relationships between identity and action. Callers orient to their own identity, and that of the person in need, as relevant for seeking help. Establishing someone's need for Victim Support, as documented in the previous chapters, invokes their identity as a victim. When seeking help on another's behalf, callers orient to their relationship with the victim and the rights and obligations this relationship provides to seek and provide help. I analyse how participants balance relationship-based rights and obligations with the rights and obligations associated with victim categories. In my analysis, I draw upon Sack's (1967, 1972a) important work on the categorical organisation of help-seeking. Below, I briefly discuss his key findings, before turning to my analysis. The analysis examines how callers establish others as victims with no one to turn to, how participants distinguish between seeking and providing help, and how rights and obligations are made salient when a request is denied.

Common-sense knowledge about category members and their respective rights and obligations structure the social organisation of help. Sacks (1967, 1972a) argued that rights and obligations to help are organised through standardised relational pairs. Some members of relationship categories are proper to turn to in a search for help (Rp), and others are improper (Ri). Sacks argued that people who turn to institutions for help use relationship categories to understand institutional representatives as strangers whom it is improper to turn to. For example, callers to a suicide helpline accounted for talking to strangers by claiming they had no one to turn to. Even though calltakers treated themselves as proper help-providers because of their specialist knowledge about suicide, callers understood the activity of help-seeking in terms of relationships. 
I analyse how participants orient to the categorical organisation of help when seeking help on behalf of others. Sacks (1967, p. 220) noted that "the restriction to use of Rp is an obligation the suicidal have to Rp," so that members of Rp, "on being turned to for help may themselves seek out a professional" as a proper helpprovider. In this chapter, I examine how categorical rights and obligations are negotiated when seeking help for another. The analysis shows how location can inoculate against $\mathrm{Rp}$ responsibilities, and how rights and obligations associated with victim categories can trouble those associated with relationships.

\subsection{FORMULATING 'NO ONE TO TURN TO' FOR ANOTHER}

How can a caller - in the act of seeking help for someone in need - nevertheless formulate that person as having no one to turn to? As Sacks (1967) documented, 'no one' can be understood as no available members of proper relationship categories (Rp). In the first three cases below, callers refer to location to account for why incumbents of $\mathrm{R}(\mathrm{p})$ categories are not available as someone to turn to. The following two cases demonstrate how victimisation can remove a present $\mathrm{R}(\mathrm{p})$ incumbent from the category of people whom it is proper to turn to.

In the first case, the caller uses the category friends to invoke self-other relations and account for why he is seeking help on behalf. 


\subsubsection{Ellie 1}

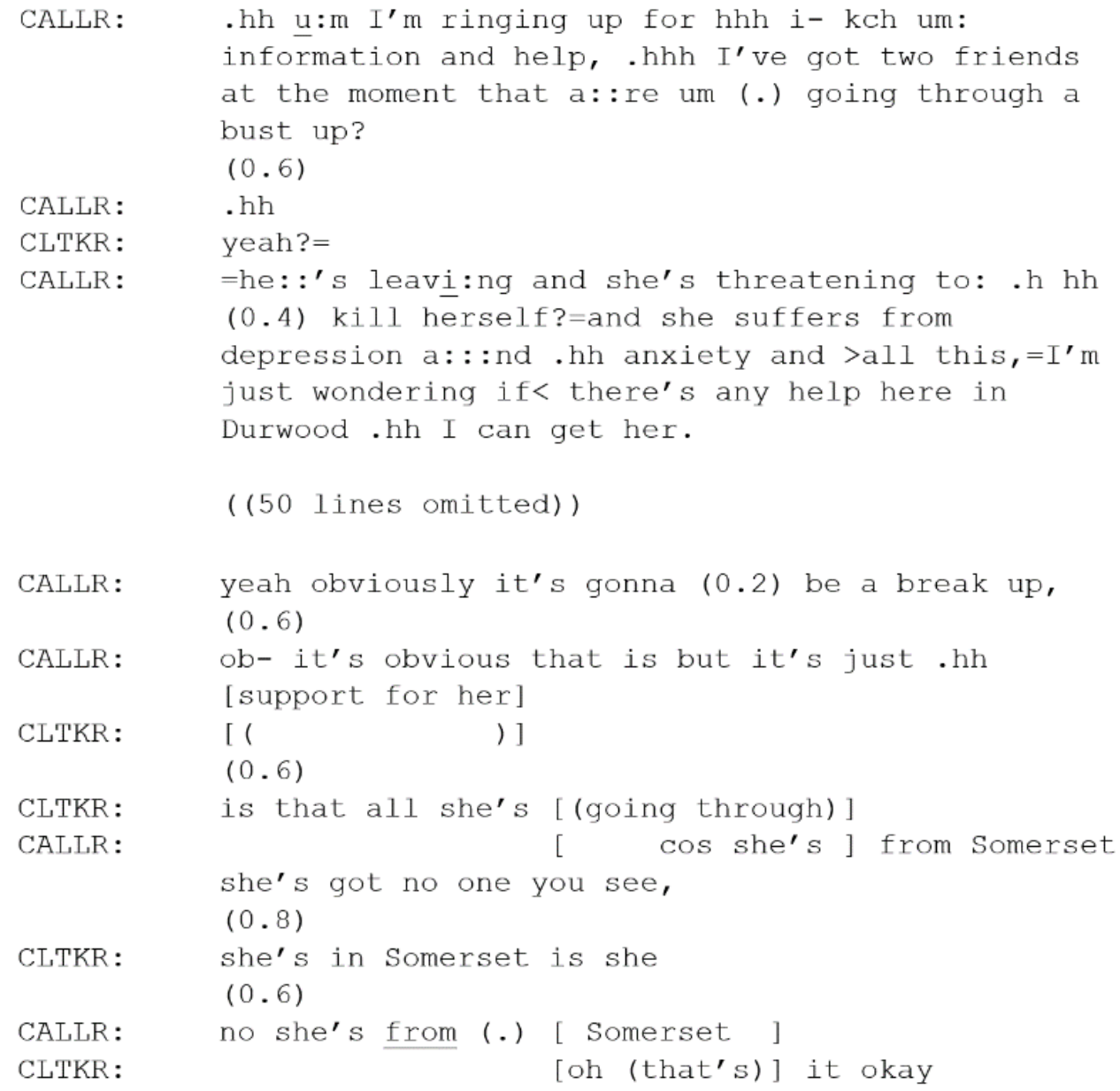

The caller identifies who he is seeking help for and his relationship to them through categorical references. Referring to "two friends" (line 2) makes relevant the caller's own membership in the category friend. The description of a relationship break-up and the use of gendered pronouns (line 8) provide the inference that the two friends are members of a couple (Kitzinger, 2005). The description of suicide threats made by one member of the couple (lines 8-9) and the caller's subsequent request for help for "her" (line 12) display that he is seeking help on behalf of one member of the couple. Spouses are first position members whom it is proper to turn to first in a search for help (Sacks, 1972b). Yet leaving the relationship severs the categorybound rights and obligations associated with membership, and this 
break-up is the very reason for the suicide threats (lines 8-9). Thus, it can be inferred that the spouse is not available as someone to turn to.

The caller's request, 'I'm just wondering if $<$ there's any help here in Durwood .hh I can get her" (lines 10-12) displays his orientations to the contingencies associated with getting help through the use of "wondering" (Curl \& Drew, 2008) and the inclusion of "any" which 'tilts' the answer towards preferring a no-response (Schegloff, 2007b). The problem (a suicidal friend) is not clearly a 'Victim Support-able' problem. Although the organisation does provide support to friends and family after suicide, institutional policy treats suicide threats and attempts as the purview of mental health services. The caller thus accounts for why his friend needs help and why he is the one to ask for it. He establishes her need for help by describing her mental health problems (lines 9-10). His references to other members of relationship categories both heighten his friend's need for help (by invoking the absence of other relational support networks) and account for why he is the one to call.

Although the caller, as a friend, is a member of an $R(p)$ category, different categories within $R(p)$ have hierarchically organised rights and obligations (Sacks, 1972b). The caller displays an understanding that other category members may have greater rights than he to seek help on his friend's behalf. At lines 69-70, he produces an explicitly marked account, "cos she's from Somerset she's got no one you see," which formulates location as the reason his friend has no one. The caller here orients to a distinction between where his friend is "from" (line 69) and where she currently resides (lines 11-12). This description invokes normative understandings of the home town, and the connections to family and belonging (Taylor, 2010). Although the caller may very well have incumbents of proper pair positions she could turn to in Somerset, the caller orients to this as too far away to provide the help needed. Thus, although he is not a first position $R(p)$ member, by virtue of his location (in the same city 
as his friend), he has the ability to provide help which first position members lack (cf. Hunt, 1991).

The caller in the case below also refers to someone threatening suicide, yet designs her request for help quite differently. Nonetheless, she likewise accounts for why the person needs help and why she is calling by reference to relationship categories from standardised relational pairs.

\subsubsection{Samuel 43}

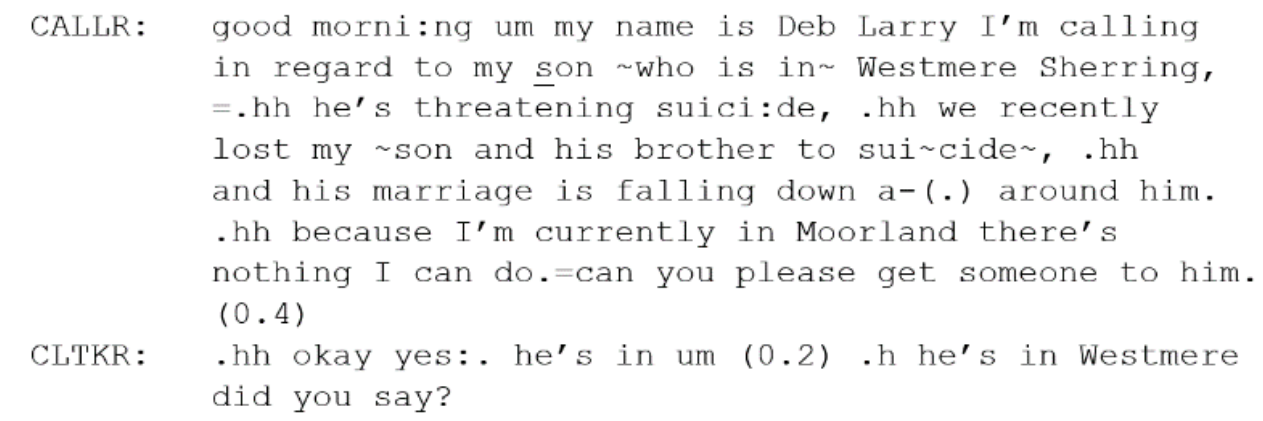

By categorising who she is calling for as "my son" (line 2), the caller invokes her identity through membership in the category mother. These categories are part of the standardised relational pair child-parent, which is a locus for rights and obligations to help (Sacks, 1967). The caller's relationship with her son - and the absence of other available members of proper relationship categories accounts for why she is calling for help on his behalf.

Like 7.1.1, the caller describes the problem as her son "threatening suici:de" (line 3 ). In contrast to the previous case, her request for help (line 7) claims entitlement to help from Victim Support through the interrogative format and use of the modal verb "can" (Curl \& Drew, 2008). The caller presents the problem as institutionally relevant by invoking her (and her son's) relationship with the organisation. The description "we recently lost my $\sim$ son and his brother to sui $\sim$ cide $\sim$ " (lines 3-4) performs three functions. First, it identifies both caller and her son as institutionally relevant victims - 
people who have lost a family member to suicide. The caller later reveals that her son has already been allocated a support worker (not shown), and this description makes inferentially available his identity as a client. Second, the description identifies another member of a proper relationship category, a brother, who is unavailable as someone to turn to. Third, it provides a reason why the caller's son may be suicidal, lending credence his threats (see Horne \& Wiggins, 2009).

Despite the fact she is calling on his behalf, the caller claims there is "nothing" she can do (line 7). She accounts for her unavailability by formulating her location as "currently in Moorland" (line 6), a city over five hours' drive from her son's location. Using place names displays the caller's expectation that the call-taker will recognise these locations, invoking a "common sense geography" (Schegloff, 1972, p. 85) in which the names of New Zealand towns and cities are presumed to be shared knowledge. The nature of this account displays the caller's orientation to a distinction between seeking support (which she currently doing) and providing support (which she accounts for being unable to do). This displays the caller's understanding that the kind of help needed is something which must be provided in person.

In the case below, the caller likewise accounts for calling by establishing that her friend has no one to turn to. In contrast to the prior cases, the caller establishes from the outset her friend's identity as a victim and the institutional relevance of the problem. The analysis attends to how the caller orients to self-other relations and moral obligation when accepting the call-taker's offer of help. 


\subsubsection{Adrian 53}

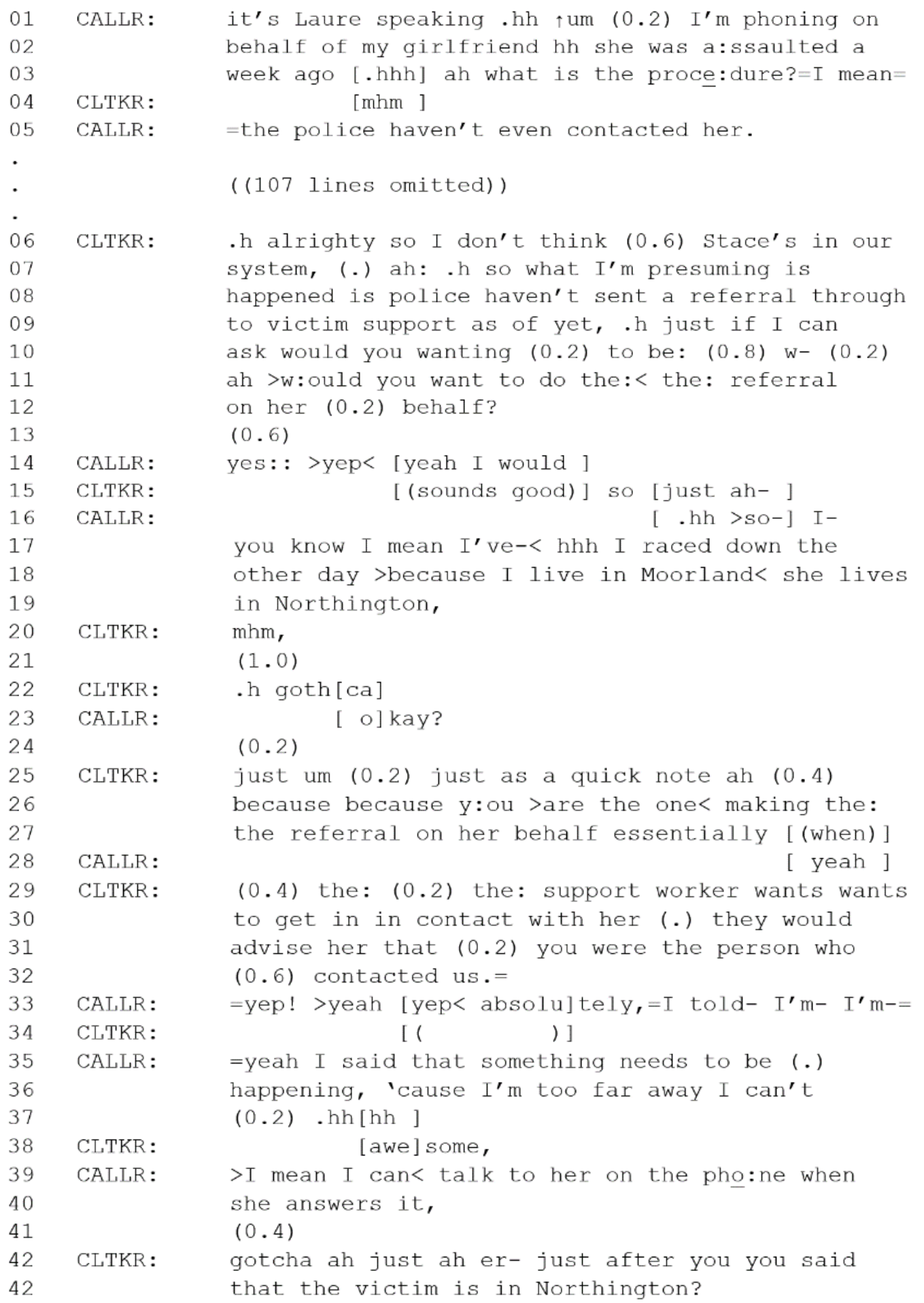


The caller opens with a complaint that her girlfriend was "a:ssaulted a week ago" but has yet to hear from police (lines 1-5). This establishes her girlfriend's identity as a victim and displays the caller's stance on the noticeable absence of help from police (see Watson, 1978). In the omitted lines, the call-taker explains what Victim Support can provide and searches the database for a possible casefile. In doing so, he ratifies the caller's understanding that her girlfriend is a victim entitled to Victim Support. At line 6 of this extract, he announces the results of his search. Since proper police procedure has not been followed (to send a referral to Victim Support), he offers to take a referral from the caller. Although she accepts this offer, she orients to the accountability of enlisting institutional help, and both participants treat the referral as nonnormative.

The caller's accounts display her orientation to her rights and obligations as an Rp member. After accepting the referral offer (line 14), she describes her previous attempts to provide support. The description, "I raced down the other day" (lines 17-18) makes inferentially available that she visited (in a state of urgency) after the assault. With a lexically marked account (line 18) she names the cities where she and her friend live. Using place names provides inferential resources for her recipient to understand that she has travelled a considerable distance (over two hours' drive), but because they live in different places, the caller cannot continue to provide this kind of support (see Schegloff, 1972).

The call-taker likewise displays an orientation to the caller's help-seeking as potentially accountable, informing her that she will be identified as the one who enlisted her girlfriend for support (lines 25-32). This orients to the expectation that people in need may not welcome help provided by strangers (Sacks, 1972b). The caller provides an upgraded agreement (line 33) and claims her girlfriend is aware she is seeking help on her behalf. With reported speech, she conveys that the assertion "something needs to be (.) happening," 
(lines 35-36) was directed to her girlfriend as an account for why she is seeking help. The caller orients to the accountability of seeking help from Victim Support (strangers) rather than providing it herself with the claim "I'm too far away I can't" (line 36).

As member of a proper relationship category, the caller has the right to be turned to in a search for help, and an obligation, once turned to, to provide help if she recognises the problem as serious (Sacks, 1972b). Here, the caller treats travelling to visit her girlfriend after an assault as a common-sense thing to do, but treats the provision of ongoing support as beyond her ability to provide. She treats the help she can provide - talking over the phone (line 39) - as insufficient, which accounts for her calling the helpline. Although she has the right (and obligation) to provide support over the phone, she orients to the provision of support in person as something she is unable to do, and thus turns to an institution to provide this.

In the following two cases, callers formulate their relationship with victims differently. These callers accomplish a shared understanding of 'no one to turn to' by categorising incumbents of proper relationship categories as perpetrators.

\subsubsection{Samuel 55}

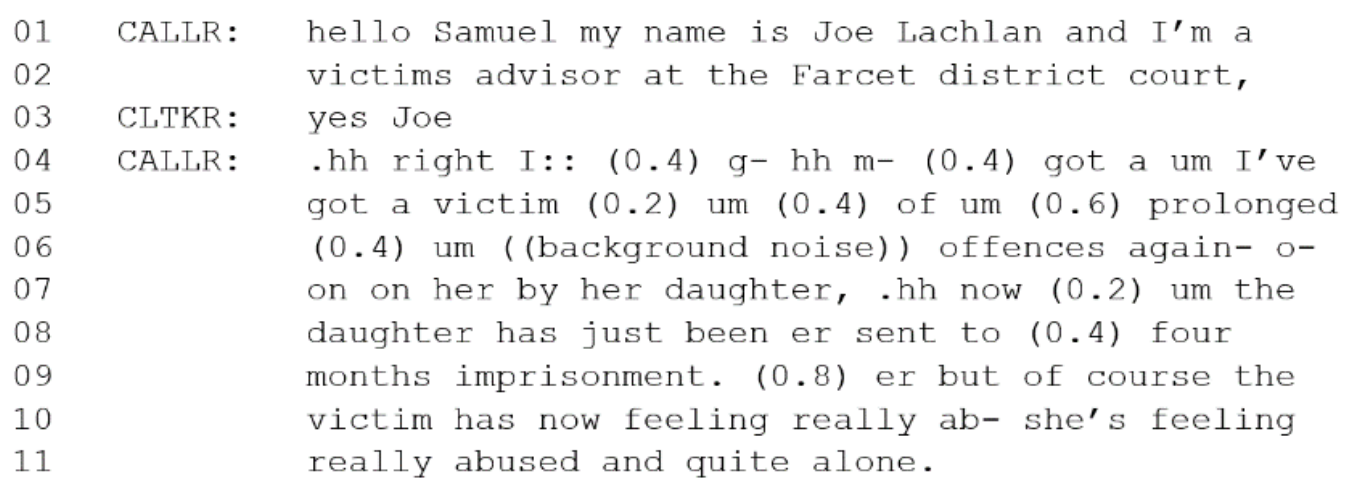

The caller categorises himself as "a victims advisor" at a district court (line 2) and the person he is calling for as "a victim" (line 5). These categories are part of a membership categorisation 
device. The activity of committing "offences" (line 6) is bound to the category offender, another member within that collection. Yet rather than using the category within this collection, the caller refers to the offender as "her daughter," (line 7). Thus, the relationship between victim and offender is not one merely created by the act of crime, but is located within the collection of relationship categories. The standardised relational pair child-parent is a locus for a set of rights and obligations concerning helping, such that daughters can be understood as first position members whom it is proper to turn to (see Hunt, 1991). Yet here, an incumbent of the first position $R(p)$ category is also an incumbent of the category offender (a decidedly improper person for a victim to turn to!).

Just because first position members cannot be turned to does not mean it is proper to turn to others (Sacks, 1972b). The caller articulates this common-sense upshot with "of course" (line 9). Not only is the victim "feeling really abused" and in need of help, she is also "quite alone" (lines 10-11) as she has no one to turn to. Similarly, the caller in 7.1.5 invokes his identity as a member of an occupational category. Yet, in contrast to the case above, he indicates that he is calling in a personal rather than professional capacity. Nonetheless, he treats his occupational membership as relevant for how the victim identified him as someone to turn to. 


\subsubsection{Claire 16}

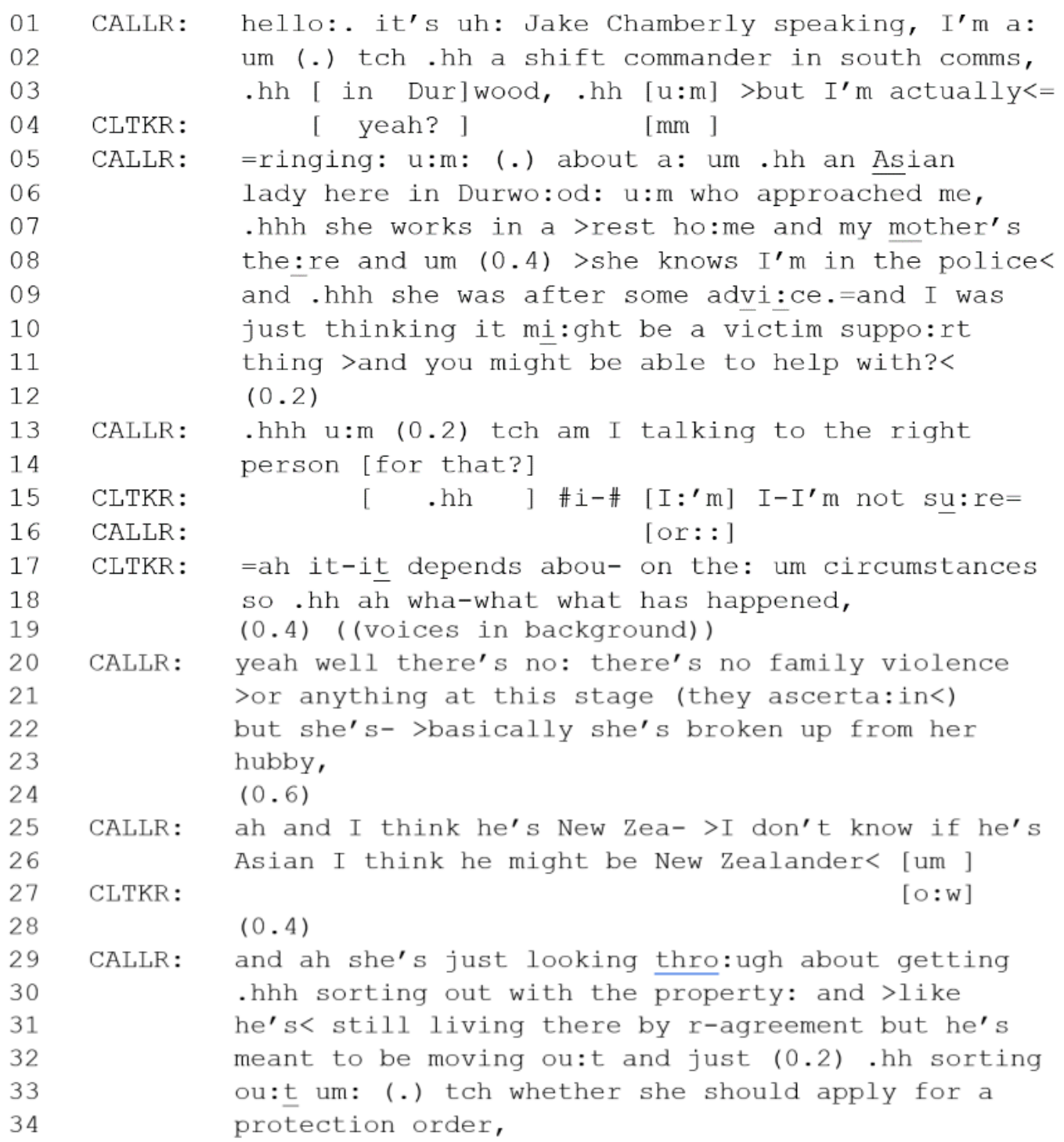

The categories "shift commander" (line 2) and "Asian lady" (lines 5-6) are not paired; nor are they relational. Thus, it is not by reference to relationship categories that the caller has been turned to and is now seeking help on behalf. The caller claims that the woman's knowledge of his membership "in the police" (line 8) was the reason she approached him for advice. Why though, was police a relevant category for the woman to select someone to turn to? 
After the call-taker prompts the caller to describe the problem (line 18), he describes the category "family violence" (line 20). Although he disavows it (notably, "at this stage" line 21), the category provides inferences to understand his subsequent description of a relationship break-up. The colloquial term "hubby" (line 23) references a member of a relationship category. Husbands and wives are members of standardised relational pairs, and the woman's husband is a first position member of a category whom it is proper to turn to (Sacks, 1972b). As with Extracts 7.1.1 and 7.1.2, describing a relationship break-up provides for the unavailability of the husband as someone to turn to. However, when the husband is also a (potential) perpetrator of violence, the rights and obligations associated with relationship categories intersect with those associated with the categories victim and perpetrator. Perpetrators (irrespective of their relationship to victims) are not someone victims can turn to for help. The categorical organisation of the search for help thus provides an ideological dilemma for victims of domestic violence attempting to seek help.

When calling on behalf, formulating 'no one to turn to' is both a resource to demonstrate another's need for help and an account for why the caller is the one to seek help. Thus, the link between identity and help concerns not only the victim's identity (relative to the problem and the institution), but the caller's identity and relationship to the one they are calling for. In the following section, I further explore how participants orient to the relationship between identity and help when callers seek help on behalf. Participants distinguish between arranging and providing help and orient to different self-other relations as relevant for these kinds of help. 


\subsection{RIGHTS AND OBLIGATIONS OF SEEKING OR PROVIDING SUPPORT}

Both callers and call-takers distinguish between seeking help on behalf and providing it directly. In the previous section, callers accounted for calling by describing their inability to provide help directly. In the cases below, participants likewise treat different identities and self-other relations as relevant for either arranging or providing help.

Extract 7.2.1 is a continuation of 7.1.1 where the caller is seeking help for his friend. Here, the call-taker's recommendations display her understanding of the relative distribution of rights and obligations for people with different relationships to the person in need.

\subsubsection{Ellie 1}

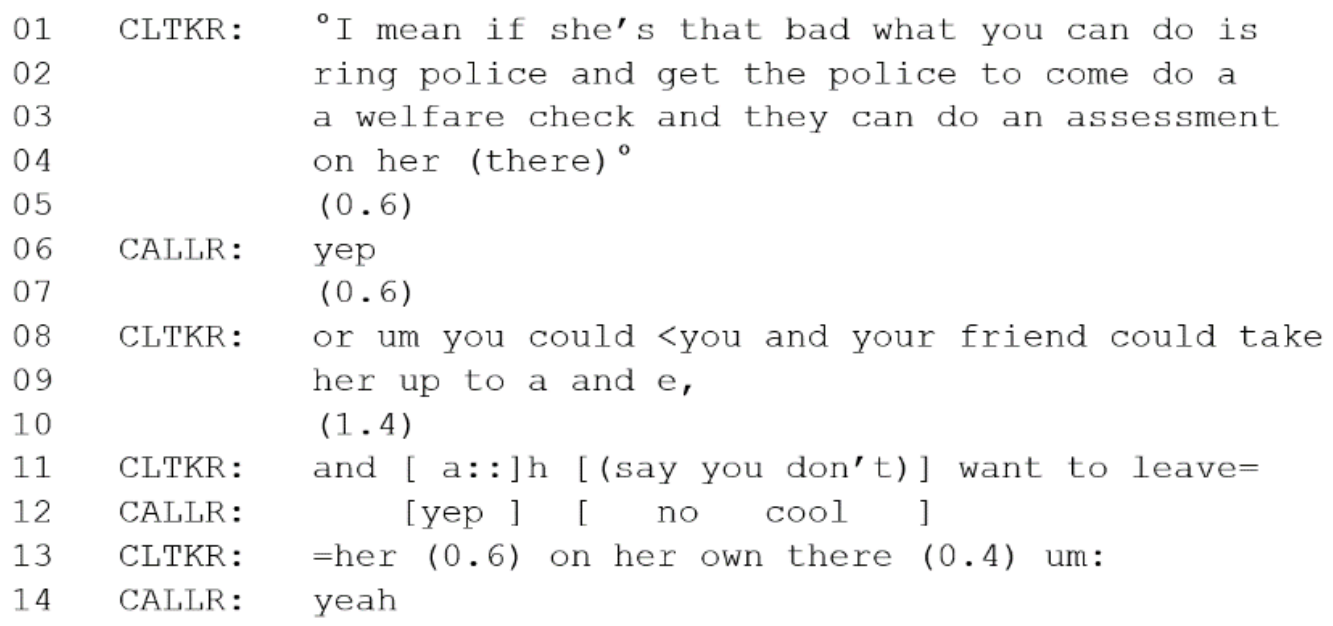

The call-taker orients to the link between identity and action when she gives advice about different kinds of help that are available to the caller as a friend. She treats the activity of calling police as something the caller "can do" (line 1) - just as he is currently seeking help by calling Victim Support. In this first recommendation, she treats the caller as able to seek help, and names "the police" (line 2) as an occupational category who can provide the help needed. However, her second recommendation - to take the woman to the 
accident and emergency department of the hospital (lines 8-9) displays a different understanding of ability and obligation. The calltaker repairs from "you" to "you and your friend" (line 8), an aggregation repair which shifts responsibility from the caller to a collective (Lerner \& Kitzinger, 2007). This collective comprises of the caller and his friend, the same person who is the soon-to-be-exspouse of the suicidal woman. Notably, the recommendation here is to "take" (line 8) the woman to the hospital, an activity the call-taker treats as a form of providing support.

In both recommendations, the call-taker orients to members of occupational categories (police and hospital staff respectively) as having special knowledge about how to deal with the problem of suicide. As professionals, members in these categories can be proper to turn to (Sacks, 1972b). Yet the caller's role in connecting his friend to these professional involves either calling for help or directly participating in bringing her to hospital. By formulating the first activity as within the caller's ability, the call-taker aligns with the caller's tacit claim (enacted by calling Victim Support) that he has a right to seek help on his friend's behalf. In contrast, by treating the second activity as a shared responsibility, she orients to the continuing obligations of the soon-to-be-ex-spouse, despite the relationship break-up. Thus, different relationships with someone in need make accountable different forms of help.

Participants negotiate both relational and institutional obligations to help victims. In 7.2.2, the participants orient to the caller's professional identity and the kind of help her occupational category membership makes accountable. Caller and call-taker orient to her seeking support as beyond the normal kind of help she is obligated to provide. 


\subsubsection{Samuel 97}

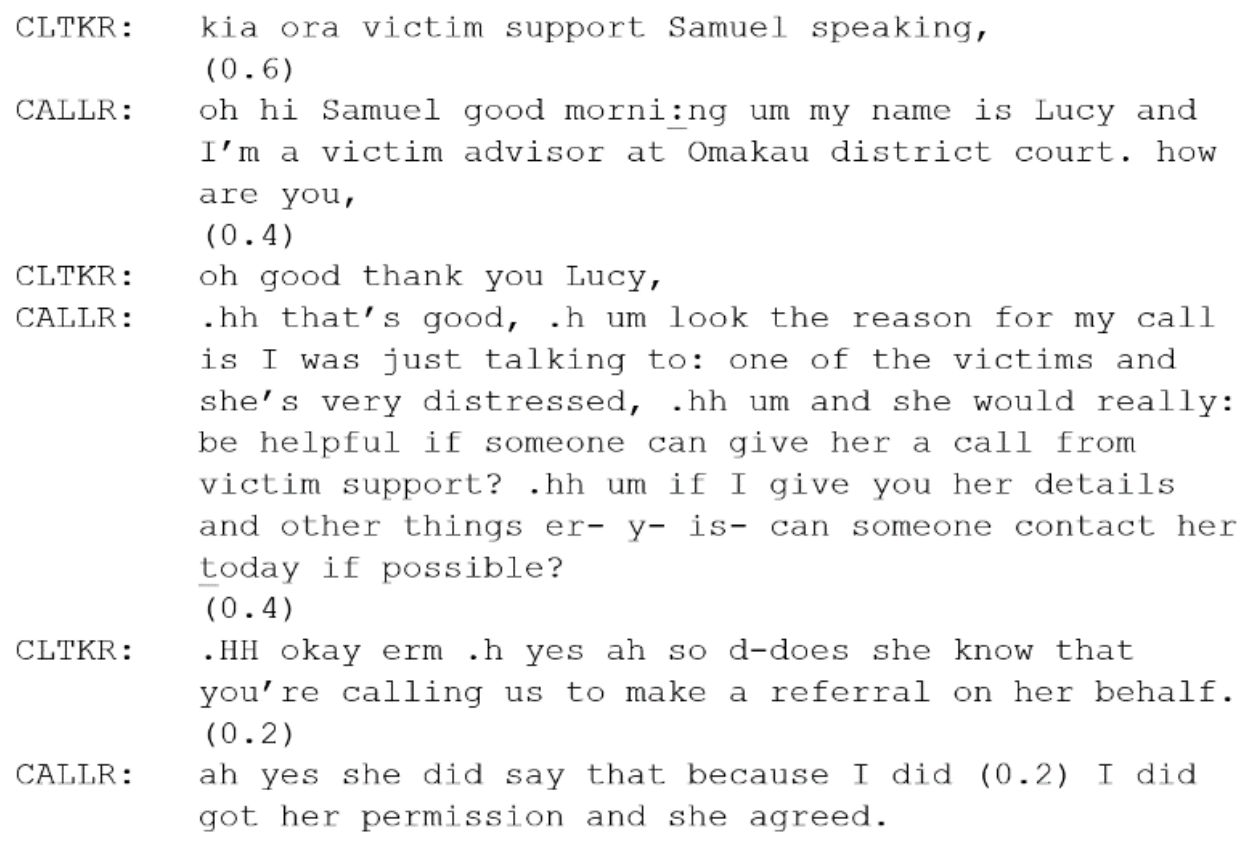

As in 7.1.4, the caller identifies herself as "a victim advisor" at a district court (line 4). Members of this occupational category have special knowledge about how to deal with victims as professionals (Sacks, 1972b). The caller categorises the person she is calling for as "one of the victims" (line 9). These two categories are not a relational pair, but an institutional pairing. While some rights and obligations concerning help are organised by the relationships between people, other rights and obligations to help are organised institutionally (Psathas, 1999). Here, the caller's self-categorisation as "a victim advisor" infers certain rights and obligations concerning the provision of help to someone categorised as a victim.

Despite this, the caller treats emotional support as a form of help she cannot provide. She accounts for calling by describing a prior conversation that has occasioned her call. The assessment of her client's emotional state as "very distressed" (line 10) accounts for why she has turned to Victim Support for help. The woman's membership in the category victim grants her the emotional status to express emotion regarding this domain of experience (Stevanovic \& 
Peräkylä, 2014). However, this expression of emotion has been directed to the wrong recipient, and the caller orients to providing emotional support as an activity that is not bound to her institutional category membership. The relationship between caller and her client - their shared sense of who they are to each other - influences what kind of help can be given.

The caller is not a member of a proper relationship category, and her client has not turned to her seeking help. Instead, she has inferred a need for emotional support due to her client's expression of emotion. The call-taker's question (lines 16-17) treats the caller's activity of arranging support as non-normative and potentially problematic if her client is unaware of it (see Sacks, 1967). By confirming that she explicitly sought permission (lines 19-20), the caller likewise displays an orientation that arranging support for her client is not a straightforward right or obligation of her category membership, but a marked activity beyond the normal remit of her role.

In contrast, in 7.2.3, the caller - who is likewise categorised within an occupational device - presents herself as able to both arrange and provide support. In contrast to the previous cases, the caller is not seeking help, but calling to cancel arrangements that may have been made for her client. 


\subsubsection{Molly 44}

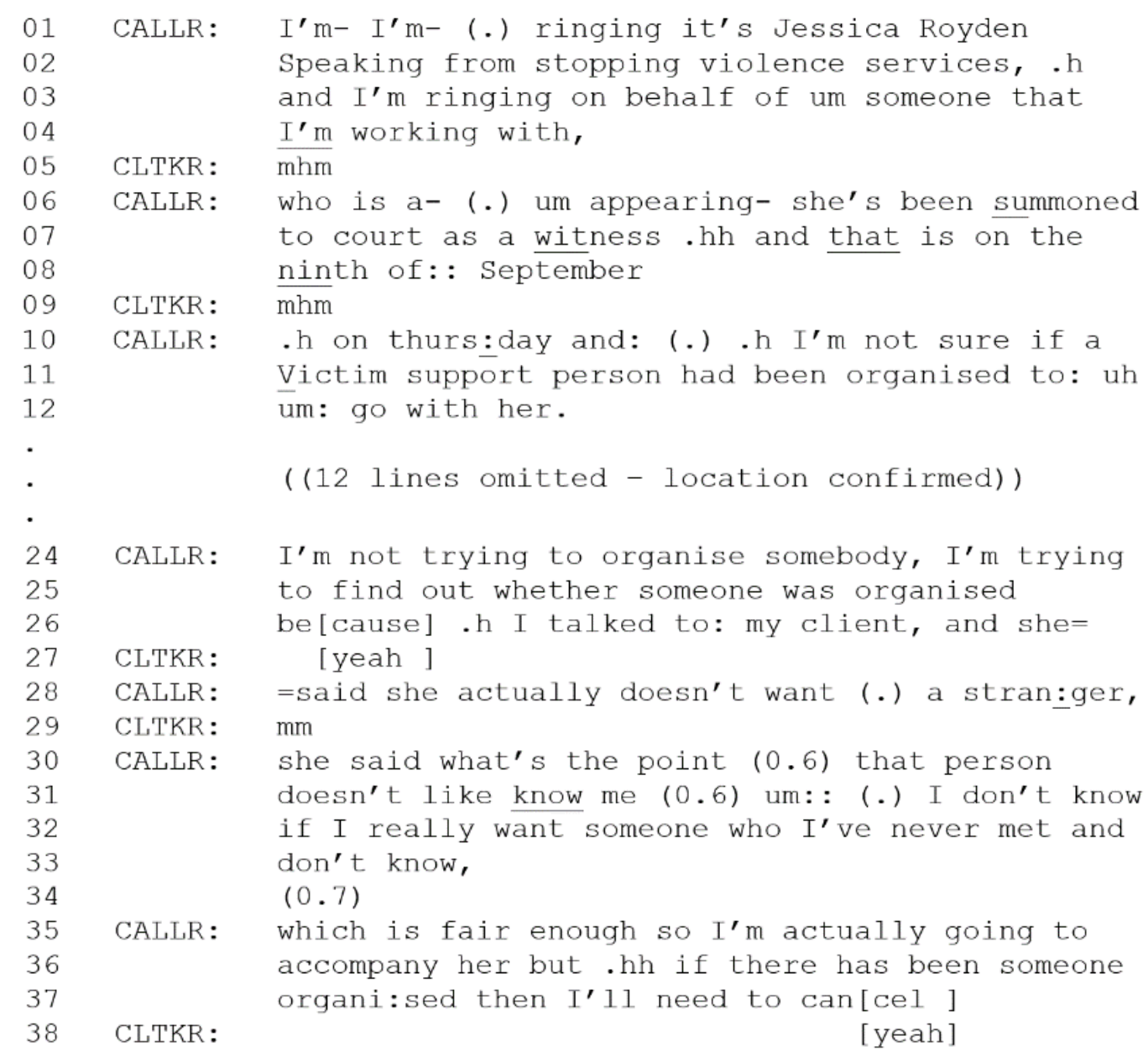

The caller orients to identity and self-other relations when accounting for calling. She identifies as an institutional representative (lines 1-2) and uses the non-recognitional description "someone that I'm working with," (lines 3-4) to refer to the person she is calling for. This description infers the category client, and in this context, clients can also be understood as victims. The caller displays her understanding that her client's victim membership may have been ascribed by other institutional representatives, and a support worker organised to accompany her to court (lines 10-12).

The occupational category of "a Victim support person" (lines 10-11) can be seen as a professional with special knowledge regarding how to support victims. As a victim, the client is entitled to 
receive this kind of support. Yet, the caller re-categorises the support worker within the collection of relationship categories, as "a stran:ger" (line 28), to account for her client's rejection of this offer. As Sacks (1967) documented, the same incumbent may be at once proper in terms of knowledge categories, but improper under a relational categorisation. For the client (much like callers to the suicide helpline), relationship categories are a resource to understand potential help-providers and reject strangers as improper to turn to. Using reported speech, the caller unpacks the predicates of the category stranger as someone who "doesn't like know" the client because she has "never met" them and correspondingly does not know them (lines 30-31). The caller thus constitutes the link between identity and action, claiming that support cannot be provided by strangers.

When the caller reveals that she is "actually going to accompany her" (lines 35-36), she tacitly claims that she can provide the kind of help her client needs. The caller is not a member of a standardised relational pair with her client. Their relationship is institutional: that between professional and client. But by the criteria laid out in lines 30-33, caller and client do have an established relationship - she knows her client, her client knows her, they have met and talked together - and so at least is not a stranger. Thus, the caller configures self-other relations to account for why she, unlike the support worker, can provide help in this case.

While the callers in 7.2.2 and 7.2.3 do not have an obligation to help (because they are not members of proper relationship categories), they nonetheless orient to an opportunity to provide help. Even when callers are members of proper relationship categories, the nature of their obligation can be negotiated relative to other members of standardised relational pairs. Thus, different kinds of identities and social relations make available different forms of help. The moral accountability of providing help is inexorably linked to identity. 


\subsection{DENYING A REQUEST FOR HELP ON BEHALF}

In this final section, I analyse two extracts from a call in which the call-taker denies the caller's request for help for her mother. The participants display competing understandings of the relevant self-other relations. The caller orients to the relevance of relationship categories to demonstrate her mother's need for help and account for why she is seeking help on behalf. The call-taker, however, treats the rights and obligations bound to victim and offender categories as more relevant in assessing whether the request can be granted.

\subsubsection{Samuel 54}

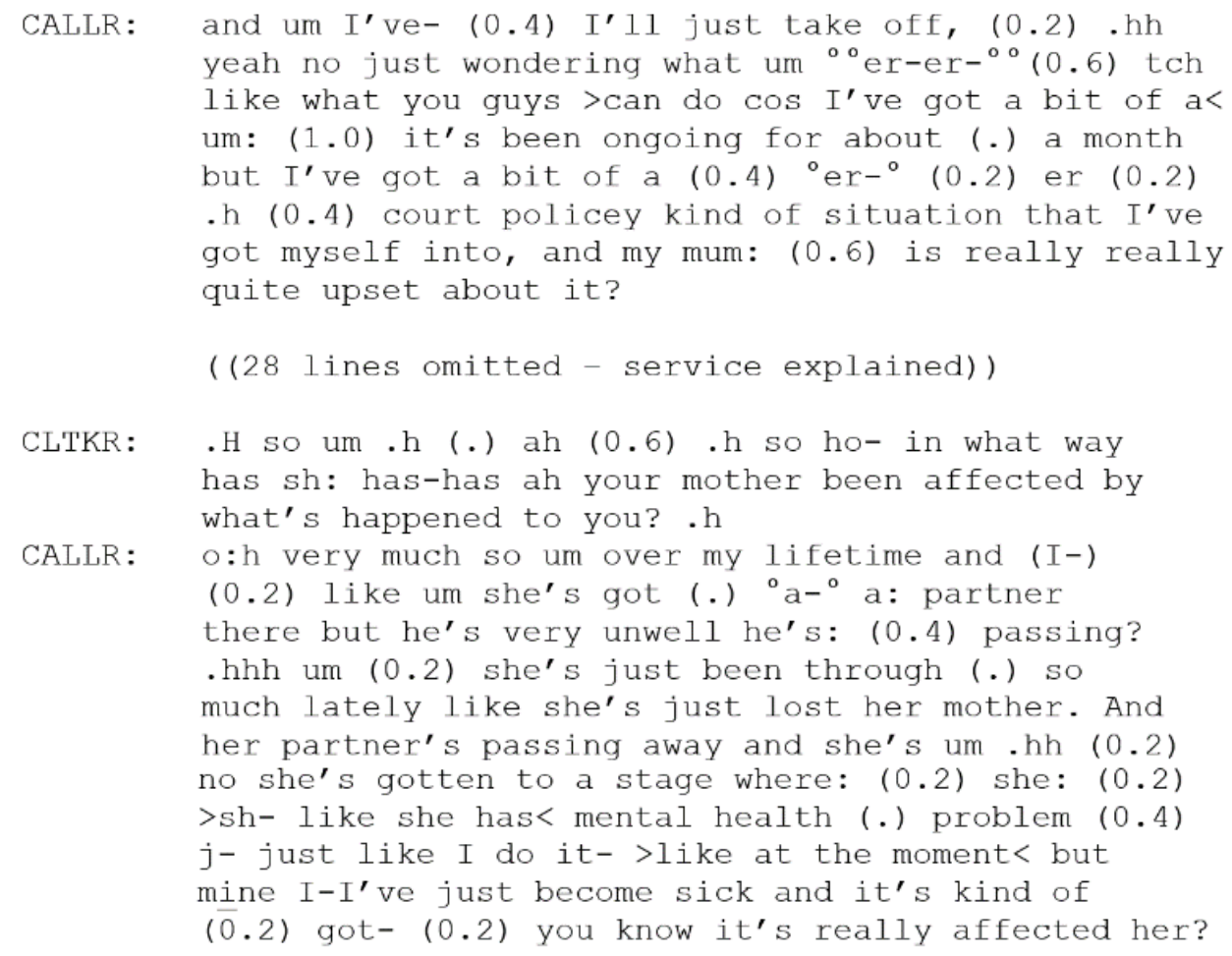

The caller claims to be uncertain about "what you guys $>$ can do" (line 3), displaying herself as a first-time help-seeker. She describes an ongoing problem which she formulates as a "court policey kind of situation," (line 6) after marked perturbations which display difficulty in word selection (line 5). However, by describing the emotional impact on her mother (lines 7-8), the caller displays that she is seeking help on behalf. In the omitted lines, the caller describes 
how her attempts to support her mother over the phone have been unsuccessful, accounting for her request for a support worker visit.

However, at line 36 the call-taker displays that he has not yet determined if the caller's mother is eligible for help from Victim Support. His question displays a presupposition that the caller is a victim whose experiences have had an adverse effect on her mother (in institutional terminology, the mother would be listed as a 'secondary victim', see 5.1.3). In contrast to the caller's attribution of personal responsibility (line 7), his reference to "what's happened to you?" (lines 37-38) treats the caller as victim of events for which she is not responsible (Lindholm et al., 2014). Thus, the relevant social relations for the call-taker are those between primary and secondary victim - in other words, how the caller's mother has been affected by the caller's victimisation.

The caller, however, orients to quite different social relations. Although she claims that her mother has been "very much" affected by her own experiences (line 39), she orients to why her mother needs help rather than describing an experience of victimisation. As in the previous cases, she orients to members of relationship categories as possible people to turn to. One member of a proper relationship category is her mother's partner, but he is "very unwell" (line 6) and "passing away" (line 9) and thus not available to turn to. Another member is "her mother" who is unavailable having died recently (line 8 ). The caller herself, as a daughter, has a proper obligation to provide help, yet her recent illness is a cause of her mother's distress (lines 48-49), which suggests she is unable to provide help. By exhausting relevant other options, the caller makes understandable that her mother has 'no one' and thus accounts for turning to an institution on her behalf.

The call-taker, however, treats 'no one to turn to' as an insufficient reason for seeking help from Victim Support and pursues details from the caller in the following case. 


\subsubsection{Samuel 54}

CLTKR: $\quad$ H okay so um y- can you tell me more about um uh th- the cri: :me or the trauma that you've been um.h that you've been subject to lately that ah that-that's happened to you? $(0.8)$

CALLR: oh for me?=um it's been ah I breached.=I went away to a t-to: >another town< to visit and I was too far away to make my probation. .h and I breached and um (0.2) got really worried and started to try and avoid it over the last two and half three weeks.

$$
(0.4)
$$

CALLR: .h $[$ Um $]$

CLTKR: [.H]

$(0.6)$

CALLR: I went ho:me a:nd well wasn't in a (0.2) state to be able to \#um\# (0.4) .h to settle down or do: anything that I was meant to do? um (.) ye:ah .h (0.4) that's [my buzz]

CLTKR: (0.4)

CLTKR: in-in which cas:e um that-that-that's where you're um you're. h the offender aren't you? like not ah: not so much the victim? (.) .h it's ah: (1-) it was your responsibility to $>\mathrm{y}^{\prime}$ know< to be where you were supposed to be for the: um you know .h for the probation. (.)

CLTKR: .hhh s[o um ]

CALLR: [>yeah yeah $I-<]{ }^{\circ}\left(\right.$ exactly) ${ }^{\circ} I^{\prime} m$ not trying to ask for support $I^{\prime} m$ trying to ask $(0.2)$ to see if there's any support for my mum being the victim >a-a- a- A victim of (.) of:

CLTKR: (0.2) you know $\mathrm{m}$ - what's $(0.4)$ [ g]one on.= $[(. \mathrm{h})]$

CALLR: =yeah [exact]ly I'm (0.2) owNing that that's= CLTKR: $\quad[(d-)]$

=why I'm ringing ya(h) hh $(0.2)$

CLTKR: .h YE:ah yeah .h so victim support wouldn't unfortunately be: um the appropriate place to offer support to your mother.h in that situation.

The call-taker's question makes explicit that the relevant aspect of the caller's problem is the "the cri::me or the trauma" (line 2) she has experienced. The design of this question displays the call- 
taker's presupposition that the caller is a victim who has "been subject to" (line 3) events which have "happened" (line 4) to her for which she is not responsible. Associations of passivity have common-sense links to victimhood (see Lindholm et al., 2014). This question also displays the call-taker's understanding that the caller's identity as a victim is relevant for understanding her request for support for her mother.

The caller, however, treats her mother's identity as relevant for her request. Her oh-prefaced response, "oh for me?" (line 6) treats the call-taker's question as inapposite (Heritage, 1998), treating her identity as unrelated to the help she is seeking. Rather than describing a crime or trauma that has happened to her, the caller describes how she breached her probation (lines 6-11). Both participants orient to the way this description of events makes inferences available about the caller's identity. The call-taker explicitly categorises the caller as "the offender" (line 23), marking this as the upshot of her description. The call-taker displays his understanding of victim-offender categories as mutually exclusive, claiming that her identity as an offender means she is "not so much the victim?" (line 24). He articulates the moral upshot of the caller's category-bound "responsibility" to meet her probation conditions (lines 25-26). While the call-taker treats victims as lacking agency (lines 3-4), he attributes responsibility (and blame) to the caller as an offender (see Watson, 1983). By articulating her failure to fulfil her category obligations, the call-taker attributes blame (Watson, 1978), meaning her identity can be morally qualified into something like 'bad offender' (Cuff, 1993). Thus, different interpretative repertoires construct the caller's identity as either a victim or an offender, making accountable the alternative actions of offering or denying support.

Rather than deny her category membership, the caller challenges the associated moral inferences. She disavows that she is seeking support for herself, instead describing that she is "trying to ask (0.2) to see if there's any support for my mum” (lines 31-32). By 
formulating her conduct in this way, she addresses the accountability of her action (Sidnell, 2017). She displays an understanding that, as an offender, seeking help from Victim Support for herself is morally accountable, and denies doing so. Instead, her formulation of seeking help on behalf displays her understanding of categories that licence help-seeking. The caller orients to her mother's identity as relevant (as the person in need of help), rather than her identity as the one seeking help. Categorising her mother as "A_victim" (line 33), the caller establishes her mother's entitlement to support - irrespective of her own categorical identity as an offender. For the call-taker however, the caller's categorical identity as an offender invalidates her rights to seek help for herself or others, reflecting institutional policy that states Victim Support cannot assist offenders or their families.

Sacks (1967) demonstrated the way callers and call-takers used categories from relationship or knowledge collections, often coming up with different understandings of who was proper to turn to. For example, a call-taker is proper when categorised as a professional with special knowledge and competence about suicide; but improper when categorised as a stranger with no personal relationship with the caller. The analysis above adds a third collection of categories, which we may gloss as a 'victimhood collection'. The paired categories of victim and offender can undercut or even replace the relevance of both relational and knowledge-based categories, which may result in denials of service. 


\subsection{SUMMARY}

Seeking help on behalf of others highlights participants' orientations to the moral accountability of help. Participants invoke self-other relations to make sense of who they are relative to others, and to organise rights and obligations to help.

When callers identified as members of relationship categories, they treated calling Victim Support as accountable. Callers accounted for why they were seeking help rather than providing it, orienting to their category-bound rights to provide help. Formulating their location as too far away to help was a key resource for callers to account for seeking help on behalf of others. Conversely, callers who identified as members of occupational categories accounted for seeking help on behalf by claiming the person they were calling for had no one else. This was particularly salient in cases of domestic or family violence where members of proper relationship categories were also perpetrators. As feminist research has documented, people who find themselves in such situations are often left with no one to turn to (Frías \& Agoff, 2015; Sabina, Cuevas, \& Rodriguez, 2014; Towns \& Adams, 2009) as members of other categories do not have the same rights and obligations to be turned to for help (Sacks, 1972b).

Participants oriented to the way that calling on behalf structured the relationship between identity and help. Callers who identified themselves in different ways treated different kinds of help as part of their rights or obligations. Participants negotiated who could seek and provide help, and how help was rendered accountable through participants' social relations. Some forms of help (such as calling support services) could be carried out by certain members of relationship categories, while others (such as taking someone to hospital) were treated as an entitlement of first-position pair members only. Yet the relevant basis of a relationship which renders help accountable was negotiated by participants. 
Although rights and obligations organised by reference to relationships are a common-sense way to understand help, in the institutional context of Victim Support, rights between victims and institutions can trump those based on relationships. In the final section, a caller categorised her mother as a victim with no one to turn to, but the call-taker denied her rights to seek help. As discussed in the previous chapter, denying requests rejects claims of victimhood. In this case however, the call-taker did not deny the mother's category membership, but explicitly categorised the caller to reject her rights to seek help from the service. This move made a strong epistemic claim to categorise the caller's identity, which was consequential in the ultimate withholding of support. Thus, it is not only the kind of help requested, but the identity of the requester that can be at stake when seeking help in calls to Victim Support. 


\section{DISCUSSION}

In this final chapter, I synthesise the findings of my analyses to argue for the mutually constitutive link between identity and help in calls to Victim Support. I begin by summarising the findings of each analytic chapter. Then, I discuss how my findings shed light on the psychological question of the relationship between identity and action. Although identity is particularly salient when seeking help in this institutional context, I argue that identity and help are always related in social interaction.

This thesis is the first interactional examination of a victim support organisation. In the final section, I discuss how my work contributes to the interactional literature on help in institutional contexts, and how the link between identity and help constitutes the institutional context of Victim Support. I highlight some limitations of the data, and end by suggesting implications for practice that could help the organisation improve service-provision.

\subsection{IDENTIFYING AS A VICTIM IN REQUESTS FOR HELP}

In the first analytic chapter, I documented how the nature of the help sought was part and parcel of participants' identities. The kind of help callers sought - and how they asked for it - displayed their understanding of who they were relative to their recipient and the social context of the call (see Lindström, 2005).

On the Victim Support helpline, requests for help invariably invoked callers' identities and help-seeking was rendered accountable through a shared sense of who participants were to each other (cf. Stevanovic \& Peräkylä, 2014). I am referring to both senses of accountable conduct here. Asking for help was account-able or intelligible (Garfinkel, 1967; Heritage, 1990) through callers' identities. Callers were understood as asking for help (even in the absence of a linguistic request) when they were understood as 
victims. Asking for help was also accountable in the moral sense, explainable or justifiable (Robinson, 2016), with reference to identity. Callers oriented to the ways their identities as victims granted them the moral rights (or category-bound entitlements) to seek help from Victim Support. In this sense, identity and help are mutually constitutive. Asking for help constituted callers' identities as victims; and callers' identities as victims constituted their requests for help.

In this section, I discuss the different ways callers oriented to their identities as relevant and procedurally consequential. Callers oriented to identity through displays of knowledge, descriptions of experience, self-categorisation, and negotiations of category-bound rights.

\subsubsection{Displaying knowledge and entitlement}

Callers who sought support workers displayed an expectation of who their recipient was and what could be done for them. These callers designed their requests to display their entitlement to help and their knowledge that transfer was an available form of help. Using interrogative request forms with modal verbs like "can" (5.2.1) or "could" (5.2.2) displayed speakers' understanding of their entitlement (Curl \& Drew, 2008). By specifying the desired solution, callers also displayed their knowledge of the kind of help available (see Fox \& Heinemann, 2017). Callers' epistemic access knowledge of what help was available - and their deontic rights - to determine how help would be provided - were two key ways they oriented to their identities as clients as linked to their rights to access help.

Participants jointly oriented to clients as victims whose eligibility for the service had been previously established. Call-takers conflated the categories victim and client, treating a case-file in the database as relevant predicate of victim category membership (e.g. 5.2.2). Although callers displayed similar understandings, the use of 
alternative categories such as friend (5.1.2) or survivor (5.1.3) demonstrated that, for callers, the implications of a victim identity extended beyond institutional relevance. Interview research has suggested that people attempt to modify their identities as victims when seeking help from victim support services (Åkerström et al., 2011; Jägervi, 2014). My analyses demonstrate how participants orient to the relevance of identity in the act of seeking help. As the first interactional analysis of calls to a victim support service, my work shows that identity concerns are demonstrably relevant and procedurally consequential for callers when they seek help.

\subsubsection{Describing experiences and displaying emotion}

When callers described experiences of victimisation, they were understood as seeking emotional support. In the social context of Victim Support, call-takers understood descriptions of a relevant experience as requests for help. My findings complement research which has shown requests are social actions that can be built and understood from different resources in different contexts (Fox \& Heinemann, 2016; Lindström, 2005; Stevanovic, 2011). On the Victim Support helpline, describing an experience of victimisation was sufficient to be understood as requesting emotional support.

Displays of emotion were another resource for building and interpreting requests for help (e.g. 5.2.1). The nature of the help available - emotional support - meant displaying or claiming emotional need presented callers as relevant service-seekers. When such displays were coupled with descriptions of institutionally relevant experiences, call-takers treated callers as potential clients. Thus, the rights to own and express emotions about victimisation configured self-other relations and made requests for help intelligible. This relationship between emotion, identity, and help demonstrates how the emotional order is a resource for participants to understand who they are and what they are doing (Stevanovic \& Peräkylä, 2014). 
When call-takers treated descriptions of victimisation as requests for service, they treated callers as victims traumatised by their experience and entitled to emotional support. This link between experience, identity, and help was one way participants invoked and constituted common-sense knowledge that victimisation causes trauma (see Gavey \& Shmidt, 2011). Yet callers also challenged the relevant ways to understand who they were and what they needed. For example, in 5.2.2, the caller described an experience of victimisation, but denied that she was seeking the kind of support offered. Although participants may treat relationship between identity and help as taken-for-granted, my analyses show that this relationship is a joint accomplishment.

\subsubsection{Self-categorisation}

Callers categorised themselves as victims when seeking practical advice for problems involving different institutions. Callers distinguished between their experience of victimisation and their current problems which distinguished them from callers seeking emotional support directly after being victimised (cf. 5.2.1). Claiming category membership makes relevant speakers' category-bound rights to help (Watson, 1978). Callers categorised themselves to establish their rights to help from Victim Support (see 5.3.1 and 5.3.2), or comment on the noticeable absence of help they were entitled to (e.g. 5.3.4).

When callers categorised themselves as victims, they displayed their understandings of the people and problems the organisation recognises. Although prior research has documented the importance of establishing a joint understanding of a 'doctorable' problem for medical help (Heritage \& Robinson, 2006), a 'policeable' problem for emergency assistance (M. Whalen \& Zimmerman, 1990), and a 'mediatable' problem to access mediation services (Edwards \& Stokoe, 2007), seeking help from Victim Support requires both an institutionally relevant problem and an institutionally relevant 
identity. By claiming membership in the category victim and by categorising their experiences as domestic violence (5.3.1), assault (5.3.2) or burglary (5.3.3), callers oriented to crime as the kind of experience which made them eligible for help from Victim Support. Thus, callers oriented to who they were and what had happened to them as relevant considerations when seeking help.

\subsubsection{Claiming rights to information}

Through requests for help, participants negotiated which rights, predicates, and activities were associated with victim category membership. Predicates "which reference motives, rights, entitlements, obligations, knowledge, attributes and competencies" can be linked to different categories to describe and reason about members' conduct (Psathas, 1999, p. 144). My analyses show that participants built the link between victim categories, activities, and predicates in relation to different interactional demands. Callers displayed an understanding that membership in different categories provided different rights to certain kinds of information. For example, members of the category ex-partner lack rights to knowledge about ex-partners' whereabouts, while members of the category victim are entitled to know whether perpetrators are still in custody (5.4.2).

Callers displayed their understanding of the link between identity and action when they oriented to (and constituted) categorybound activities. Sacks (1972b) argued that simply seeing or describing someone carrying out an activity is enough to infer their category membership. Callers displayed an understanding that pressing charges (5.4.3) or reporting money stolen (5.4.4) was enough for others to ascribe their membership as victims. By contrast, they treated the activities of dropping charges or finding lost money as lacking common-sense associations with victim membership. Thus, the nature of the help sought could undermine callers' identities as victims. Callers oriented to the moral accountability of seeking help while disavowing victimhood by attempting to neutralise the 
inferences available in the request for help (5.4.3) or apologising directly (5.4.4).

When participants negotiated which activities or predicates were associated with being a victim, they constituted shared commonsense knowledge in what Hester and Eglin (1997) called culture in action. My work contributes to research in membership categorisation analysis which has shown that activities, predicates, and categories are not linked in some objective way, but are locally produced and managed by cultural members in response to different interactional demands (see Reynolds \& Fitzgerald, 2015; Stokoe, 2012; Watson, 1978). In this setting, participants oriented to the way that different category-bound activities or predicates could be consequential when seeking help.

\subsection{HELPING VICTIMS}

The second analytic chapter examined how call-takers oriented to the relationship between identity and help as procedurally consequential. When carrying out routine tasks like denying requests, enlisting callers for support, or offering transfer, call-takers determined who callers were for institutional purposes. Negotiating whether or how callers could be helped involved epistemic and deontic considerations. Determining if callers were (legitimate) victims was necessary for access to help. Yet even if call-takers understood callers as legitimate victims, they negotiated what kind of help they needed and which institutions were obligated to support them.

\subsubsection{Gate-keeping access to help}

Call-takers' denials were an instance of institutional gatekeeping. When call-takers denied callers' requests, they displayed their understanding of the relationship between identity and help. Call-takers denied that callers (or those they sought help for) were victims (6.1.2) or formulated callers' problems as beyond the remit of 
service (6.1.1). In many contexts, institutional representatives orient to their deontic rights to determine callers' eligibility for service. For example, in emergency calls, call-takers determine whether callers' problems warrant emergency assistance and may directly question callers regarding the basis of their knowledge or their motives for calling (Heritage \& Clayman, 2010a). Victim Support call-takers are involved in similar judgements about whether callers' problems warrant help. In contrast to other gate-keeping contexts, determining eligibility for Victim Support inescapably involves judgements regarding callers' identities. My analyses demonstrate how call-takers negotiated epistemic and deontic rights when determining who callers were and how they should be helped.

Ordinarily, people are treated as having privileged rights to define and describe their experiences, feelings, thoughts and identities (Sacks, 1984). However, institutional representatives regularly claim rights to determine others' identities, experiences, and needs. For example, in medical consultations, patients may have greater knowledge about their feelings and experiences, but doctors claim epistemic authority to determine patients' symptoms and diagnoses (Heritage \& Clayman, 2010b). The management of knowledge - and the associated rights to describe or evaluate events - is a resource to constitute identity and social relations (Raymond \& Heritage, 2006). Call-takers oriented to their identities as institutional representatives when they claimed rights to make judgements about callers' identities and experiences. For example, in 6.1.1, the call-taker deferred to the caller's epistemic rights to assess her experience as "not a nice thing", but claimed the rights to categorise her problem as "not a (.) cri:me?" Although the call-taker treated the caller as able to formulate her emotional stance towards her experience, he claimed the rights to determine (and in this case, deny) her eligibility for help. Call-takers oriented to the way that their identities as members of Victim Support gave them epistemic rights to determine who callers were, and by extension, deontic rights to determine who could help them. 


\subsubsection{Identifying potential clients}

When call-takers offered referral (the first step in allocating a support worker), they treated callers as relevant people with relevant problems. In some cases, call takers deferred to callers' epistemic rights to describe their experiences and the deontic rights to determine what help they needed. For example, in 6.2.1, the call-taker's request for confirmation oriented to the caller's rights to describe her experience and determine what help she needed. In contrast, the calltaker in 6.2.2 claimed the epistemic rights to define the caller's experience, applying the category "verbal dispute" which she had not previously used. In both cases, call-takers linked the nature of callers' experience with their need for help.

Call-takers are accountable - not merely to callers, but to other members of the organisation. Just as emergency call-takers enter details into a database accessed by dispatch personnel (J. Whalen, 1995), Victim Support call-takers enter callers' details into casefiles that are later accessed by support workers and other staff. Call-takers' decisions to offer help to callers can thus be scrutinised by other members of the organisation. Call-takers must record and potentially transform callers' descriptions to fit the constraints of the institutional case-file (see J. Whalen \& Zimmerman, 1998). To render their offers of help accountable, call-takers must record an institutionally relevant experience for callers, which is operationalised with police incident codes. The procedural consequentiality of the link between experience, identity and help was particularly salient in 6.2.2 where the call-taker transformed the caller's description into an institutionally relevant category to make her offer of help accountable.

\subsubsection{Negotiating an obligation to help callers}

Call-takers oriented to support as an activity that could be bound to different categories. Call-takers treated support as a category-bound activity for themselves (as members of Victim 
Support) when they understood callers to have relevant problems for the organisations. Call-takers displayed this understanding by offering referral, fulfilling their category-bound obligations to provide this form of support. When call-takers determined callers were not victims, they denied callers' category-bound entitlement to help, and at the same time their own category-bound obligation to provide it.

Yet call-takers also separated callers' entitlement to help from their obligation to provide it. When offering transfer, call-takers affirmed callers' identities as victims and their category-bound rights to help, while nonetheless denying Victim Support's obligation to help them. Call-takers accounted for transfer offers by formulating callers' problems as beyond the institutional remit of service (see 6.1.1). These formulations presented the moral obligation to help callers as bound to another organisation. For example, describing a breached protection as a properly police matter accounted for transfer by presenting police as the institution obligated to help the caller (6.3.1). Explicitly formulating callers' rights to help from other institutions (6.3.2) also accounted for transfer offers. In these cases, call-takers treat transfer (rather than support) as a form of help they can legitimately provide.

On one hand, aligning callers with service-providers might seem a technical matter of service-provision. Yet on the other hand, negotiating rights and obligations involves moral judgements about who victims are, what they need, and who is obligated to help them. Thus, broader socio-political arguments about victims' needs or rights (Dunn, 2007; Simmonds, 2009) are invoked as interpretative repertoires and used practically to account for actions like seeking, offering, or denying help. 


\subsection{SEEKING HELP ON BEHALF OF OTHERS}

The final analytic chapter examined participants' orientations to the relationship between identity and help when callers sought help on behalf of others. My analysis drew upon Sacks'(1967, 1972a) categorical framework to demonstrate how callers treated identity categories and social relations as relevant when seeking help for others. Although Sacks noted the accountability involved in turning to strangers on another's behalf, my analyses have provided the first systematic investigation of how people orient to self-other relations, identity, and accountability when seeking help for others.

\subsubsection{No one to turn to}

Sacks (1967) was primarily concerned with how suicidal callers could claim they had 'no one to turn to' while speaking with a helpline counsellor. When calling on behalf, the paradox of 'no one to turn to' seems even stranger. Sacks showed that callers concluded they had no one if they had no available members of proper relationship categories (Rp). My analysis demonstrated that callers drew similar conclusions on behalf of others, even when categorising themselves as members of proper relationship categories, such as friends or family members. In these cases, the person in need does have someone to turn to, and callers sometimes described being turned to as motivating the current call. How, then can claims like "she's got no one" (7.1.1) be understood?

Callers invoked three different ways victims could have available $\mathrm{Rp}$ members who were nonetheless unable to turn to. First, callers treated relationship troubles as reasons spouses or partners were unavailable (e.g. 7.1.1 and 7.1.2). If a relationship break-up is the reason someone feels suicidal, an ex-partner is not available as someone to turn to (Sacks, 1967). Second, when callers categorised perpetrators as first position pair members, they treated them as unavailable to turn to (e.g. 7.1.4 and 7.1.5). People who have been 
victimised by a spouse or family member may have no one to turn to, because the search for help does not licence turning to other members of Rp if a first position member is available (Sacks, 1972b). This problem has long been documented in feminist research, where women who experience violence from partners or family members feel unable to tell others, even those whom they are close to (e.g. Othman, Goddard, \& Piterman, 2014; Towns \& Adams, 2009). Third, some callers claimed they themselves were unavailable members of Rp categories (e.g. 7.1.2 and 7.1.3). Callers accounted for being unavailable by formulating their location relative to the person in need. Thus, when members of standardised relational pairs were leaving a relationship, the perpetrator of violence, or too far away to help, callers treated them as unavailable, leaving the person in need with effectively no one.

\subsubsection{The rights to provide help to others}

One key finding was that participants distinguished between seeking and providing help. In this section, I discuss participants' orientations to the entitlements and obligations associated with providing help, and in the following section I discuss how participants understood the rights and entitlements for seeking help on behalf of others.

Sacks (1967) argued that the search for help is organised around category-bound rights and obligations for giving help. As members of a proper relationship categories, callers who identified as friends (e.g. 7.1.1 and 7.1.3) or family members (e.g. 7.1.2 and 7.3.1) oriented to their rights and obligations to help members of paired categories. Category members who do not enact their category-bound obligations can be held accountable (Watson, 1978). Callers oriented to their obligations by accounting for why they were unable to provide help. No-fault accounts that describe inability rather than unwillingness orient to social relations (Heritage, 1990). By formulating their location as "too far away" (7.1.3), callers accounted 
for their inability to provide help, and in so doing, justified calling the helpline. By referring to place names, callers invoked a "common sense geography" (Schegloff, 1972, p. 85), relying on their recipients' understandings of New Zealand towns and cities to build recognisable accounts like "because I'm currently in Moorland there's nothing I can do" (7.1.2). The nature of these accounts also displayed callers' understandings that face-to-face support was preferable to that provided over the phone (e.g. 7.1.3).

Participants distinguished between the help different members of relationship categories could rightfully provide. Sacks (1972a) documented that members of proper relationship categories have hierarchically organised rights and obligations. Participants oriented to this normative hierarchy when they treated different kinds of help as relevant for different category members. For example, participants treated spouses as having greater rights than friends to provide direct intervention. Some forms of help (such as calling support services) could be carried out by certain members of relationship categories, while others (such as taking someone to hospital) were treated as entitlements of first-position pair members (e.g. 7.2.1). Notably, in 7.2.1, the call-taker treated a partner as having first-position rights even though the relationship break-up was the cause of the problem. Thus, participants jointly established what counted as sufficient Rp membership and how rights and obligations could be distributed between members of relationship categories.

Certain kinds of help can be understood as either an obligation for members of relationship categories or for members of professional categories. For example, care-giving is, at times, treated as a common-sense obligation for family members, and at others, as an obligation for members of the medical profession (Hunt, 1991; Izumi, 2017). My analyses suggest that participants orient to Victim Support in a similar way. The organisation treats supporting victims as a proper role for trained support workers. Yet these support workers are volunteers, which suggests emotional support and 
practical advice are forms of help normatively available to competent members of a community (Roose et al., 2012). Callers seeking help for others oriented to the way that supporting victims can be a proper obligation for members of either professional or relationship categories. Callers seeking help on behalf of others (in contrast to those who have directly experienced victimisation) can be understood as competent members with a potential ability to provide the kind of help they are seeking for another. By accounting for why they were unable to provide help, these callers treated support as normatively associated with friends or family members.

Members of proper relationship categories are obligated to provide help to pair members, while members of other categories have an opportunity to provide help. Thus, callers who identified as friends and family members accounted for not fulfilling their category-bound obligations to help and arranging Victim Support instead, while callers who identified in other ways (such as institutional representatives) oriented to help as an opportunity rather than an obligation (e.g. 7.2.3). Thus, the moral accountability of help depends on participants' sense of who they are to each other.

\subsubsection{The rights to seek help for others}

Callers who identified as members of relationship categories accounted for seeking help they might otherwise be expected to provide themselves. The same category membership that grants friends and family members rights to provide help made seeking help from Victim Support morally accountable. Callers displayed the understanding that it was only in the absence of their ability to provide help (i.e. being too far away) that they could accountably seek help for others. However, callers who constituted different self-other relations between themselves and who they were calling for oriented to the accountability of seeking help differently. 
Callers who identified as institutional representatives negotiated their category-bound rights to seek help for others through the ways they configured self-other relations. Callers who identified as court victim advisors (7.1.4 and 7.2.2) oriented to a different set of categories as a locus for rights and obligation to help. Yet even then, participants negotiated what kind of help callers were entitled to seek. In 7.1.4, the caller treated seeking support (by calling the helpline) as a proper entitlement of his institutional role. Yet in 7.2.2 both participants oriented to the caller's activity as non-normative. The caller accounted for seeking support by formulating her client's emotional state as "very distressed." In contrast to callers who identified as members of relationship categories, this caller demonstrated that the provision of emotional support was not a category-bound right. Instead, by calling Victim Support, she displayed her expectation that Victim Support was obligated to provide support to an emotionally distressed victim. By describing her previous conversation with her client as occasioning her call, the caller accounted for why she was seeking help. Here then, the rights and obligations associated with the expression of emotion in the emotional order (Stevanovic \& Peräkylä, 2014) intersected with categorically-organised rights and responsibilities to provide help (Sacks, 1972b).

Call-takers also claimed the rights to determine callers' entitlements to seek help on behalf of others. In 7.3.1 and 7.3.2, the caller oriented to her relationship with her mother as providing the category-bound rights to seek help on her behalf (cf. 7.1.1 - 7.1.3). Yet, by categorising her as an offender, the call-taker denied her rights to seek help for herself or others. In this case, the rights organised with reference to the categories victim and offender took precedence over those organised with reference to the categories mother and daughter. Although relationship categories provide one commonsense way to reason about the moral accountability of help (Sacks, 1967), relational rights and obligations to help can be superseded by 
different institutional frameworks. A key feature of institutional helpseeking is that institutional representatives claim the rights to determine which identities and self-other relations are relevant to understand and respond to callers' requests (Heritage, 2004). In calls to Victim Support, call-takers claimed the rights to determine who callers were relative to others, which was consequential in the provision or withholding of support.

\subsection{DISCURSIVE PSYCHOLOGY, HELP, AND SELF-OTHER RELATIONS}

\subsubsection{Self-other relations in action}

The nature of the self and its relation to others is a fundamental question for the social sciences. Social psychologists have theorised the cognitive basis for self-other relations using Social Identity Theory or Self-Categorisation Theory to explain how individuals see themselves and others as members of groups (Hogg et al., 1995; Tajfel \& Turner, 1986). However, my work demonstrates the potential of a discursive psychology of self-other relations. Contemporary interactional research theorises that the social organisation of knowledge, power, and emotion are fundamental facets of self-other relations (Stevanovic \& Peräkylä, 2014). Although identities and experiences are often treated as belonging to individuals (Benwell \& Stokoe, 2006), participants negotiate ownership of these psychological phenomenon in interaction. My analyses have shown that participants observably constitute and use self-other relations to build interpretable actions. Thus, my work demonstrates how identities and action can be analysed as intertwined phenomena.

Although the mutually constitutive relationship between identity and action is particularly salient for victims seeking help, I argue that identity and action are always inexorably linked. Identity is not fixed, but constituted in different ways at different moments of interaction (Benwell \& Stokoe, 2006). In interaction, identity is 
inseparable from self-other relations. People identify themselves in different ways depending on who they understand their recipient to be and what they are doing at any given interactional moment. In other words, who participants are to each other shifts and changes with the sequential unfolding of interaction.

The social organisation of knowledge, power, and emotion are key facets of the "momentary relationship" between participants that is a resource for building recognisable actions (Stevanovic \& Peräkylä, 2014, p. 186). My work demonstrates how this theoretical framework of social relations provides a grounded approach to the relationship between identity and action. Although this framework was developed to explain how actions are built and interpreted in interaction, I argue for the productive possibilities for discursive psychology.

The way people use and orient to knowledge, power, and emotion are fundamental psychological concerns. The distribution of knowledge and how rights to knowledge configure social relations are intrinsic social psychological matters (see Raymond \& Heritage, 2006). Analysing deontics in interaction provides an interactional demonstration of psychological concepts like authority and coercion (see Clift, 2016). My analyses contribute to interactional research which has shown the importance of epistemics and deontics in determining how help is sought and provided in institutional contexts. Likewise, emotion is a key site of psychological inquiry. This thesis advances interactional analyses of emotion by demonstrating the consequential relationship between emotion, identity, and help in calls to Victim Support.

Discursive psychology has examined how emotions are described or formulated (Edwards, 1999), and how emotions are displayed and responded to in interaction (Hepburn \& Potter, 2007, 2017). Research in institutional contexts has demonstrated how different ways of responding - such as displaying empathy or offering 
advice - can configure self-other relations (e.g. Pudlinksi, 2005) and social contexts (Weatherall \& Stubbe, 2015). Yet the way emotions are associated with different identity categories, and how emotions and help are interrelated deserves further investigation. On the Victim Support helpline, emotion has common-sense associations with both a victim identity and the kind of help available. The analyses demonstrate that displays of emotion can accomplish a request for help and constitute a caller's identity as a victim (e.g. 5.2.1). The rights to express different emotions to different participants is tied to the moral accountability of help-seeking. For example, in 7.2.2, the expression of emotion to the wrong institutional recipient occasioned seeking help on behalf. My work thus demonstrates the productive possibilities for analysing the relationships between emotion, identity, and help.

By integrating Sacks' (1967, 1972a, 1972b) insights with recent developments in the interactional organisation of social relations (Stevanovic \& Peräkylä, 2014), I have demonstrated how rights, entitlements, and obligations to help are constituted and understood through participants' sense of who they are to each other. Membership categorisation analysis has demonstrated how different predicates like rights, obligations, and knowledge can be bound to different category membership (e.g. Psathas, 1999; Stokoe, 2012). My analyses show that participants orient to different category-bound rights to know about themselves and others, determine how help will be given, and express or respond to emotion. Thus, moral rights and obligations to help are grounded in participants' orientations to selfother relations.

My work contributes to research on help as social action by explicating how identities and self-other relations are demonstrably relevant considerations for participants when seeking, giving, or withholding help. Research on requests in interaction has demonstrated that the nature of what is being requested is consequential for how requests are built, interpreted, and responded 
to (Drew \& Couper-Kuhlen, 2014), while my work has shown that that the nature of what is being requested is consequential for how identities are constituted and used. The development of recruitment has demonstrated how different methods of recruiting help can configure self-other relations in terms of obligation or opportunity to help (Kendrick \& Drew, 2016). In this thesis, I argue that the mutually constitutive relationship between self-other relations and help is a resource for participants to negotiate the moral accountability of seeking or providing help on the Victim Support helpline.

Calls where help is sought on behalf provide a unique perspective on participants' orientation to the moral accountability of help. Seeking help on behalf of others is a social action which has received limited analytic attention (see Gordon \& İkizoğlu, 2017). This social action seems a fruitful area for discursive psychology, which offers potential for developing new ways to conceptualise how help is sought and provided in social interaction. The social configuration of participants in these calls complicates the analytic concepts of self-other used in recruitment, where self refers to helpseeker and other as help-provider (see Kendrick \& Drew, 2016). In these cases, the one seeking help (the caller) is not the one in need and the immediate recipient (the call-taker) is not the help-provider, but a conduit to service - although callers may not always be aware of this.

\subsubsection{Participants' orientations to identity}

In this thesis, I adopted a grounded approach to identity. Following Schegloff (1997), I aimed to show how identities were demonstrably relevant and procedurally consequential for participants. In my analysis, I did not presuppose callers' identities as victims, nor did I approach the data with hypotheses or expectations about how or where common-sense conceptions of victims would shape the interaction. Instead, I analysed how callers made different identities relevant for themselves and others and how these identities 
were deployed for the practical goal of accomplishing help. This approach allowed me to examine identity as it mattered for participants.

My findings also contribute to the ongoing analytic project of documenting what participants' orientations to identity look like in practice. When participants used the word victim (e.g. Section 5.3) they seemed quite clearly to be orienting to identity as relevant. Yet, explicit references to a victim identity were comparatively rare in the data. Prior research has demonstrated that category terms (such as man or woman) do not always demonstrate an orientation to identity (Kitzinger, 2007), while non-categorical references, such as 'I', can at times be used to invoke identities like gender (Jackson, 2011). My work has likewise demonstrated that callers orient to identity through a range of different practices including explicit categorisation, descriptions of experience, and displays of knowledge. The mutually constitutive link between identity and help means callers' requests for help constitute - and are rendered accountable through - their identities as victims.

Although I followed Schegloff's (1997) mandate to analyse those identities participants treated as relevant, my analyses were sensitive to the ways that common-sense and ideology could pose dilemmas for victims seeking help.

\subsubsection{The dilemma of seeking help as a victim}

Ideology and common-sense are made up of contrary themes which allow people to puzzle over everyday life and experience dilemmas about how to act in certain situations (Billig et al., 1988). Seeking help as a victim is one such ideological dilemma. On the one hand, society has a moral obligation to help victims (Mawby, 1988). Someone who is a victim has been harmed by forces beyond their control, with common-sense rights to seek and receive public sympathy, support, and justice. These shared forms of social knowledge suggest identifying as a victim is beneficial to receive 
access to help (see Åkerström et al., 2011; Jägervi, 2014). On the other hand, victims may be blamed or shamed for what happened to them. People whose experiences do not fit cultural conceptions of victims may find themselves subject to hostility, disbelief, or moral judgements (Jordan, 2004; MacLeod, 2016; Othman et al., 2014) that has been termed secondary victimisation (Campbell \& Raja, 1999). Social knowledge about how certain victims are treated provides common-sense reasons to avoid identifying as a victim or seeking help from support services.

Shared social knowledge represented by maxims or proverbs express moral evaluations and allow opposing moral judgements (Billig et al., 1988). For example, the proverb 'God helps those who help themselves' suggests people should engage in self-help before turning to others. This social norm has been documented in the organisation of recruitment methods (Kendrick \& Drew, 2016) and the way people account for calling institutions by explaining their prior attempts to fix the problem (Edwards \& Stokoe, 2007). Opposing maxims, like 'ask and you shall receive,' provide different ways of understanding the moral accountability of seeking help. This kind of social knowledge has been demonstrated in the ways participants ask for help in different contexts and display different expectations or entitlements to receive help (e.g. Heinemann, 2006; Heritage \& Clayman, 2010a).

Returning to discursive psychology's theoretical roots, the analytic concepts of ideological dilemmas and interpretative repertoires can demonstrate how negotiating rights and obligations to help victims are associated with broader social moral systems of common-sense knowledge (e.g. MacLeod, 2016; Towns \& Adams, 2009). My analyses showed that different ways of describing people and events made certain conduct accountable, such as offering or denying help, and constructed certain versions of reality, such as the criminal nature of callers' experiences (e.g. 6.2.2 and 6.3.3) or different category members' obligation to help (e.g. 6.3.2 and 7.2.1). 
An analytic focus on how versions of reality are constructed (Edwards, 1997) can demonstrate how identities and actions are linked in consequential ways.

The relationship between interpretative repertoires and sequential analysis has been a source of contention within conversation analysis and discursive psychology (Schegloff, 1997; Weatherall, 2016; Wetherell, 1998). In an attempt to reconcile these two analytic frameworks, I started with close analysis of the turn-byturn unfolding of the interaction. Many of the patterns in the ways help was sought and given connect to broader social-moral understandings of what it means to be a victim. Thus, interpretative repertoires provide an analytic framework to examine how victimhood was constructed at different interactional moments to account for actions like seeking, offering, or withholding help. However, the language of interpretative repertories can suggest an either/or logic. For example, participants often display orientations to two alternative versions of reality (e.g. the caller as a victim or offender, 7.3.1; or the situation as criminal or simply unfortunate, $6.1 .1,6.3 .2)$. I do not mean to suggest that there are only two ways to understand callers and their problems. There are potentially infinite possible descriptions available. However, participants descriptions themselves are often built with an orientation to an alternative (Edwards \& Potter, 1992) and in this institutional context, the categories of victim and offender are omnirelevant categories that provide inferential frameworks for understanding who the participants are and what they are doing (see Housley \& Fitzgerald, 2015).

The relationships established between categories, activities, and predicates "often gain a normative quality, making the links significant in the reproduction of what is societally seen as moral and normal" (Stokoe, 2003, p. 429). When participants negotiated category-bound rights and obligations to seek and provide help to victims, they maintained and policed common-sense boundaries 
regarding who victims are and how they should be helped. Constituting links between categories, activities, and predicates allows participants to make claims about the world, organise social relations which is central to how politics are accomplished in everyday life (Baker, 2000). Thus, the political struggle over what kind of people are treated as victims and how help should be provided to them can be observed in participants' interactional practices on the victim helpline.

My attention to the importance of common-sense reasoning and the dilemmas associated with Victim Support demonstrate the productive possibilities for integrating analytic concepts like interpretative repertoires and ideological dilemmas into interactional analysis of help as social action. Although conversation analytic research recognises the moral accountability of seeking help from others (e.g. Clayman \& Heritage, 2014; Kendrick \& Drew, 2016), particularly from institutions (Edwards \& Stokoe, 2007), my analyses show that certain kinds of help have common-sense associations with identity that can pose ideological dilemmas. I suggest that attending to the common-sense reasoning about identity and help might usefully inform further studies of the interactional accomplishment of help in different settings.

\subsubsection{Feminist interrogation of victimhood}

Although I did not approach the data with an expectation of the gendered construction of victimhood (see Schegloff, 1997), I am sensitive to the ways cultural understandings of victimhood are located in broader gendered systems of meaning (Lamb, 1999b). By documenting how common-sense knowledge can be consequential in the delivery of help, my analyses contribute to the feminist interrogation of social-cultural understandings of victims.

Feminists and critical victimologists recognise that "victim services mirror the views and attitudes of the larger society" and so "they are bound to share the prejudices and biases of the society in 
which they operate." (Fattah, 2010, p. 76). I argue that support services not only mirror social understandings of victims, but are a key site in which these understandings are constituted. Calls to Victim Support are a consequential site where participants use and constitute common-sense reasoning about who victims are and what help they need. Conversation analysis and membership categorisation analysis offer unique tools for feminist research by demonstrating how cultural common-sense is built and used in consequential ways in interaction (Tennent \& Weatherall, in press). My analyses of calls to Victim Support sheds new light on feminist questions regarding the relationship between victims and help.

Feminists have long documented the impact of commonsense cultural knowledge on victims' understanding of their experiences and access to support. Research has examined why victims avoid seeking help, with one commonly cited reason that people do not understand their experiences as victimisation and thus fail to identify themselves as victims (Fohring, 2015; Kelly \& Radford, 1990; Weiss, 2011). Although post-structuralist critique points to the ways violence against women and minorities is normalised (Lamb, 1999b), Gavey (1999) argued that feminist research should attend to how and why people might avoid a victim identity, rather than imposing labels onto their experiences. My analytic focus on participants' orientations allowed me to attend to how callers understood themselves and their experiences, without presuming their identities as victims. Documenting participants' orientations is one grounded way to produce research that honours the voices of participants (Kitzinger, 2000).

Further reasons people may not seek help is fear of how others will respond, or a lack of confidence in institutional responses (Jordan, 2011; Meyer, 2015). Interview research has documented the reasons people give for choosing not to disclose their experiences to others (e.g. Othman et al., 2014). My research documents the reasons people give for or against seeking help - as they seek help from a 
Victim Support call-taker. For example, in 6.3.3, the caller claimed if she were to talk to police, her husband would kill her. Rather than simply responding to an interviewer's question, the caller's disclosure accounted for rejecting the call-taker's offer to transfer the call. Analysing situated actions demonstrates how descriptions are produced in particular ways in response to interactional demands (Wiggins, 2016). Furthermore, her distinction between seeking help from Victim Support and turning to police demonstrates that cultural members can have different understandings of where to turn to and the consequences for doing so.

For "feminists and other critical scholars who want to change the world for the better, an essential prerequisite is an accurate understanding of how the world is now" (Wilkinson \& Kitzinger, 2014, p. 154). Analysing social interaction provides an empirical basis of knowledge about the social world and how participants understand it. My work documents the practical ways people can seek help as victims. Examining real-life cases where people turn to an institution for help can demonstrate whether or how common-sense knowledge shapes how callers see themselves and understand their rights to help. I pick up the implications for improving services in 8.5.3. Below, I first discuss how my findings shed light on the institutional context of Victim Support. 


\subsection{TALKING THE INSTITUTION INTO BEING}

In this section, I discuss how the relationship between identity and help constituted the social context of the Victim Support helpline. The mutually constitutive link between identity and help was a key way the institution of Victim Support was talked into being (see Heritage \& Clayman, 2010d). Below, I first justify my choice of audio recordings, before discussing how my analyses can elucidate the organisation of help in institutional contexts. I end with some implications for practice.

\subsubsection{The limitations of audio recordings}

One limitation of my research is that the analyses are based solely on audio recordings of calls. Conversation analytic research using video recordings has demonstrated how call-takers' work is made up of parallel activities (Mondada, 2008) including interactions with callers, computers, and colleagues (J. Whalen \& Whalen, 2011). Even simple tasks like putting the caller on hold can involve a sophisticated coordination of verbal and embodied conduct (Näslund, 2016), while decisions about how or whether help will be provided can be accomplished through both callers' descriptions and calltakers' interactions with computer databases (Larsen, 2013; J. Whalen, 1995).

In the early stages of the project, my supervisor and I considered the possibilities of video recording the call-taker and their computer screen. My observations of the Contact Service had demonstrated the importance of the interface between what callers said and what call-takers did on the computer. However, in the end we settled on audio recordings for both pragmatic and theoretical reasons. For one, incoming calls were routinely recorded by the Contact Service, and thus an easily accessible form of data. I was particularly conscious of the need for a manageable data corpus. As it stands, I have managed to transcribe just over half of the 394 calls. 
That number of video recordings would have been untenable for the detailed multi-modal transcription needed to capture the coordination of verbal and embodied action (see Mondada, 2014b).

As the project developed, I moved away from initial attempts to document the work of the Contact Service. Some conversation analytic research documents how organisations work (e.g. Psathas, 1999; Watson, 1986; J. Whalen, 1995). However, my focus was on how the psychological matters of identity, help, and self-other relations were negotiated in social interaction. Victim Support calls provide a perspicuous setting for this investigation (Garfinkel, 2002), but the setting - its procedures and how it operates - was not the primary focus of my investigation.

Although the lack of recoding limits the observations that can be drawn about call-takers' conduct, it means as an analyst, I have access to the same level of detail as callers. Some non-verbal conduct is observable from the recordings, such as the sound of call-takers' keyboards (e.g. 6.2.1 and 6.3.1). Although I cannot tell what calltakers are writing or where, this is precisely the same position callers are in. Likewise, excluding those calls where call-takers accessed clients' casefiles, call-takers understandings of who callers are and what they need is also derived from callers' conduct during the call. Thus, to analyse how participants use the relationship between identity and help, audio recordings have proved sufficient.

\subsubsection{Getting institutional help}

In calls to Victim Support, participants regularly displayed different understandings of what counted as support and how it should be provided. Just like emergency calls, if participants were unable to establish a joint understanding of who they were to each other and how help would be given, misunderstandings could have serious consequences (J. Whalen et al., 1988). Not only do denials of help disavow callers' identities as victims, callers who are directed 
elsewhere may not access support in potentially life-threatening situations (e.g. 6.3.3). When callers have overcome the ideological dilemma of choosing to call for help, the ways call-takers respond carries implications for who they understand themselves to be, what they are entitled to, and whether they end up getting help.

Many institutions are characterised by mutual orientation to participants' relevant identities as service-seekers and serviceproviders. Yet as Jefferson and Lee (1992) demonstrated, these identities (and the sub-categories of advice-seeker and adviceprovider) do not always align with callers' presentation of their troubles. Responding to troubles-tellings as a troubles-recipient displays an interest in the teller and their experience, while responding as an advice-giver focuses on the problem and its properties. When callers use narrative descriptions on helplines, calltakers may be faced with a dilemma: attempt to solve the problem by giving advice or respond to the caller's troubles by providing empathy. Different institutional call-takers handle this dilemma differently (e.g. Butler et al., 2010; Feo \& LeCouteur, 2013; Pudlinksi, 2005). Victim Support call-takers are not trained to provide support, and so largely respond as advice-givers. Yet callers regularly oriented to the relevance of other kinds of help.

When callers rejected offers of transfer, they displayed expectations of receiving other kinds of help (see 5.3.4 where this is made explicit). However, the kind of help call-takers can provide is constrained by their institutional role. If they understand callers as legitimate victims with relevant problems, they can enlist them as clients (which occurs when they offer referral). Yet in many cases, call-takers oriented to callers as people with problems that could not be solved by the help available. In this situation, offering to connect callers to other organisations was the only form of help call-takers could relevantly provide. The implications of the institutional constraints on help are particularly salient in 6.3.3 where, despite providing compelling reasons why she does not want to talk to police, 
the caller is repeatedly offered transfer. The call-taker's offers display his understanding that the caller needs help from police. Yet by continuing to offer the same form of help in response to her rejections, he suggests she can only be helped by police. This stance on the caller's needs ultimately resulted in her ending the call without receiving help in any form.

To accountably seek institutional help, callers must present themselves as relevant people with relevant problems. In the case of Victim Support, the name of the institution is also a description of the activity - support is provided to victims. Victim Support bears similarities to helplines like Kids Help Line and MensLine that specify a category of person who can be helped. Although these services suggest that anyone with a relevant identity can access support or help, in practice, callers require a relevant institutional problem fitted to the kind of help the organisation can provide (see Butler et al., 2010; Danby et al., 2005; Feo \& LeCouteur, 2013, 2017). For Victim Support, callers who seek help beyond the emotional support and practical advice the organisation offers are inevitably directed elsewhere.

My analyses show that call-takers on the victim helpline do not act merely as a conduit to service. Instead, call-takers determine whether callers are victims and whether they are entitled to help. Thus, in the course of routine workday tasks, call-takers are involved the political, moral, and psychological enterprise of determining who callers are and who is obligated to help them. Below, I discuss how my empirical analysis of helpline calls might improve the delivery of service.

\subsubsection{Implications for practice}

Although service-providers operate with the assumption they have unique and special competence for dealing with problems like victimisation, categorically organised common-sense knowledge 
about who can be turned to shapes how services are approached and understood by members of a community (see Sacks, 1972b). Understanding the common-sense rights and obligations associated with help is important for services and policy makers to provide meaningful social support (Broadhurst, 2008).

One problem that regularly occurs on the Victim Support helpline is that callers ask for kinds of help which cannot be given. The mismatch between the kind of help callers seek and what institutional representatives can provide has been documented in a range of other settings including counselling helplines (Butler et al., 2010), dispute resolution services (Weatherall, 2015), and medical information lines (Butler, Danby, Emmison, \& Thorpe, 2009b). Difficulties can arise when callers lack familiarity with the service. For example, callers to a neighbourhood mediation service faced difficulty designing relevant requests because they lacked knowledge of the kind of help available (Stokoe, 2013a). Like mediation services, what 'Victim Support' is and how it operates is less widely known than, for example, police services. Yet even though participants generally share common-sense knowledge about when and how to call police, callers may not always be aware of what constitutes a relevant police matter (Rønneberg \& Svennevig, 2010).

In some cases, the name of the service can exacerbate the mismatch between the help callers ask for and what can be provided. For example, callers to the Child Health Line regularly seek medical advice which nurse call-takers cannot provide. Butler and colleagues (2009b) noted that callers' requests displayed an expectation nurses that have professional authority and expertise to give advice when in fact, nurses are trained only to provide information and support. On the Victim Support helpline, callers display similar expectations of receiving support from call-takers directly, while call-takers are not trained to provide this form of help. 
In nearly a fifth of the sample, callers displayed an expectation that the call-taker was 'someone to talk to.' In some cases (such as 5.2.1 and 6.2.1), call-takers corrected callers' displayed misunderstanding of the service by identifying themselves as contact service workers, specifying that support available was delivered support workers, or explaining the process of referral. Yet in others, callers treated call-takers' details-gathering questions (such as "could you tell me about what happened?") as story-solicitations, producing troubles-tellings that could substantially disrupt the progress of the call (see Jefferson \& Lee, 1992). Callers' misunderstandings of the help available not only interfere with the accomplishment of institutionally relevant tasks, but are potentially traumatising for both participants. Call-takers are not trained to provide support, and largely avoid giving affiliation, meaning a caller's telling may be met with minimal responses or abrupt returns to business. It seems fair to suggest that callers who recount their experience of victimisation to an unsympathetic recipient may not feel supported.

Callers' expectations of receiving help in the here and now of the call seem exacerbated by the advertisement of 0800 Victim as a helpline and the way that call-takers answer the phone by identifying as "victim support". One solution would be to change the routine opening, such as by identifying as the Victim Support Contact Service, or for call-takers to explain their role to callers when offering referral. This could be accompanied by clearer advertising about the role of the 0800 Victim line.

A different solution would be to broaden the scope of the activities call-takers are trained to provide during calls, such as explanations of service or affiliative responses. Using research findings to develop evidence-based training can provide call-takers with grounded ways of responding to callers, rather than the takenfor-granted concepts currently used in training like 'active listening' or 'being empathetic' (see Hepburn, Wilkinson, \& Butler, 2014). One internationally recognised training programme is the Conversation 
Analytic Role-play Method (CARM) which develops research findings into evidence-based training (Stokoe, 2014). In contrast to traditional role-play training, CARM uses recordings of real interactions to provide practical strategies for call-takers to deal with the kinds of real problems which occur in their calls (Stokoe, 2013b).

Interactional research offers a grounded way to assess effective practice. Researchers do not need to contact callers later to ask them how satisfied they were; but can examine their responses in the moment of the interaction, often to a level of detail that would be impossible to recall. A sound first step to develop processes that effectively meet the needs of victims is to document what actually happens when they seek help.

\subsection{CONCLUDING COMMENTS}

Asking for help is a morally accountable action that necessarily constitutes self-other relations. When someone asks for help, they inevitably display their understanding of who they are to their recipient and the relevant basis upon which they are entitled to ask. In calls to Victim Support, asking for help is rendered accountable through callers' identities as victims and the social context of the institution. Likewise, the ways that help is given or denied constitutes who participants are to each other and their relative entitlement and obligation to help.

In this thesis, I examined how participants negotiated moral accountability and self-other relations when callers sought help for themselves or others, and call-takers granted or denied callers' requests. My findings demonstrate the importance of analysing the relationship between identity and help as it is constituted by participants in interaction. By negotiating their relative rights to knowledge, power, and emotion, participants determine who they are to each other and how these self-other relations matter for help. When participants link different activities and predicates with victim 
category membership, they display their understanding of who victims are and how they should be helped.

How members of society respond to victims demonstrates who they understand themselves to be. In the wake of the Christchurch terror attacks, the outpouring of love, grief, rage, and support showed New Zealanders grappling with who they were relative to the victims, and what kind of nation we want to be. I argue that these same socio-political tensions are apparent in calls to Victim Support. Far from a straightforward conduit to service, calls to the helpline are a consequential site where society's moral obligation to victims is constituted. 


\section{REFERENCES}

Åkerström, M., Burcar, V., \& Wästerfors, D. (2011). Balancing contradictory identities - performing masculinity in victim narratives. Sociological Perspectives, 54(1), 103-124. https://doi.org/10.1525/sop.2011.54.1.103

Antaki, C., \& Kent, A. (2015). Offering alternatives as a way of issuing directives to children: Putting the worse option last. Journal of Pragmatics, 78 , 25-38. http://dx.doi.org/10.1016/j.pragma.2015.01.004

Baker, C. (2000). Locating culture in action: Membership categorisation in texts and talk. In A. Lee \& C. Poynton (Eds.), Culture and text: Discourse and methodology in social research and cultural studies. (pp. 99-113). London: Routledge.

Baker, C., Emmison, M., \& Firth, A. (2001). Discovering order in opening sequence: Calls to a software helpline. In A. McHoul \& M. Rapley (Eds.), How to analyse talk in institutional settings: A casebook of methods (pp. 41-56). London, UK: Continuum.

Benwell, B., \& Stokoe, E. (2006). Discourse and identity. Edinburgh: Edinburgh University Press.

Baker, C. (2000). Locating culture in action: Membership categorisation in texts and talk. In A. Lee \& C. Poynton (Eds.), Culture and text: Discourse and methodology in social research and cultural studies. (pp. 99-113). London: Routledge.

Broadhurst, K. (2007). Parental help-seeking and the moral order. Notes for policy-makers and parenting practitioners on "the first port of call" and "no one to turn to." Sociological Research Online, 12(6), 114.

Butler, C., Danby, S., Emmison, M., \& Thorpe, K. (2009a). Managing medical advice seeking in calls to Child Health Line. Sociology of Health \& Illness, 31(6), 817-834. https://doi.org/10.1111/j.14679566.2009.01179.x

Butler, C., Potter, J., Danby, S., Emmison, M., \& Hepburn, A. (2010). Advice-implicative interrogatives: Building "client-centered" support in a children's helpline. Social Psychology Quarterly, 73(3), 265-287. https://doi.org/10.1177/0190272510379838 
Campbell, R., \& Raja, S. (1999). Secondary victimization of rape victims: Insights from mental health professionals who treat survivors of violence. Violence and Victims, 14(3), 261-275.

Christie, N. (1986). The ideal victim. In E. Fattah (Ed.), From crime policy to victim policy: Reorienting the justice system (pp. 17-30). Basingstoke, UK: Palgrave Macmillan.

Clark, H., H. (2006). Social actions, social commitments. In N. J. Enfield \& S. C. Levinson (Eds.), Roots of human sociality: Culture, cognition and interaction (pp. 126-150). New York: Berg.

Clayman, S. E., \& Heritage, J. (2014). Benefactors and beneficiaries: Benefactive status and stance in the management of offers and requests. In P. Drew \& E. Couper-Kuhlen (Eds.), Studies in language and social interaction (Vol. 26, pp. 55-86). https://doi.org/10.1075/slsi.26.03cla

Clift, R. (2016). The structure of sequences II: Knowledge and authority in the construction of identity. In Conversation Analysis (pp. 185231). Cambridge, UK: Cambridge University Press.

Clifton, J. (2009). A membership categorization analysis of the Waco Siege: Perpetrator-victim identity as a moral discrepancy device for 'doing' subversion. Sociological Research Online, 14(5), 1-11. https://doi.org/10.5153/sro.2002

Coates, L., \& Wade, A. (2004). Telling it like it isn't: Obscuring perpetrator responsibility for violent crime. Discourse \& Society, 15(5), 499526. https://doi.org/10.1177/0957926504045031

Corbett, C., \& Maguire, M. (1988). The value and limitations of Victims Support Schemes. In Mike Maguire and John Pointing (Ed.), Victims of Crime: A new deal? (pp. 26-39). Milton Keynes: Open University Press.

Craven, A., \& Potter, J. (2010). Directives: Entitlement and contingency in action. Discourse Studies, 12(4), 419-442.

Cromdal, J., Danby, S., Emmison, M., Osvaldsson, K., \& Cobb-Moore, C. (2018). "Basically it's the usual whole teen girl thing": Stage-oflife categories on a children and young people's helpline. Symbolic Interaction, 41(1), 25-44. https://doi.org/10.1002/symb.320

Cromdal, J., Osvaldsson, K., \& Persson-Thunqvist, D. (2008). Context that matters: Producing "thick-enough descriptions" in initial emergency reports. Journal of Pragmatics, 40(5), 927-959. https://doi.org/10.1016/j.pragma.2007.09.006 
Cuff, E. C. (1993). Problems of Versions in Everyday Situations. Washington, D.C.: International Institute for Ethnomethodology and Conversation Analysis \& University Press of America.

Curl, T. S. (2006). Offers of assistance: Constraints on syntactic design. Journal of Pragmatics, 38(8), 1257-1280. https://doi.org/10.1016/j.pragma.2005.09.004

Curl, T. S., \& Drew, P. (2008). Contingency and action: A comparison of two forms of requesting. Research on Language \& Social Interaction, 41(2), 129-153. https://doi.org/10.1080/08351810802028613

Daigle, L. (2018). Victimology: A text/reader. In Sage text/reader series in criminology and criminal justice. Thousand Oaks, California: SAGE Publications.

Danby, S., Baker, C., \& Emmison, M. (2005). Four observations on openings in calls to Kids Help Line. In C. Baker, M. Emmison, \& A. Firth (Eds.), Calling for help: Language and social interaction in telephone helplines (pp. 133-151). Amsterdam, The Netherlands: John Benjamins.

Danby, S., Cromdal, J., Rendle-Short, J., Butler, C., Osvaldsson, K., \& Emmison, M. (2015). Parentification: Counselling talk on a helpline for children and young people. In M. O'Reilly \& J. N. Lester (Eds.), The Palgrave Handbook of Child Mental Health (pp. 578-596). https://doi.org/10.1057/9781137428318_31

Darley, J. M., \& Latané, B. (1968). Bystander intervention in emergencies: Diffusion of responsibility. Journal of Personality and Social Psychology, 8(4), 377-383. https://doi.org/10.1037/h0025589

Davidson, J. (1985). Subsequent versions of invitations, offers, requests, and proposals dealing with potential or actual rejection. In J. M. Atkinson (Ed.), Structures of social action: Studies in conversation analysis (pp. 102-128). Cambridge: Cambridge University Press.

Davidson, J. (1990). Modifications of invitations, offers and rejections. In G. Psathas (Ed.), Interaction competence (pp. 149-179). Washington, D.C.: International Institute for Ethnomethodology and Conversation Analysis \& University Press of America.

Drew, P., \& Couper-Kuhlen, E. (2014). Requesting - from speech act to recruitment. In P. Drew \& E. Couper-Kuhlen (Eds.), Studies in Language and Social Interaction (Vol. 26, pp. 1-34). https://doi.org/10.1075/slsi.26.01dre 
Drew, P., \& Kendrick, K. H. (2018). Searching for trouble: Recruiting assistance through embodied action. Social Interaction. VideoBased Studies of Human Sociality, 1(1). https://doi.org/10.7146/si.v1i1.105496

Drew, P., \& Walker, T. (2010). Citizens' emergency calls: Requesting assistance in calls to the police. In M. Coulthard \& A. Johnson (Eds.), The Routledge Handbook of Forensic Linguistics (pp. 95110). Retrieved from http://ebookcentral.proquest.com/lib/vuw/detail.action?docID $=48$ 7985

Dunn, P. (2007). Matching service delivery to need. In S. Thompson (Ed.), Handbook of victims and victimology (pp. 255-281.). Devon, UK: Willan Publishing.

Edwards, D. (1995). Sacks and psychology. Theory \& Psychology, 5(4), 579596. https://doi.org/doi:10.1177/0959354395054006

Edwards, D. (1997). Discourse and cognition. London: SAGE Publications.

Edwards, D. (1999). Emotion discourse. Culture \& Psychology, 5(3), 271291. https://doi.org/10.1177/1354067X9953001

Edwards, D. (2012). Discursive and scientific psychology. British Journal of Social Psychology, 51(3), 425-435. https://doi.org/10.1111/j.20448309.2012.02103.x

Edwards, D., \& Potter, J. (1992). Discursive psychology. London, UK: SAGE Publications Ltd.

Edwards, D., \& Stokoe, E. (2007). Self-help in calls for help with problem neighbors. Research on Language and Social Interaction, 40(1), 932. https://doi.org/10.1080/08351810701331208

Ekström, M., Lindström, A., \& Karlsson, S. (2013). Managing troubles-talk in the renegotiation of a loan contract. Discourse Studies, 15(4), 371-394. https://doi.org/10.1177/1461445613483038

Emmison, M., Butler, C., \& Danby, S. (2011). Script proposals: A device for empowering clients in counselling. Discourse Studies, 13(1), 3-26. https://doi.org/10.1177/1461445610387734

Emmison, M., \& Danby, S. (2007a). Troubles announcements and reasons for calling: Initial actions in opening sequences in calls to a national children's helpline. Research on Language and Social Interaction, 40(1), 63-87. https://doi.org/10.1080/08351810701331273

Emmison, M., \& Danby, S. (2007b). Who's the friend in the background?: Interactional strategies in determining authenticity in calls to a 
national children's helpline. Australian Review of Applied Linguistics, 30(3), 31.1-31.17. https://doi.org/10.2104/aral0731

Emmison, M., \& Firth, A. (2012). Requesting and receiving advice on the telephone: An analysis of telephone helplines in Australia. In H. Limberg \& M. A. Locher (Eds.), Pragmatics \& Beyond New Series (Vol. 221, pp. 213-232). https://doi.org/10.1075/pbns.221.13emm

Evans, B., \& Fitzgerald, R. (2016). 'It's training man!' Membership categorization and the institutional moral order of basketball training. Australian Journal of Linguistics, 36(2), 205-223. https://doi.org/10.1080/07268602.2015.1121531

Farmer, C., Farrand, P., \& O'Mahen, H. (2012). 'I am not a depressed person': How identity conflict affects help-seeking rates for major depressive disorder. BMC Psychiatry, 12(1). https://doi.org/10.1186/1471-244X-12-164

Fattah, E. (2010). The evolution of a young, promising discipline: Sixty years of victimology, a retrospective and prospective look. In S. G. Shoham, P. Knepper, \& M. Kett (Eds.), International handbook of victimology (pp. 43-94). Florida, USA: CRC Press.

Fele, G. (2014). Requesting help with null or limited knowledge: Entitlements and responsibility in emergency calls. In A. Zuczkowski, R. Bongelli, I. Riccioni, \& C. Canestrari (Eds.), Communicating Certainty and Uncertainty in Medical, Supportive and Scientific Contexts (pp. 139-156). https://doi.org/10.1075/ds.25.07fel

Feo, R., \& LeCouteur, A. (2013). 'I just want to talk': Establishing reason for call on a men's counselling helpline. Australian Feminist Studies, 28(75), 65-80. https://doi.org/10.1080/08164649.2012.759310

Feo, R., \& LeCouteur, A. (2017). Dealing with third-party complaints on a men's relationship-counselling helpline. Discourse Studies, 19(2), 131-147. https://doi.org/10.1177/1461445617691701

Fohring, S. (2015). An integrated model of victimization as an explanation of non-involvement with the criminal justice system. International Review of Victimology, 21(1), 45-70. https://doi.org/10.1177/0269758014547993

Fox, B., \& Heinemann, T. (2016). Rethinking format: An examination of requests. Language in Society, 45(04), 499-531. https://doi.org/10.1017/S0047404516000385 
Fox, B., \& Heinemann, T. (2017a). Issues in action formation: Requests and the problem with x. Open Linguistics, 3(1). https://doi.org/10.1515/opli-2017-0003

Frías, S. M., \& Agoff, M. C. (2015). Between support and vulnerability: Examining family support among women victims of intimate partner violence in Mexico. Journal of Family Violence, 30(3), 277-291. http://dx.doi.org/10.1007/s10896-015-9677-y

Garfinkel, H. (1967). Studies in ethnomethodology. Englewood Cliffs, N.J.: Prentice-Hal.

Garfinkel, H. (2002). Ethnomethodology's program: Working out Durkheim's aphorism. Lanham, Md.: Rowman \& Littlefield Publishers.

Garfinkel, H., \& Sacks, H. (1970). On formal structures of practical action. In J. C. McKinney \& E. A. Tiryakian (Eds.), Theoretical sociology: Perspectives and developments (pp. 338-366). New York: Appleton-Century-Crofts.

Gavey, N. (1999). "I wasn't raped, but..." Revisiting definitional problems in sexual victimization. In S. Lamb (Ed.), New versions of victims: Feminists struggle with the concept (pp. 57-80). New York: New York University Press.

Gavey, N. (2013). Just sex? The cultural scaffolding of rape. Florence: Taylor and Francis.

Gavey, N., \& Shmidt, J. (2011). "Trauma of rape" discourse: A double-edged template for everyday understandings of the impact of rape? Violence Against Women, 17(4), 433-456. https://doi.org/10.1177/1077801211404194

Gene H. Lerner, \& Celia Kitzinger. (2007). Extraction and aggregation in the repair of individual and collective self-reference. Discourse Studies, 9(4), 526-557. https://doi.org/doi:10.1177/1461445607079165

Giles, D. (2006). Constructing identities in cyberspace: The case of eating disorders. British Journal of Social Psychology, 45(3), 463-477. https://doi.org/10.1348/014466605X53596

Giles, D., \& Newbold, J. (2013). 'Is this normal?' The role of category predicates in constructing mental illness online. Journal of Computer-Mediated Communication, 18(4), 476-490. https://doi.org/10.1111/jcc4.12022 
Goffman, E. (1961). Encounters: Two studies in the sociology of emotion. New York: Bobbs-Merrill Company, Inc.

Gordon, C., \& İkizoğlu, D. (2017). ‘Asking for another' online: Membership categorization and identity construction on a food and nutrition discussion board. Discourse Studies, 19(3), 253-271. https://doi.org/10.1177/1461445617701810

Heinemann, T. (2006). 'Will you or can't you?': Displaying entitlement in interrogative requests. Journal of Pragmatics, 38(7), 1081-1104. https://doi.org/10.1016/j.pragma.2005.09.013

Hepburn, A. (2004). Crying: Notes on description, transcription, and interaction. Research on Language and Social Interaction, 37(3), 251-290. https://doi.org/10.1207/s15327973rlsi3703_1

Hepburn, A. (2005). "You're not takin' me seriously": Ethics and asymmetry in calls to a child protection helpline." Journal of Constructivist Psychology, $18(3)$, 253-274. https://doi.org/10.1080/10720530590948836

Hepburn, A., \& Bolden, G. B. (2017). Transcribing for social research. London, UK: SAGE Publications Ltd. https://doi.org/10.4135/9781473920460

Hepburn, A., \& Potter, J. (2007). Crying receipts: Time, empathy, and institutional practice. Research on Language and Social Interaction, $\quad 40(1), \quad 89-116$. https://doi.org/10.1080/08351810701331299

Hepburn, A., \& Potter, J. (2017). Crying and crying responses. In A. Peräkylä \& M. L. Sorjonen (Eds.), Emotion in interaction. Oxford University Press.

Hepburn, A., Wilkinson, S., \& Butler, C. (2014). Intervening with conversation analysis in telephone helpline services: Strategies to improve effectiveness. Research on Language and Social Interaction, 47(3), 239-254. https://doi.org/10.1080/08351813.2014.925661

Heritage, J. (2015). Well-prefaced turns in English conversation: A conversation analytic perspective. Journal of Pragmatics, 88, 88104. https://doi.org/10.1016/j.pragma.2015.08.008

Heritage, J. (1984). Garfinkel and ethnomethodology. Cambridge: Polity Press. 
Heritage, J. (1990). International accountability: A conversation analytic perspective. Réseaux, $8(1), \quad 23-49$. https://doi.org/10.3406/reso.1990.3529

Heritage, J. (1998). Oh-prefaced responses to inquiry. Language in Society, 27(3), 291-334. https://doi.org/10.1017/S0047404500019990

Heritage, J. (2004). Conversation analysis and institutional talk. In R. Sanders \& K. Fitch (Eds.), Handbook of Language and Social Interaction (pp. 103-146). Mahwah, NJ: Erlbaum.

Heritage, J. (2012). The epistemic engine: Sequence organization and territories of knowledge. Research on Language \& Social Interaction, 45(1), 30-52. https://doi.org/10.1080/08351813.2012.646685

Heritage, J., \& Clayman, S. (2010a). Gatekeeping and entitlement to emergency service. In Talk in action: Interactions, identities, and institutions (pp. 69-86). Oxford, UK: John Wiley \& Sons, Incorporated.

Heritage, J., \& Clayman, S. (2010b). History taking in medicine: Questions and answers. In Talk in action: Interactions, identities, and institutions (pp. 135-153). Oxford, UK: Wiley-Blackwell.

Heritage, J., \& Clayman, S. (2010c). Talk in action: Interactions, identities, and institutions. Hoboken: John Wiley \& Sons, Incorporated.

Heritage, J., \& Clayman, S. (2010d). Talking social institutions into being. In Talk in action: Interactions, identities, and institutions (pp. 20-33). Hoboken: John Wily \& Sons, Incorporated.

Heritage, J., \& Raymond, G. (2005). The terms of agreement: Indexing epistemic authority and subordination in talk-in-interaction. Social Psychology Quarterly, 68(1), 15-38. https://doi.org/10.1177/019027250506800103

Heritage, J., \& Robinson, J. D. (2006). Accounting for the visit: Giving reasons for seeking medical care. In Heritage, J. \& D. W. Maynard (Eds.), Communication in Medical Care (pp. 48-85). https://doi.org/10.1017/CBO9780511607172.005

Hester, S., \& Eglin, P. (1997). Culture in action: Studies in membership categorization analysis. Washington, D.C.: International Institute for Ethnomethodology and Conversation Analysis \& University Press of America.

Hoey, E. M., \& Kendrick, K. H. (2017). Conversation analysis. In A. M. B. De Groot \& P. Hagoort (Eds.), Research methods in 
psycholinguistics and the neurobiology of language: A practical guide (pp. 151-173). Newark: John Wiley \& Sons, Incorporated.

Hogg, M. A., Terry, D. J., \& White, K. M. (1995). A tale of two theories: A critical comparison of identity theory with social identity theory. Social Psychology Quarterly, 58(4), 255-269. https://doi.org/10.2307/2787127

Holstein, J. A., \& Miller, G. (1990). Rethinking victimization: An interactional approach to victimology. Symbolic Interaction, 13(1), 103-122. https://doi.org/10.1525/si.1990.13.1.103

Hoorens, V. (1995). Self-favoring biases, self-presentation, and the self-other asymmetry in social comparison. Journal of Personality, 63(4), 793-817. https://doi.org/10.1111/j.1467-6494.1995.tb00317.x

Horne, J., \& Wiggins, S. (2009). Doing being 'on the edge': Managing the dilemma of being authentically suicidal in an online forum. Sociology of Health \& Illness, 31(2), 170-184. https://doi.org/10.1111/j.1467-9566.2008.01130.x

Housley, W., \& Fitzgerald, R. (2015). Introduction to Membership Categorisation analysis. In R. Fitzgerald \& W. Housley (Eds.), Advances in Membership Categorisation Analysis (pp. 1-22). London: SAGE Publications Ltd.

Hunt, M. (1991). The identification and provision of care for the terminally ill at home by 'family' members. Sociology of Health \& Illness, 13(3), 22. https://doi.org/10.1111/1467-9566.ep10492394

Hutchby, I., \& Wooffitt, R. (1999). Analysing phenomena I: Building a collection. In I. Hutchby \& R. Wooffitt (Eds.), Conversation analysis (pp. 88-115). Cambridge, UK: Polity Press.

Izumi, H. (2017). Help-search practices in rehabilitation team meetings: A Sacksian analysis. Human Studies, 40(3), 439-468. https://doi.org/10.1007/s10746-017-9430-z

Jackson, C. (2011). The gendered "I." In S. A. Speer \& E. Stokoe (Eds.), Conversation and Gender (pp. 31-47). Cambridge, NY: Cambridge University Press.

Jägervi, L. (2014). Who wants to be an ideal victim? A narrative analysis of crime victims' self-presentation. Journal of Scandinavian Studies in Criminology \& Crime Prevention, 15(1), 73-88. https://doi.org/10.1080/14043858.2014.893479 
Jägervi, L., \& Svensson, K. (2015). Conceptions of gender and age in Swedish Victim Support. International Review of Victimology, 21(2), 217-231. https://doi.org/10.1177/0269758015571473

Jayyusi, L. (1984). Categorization and the moral order. Boston, MA: Routledge \& Kegan Paul.

Jefferson, G. (1988). On the sequential organisation of troubles-talk in ordinary conversation. Social Problems, 35(4), 418-441. https://doi.org/10.1525/sp.1988.35.4.03a00070

Jefferson, G. (2004). Glossary of transcript symbols with an introduction. In G. Lerner (Ed.), Conversation analysis: Studies from the first generation (pp. 13-31). Philadelphia: USA: John Benjamins Publishing Company.

Jefferson, G., \& Lee, J. (1992). The rejection of advice: Managing the problematic convergence of a "troubles-telling" and a "service encounter." In P. Drew \& J. Heritage (Eds.), Talk at work: Interaction in institutional settings (pp. 521-548). Cambridge, UK: Cambridge University Press.

Jordan, J. (2004). Beyond belief? Police, rape and women's credibility. Criminal Justice, 4(1), 29-60. http://dx.doi.org/10.1177/1466802504042222

Jordan, J. (2008). Perfect victims, perfect policing? Improving rape complainants' experiences of police investigations. Public Administration, 86(3), 699-719. https://doi.org/10.1111/j.14679299.2008.00749.x

Jordan, J. (2011). Here we go round the review-go-round: Rape investigation and prosecution-are things getting worse not better? Journal of Sexual Aggression, 17(3), 234-249. https://doi.org/10.1080/13552600.2011.613278

Jordan, J. (2013). From victim to survivor - and from survivor to victim: Reconceptualising the survivor journey. Sexual Abuse in Australia and New Zealand, 5(2), 48-56.

Kelly, L., \& Radford, J. (1990). "Nothing really happened": The invalidation of women's experiences of sexual violence. Critical Social Policy, 10(30), 39-53. https://doi.org/10.1177/026101839001003003

Kendrick, K. H., \& Drew, P. (2014). The putative preference for offers over requests. In P. Drew \& E. Couper-Kuhlen (Eds.), Studies in Language and Social Interaction (pp. 87-114). https://doi.org/10.1075/slsi.26.04ken 
Kendrick, K. H., \& Drew, P. (2016). Recruitment: Offers, requests, and the organization of assistance in interaction. Research on Language and Social Interaction, 49(1), 1-19. https://doi.org/10.1080/08351813.2016.1126436

Kent, A. (2016). Conversation analysis and discursive psychology: Taking up the challenge of Sacks' legacy. In C. Tileagă \& E. Stokoe (Eds.), Discursive psychology: Classic and contemporary issues (pp. 4356). Milton Park: Routledge.

Kitzinger, C. (2000). Doing feminist conversation analysis. Feminism \& Psychology, 10(2), 163-193. https://doi.org/doi:10.1177/0959353500010002001

Kitzinger, C. (2005). "Speaking as a heterosexual": (How) does sexuality matter for talk-in-interaction? Research on Language \& Social Interaction, 38(3), 221-265. https://doi.org/10.1207/s15327973rlsi3803_2

Kitzinger, C. (2007). Is "woman" always relevantly gendered? Gender and Language, 1(1), 39-49. https://doi.org/10.1558/genl.2007.1.1.39

Kitzinger, C., \& Mandelbaum, J. (2013). Word selection and social identities in talk-in-interaction. Communication Monographs, 80(2), 176198. https://doi.org/10.1080/03637751.2013.776171

La, J. (2018). The interactional organisation of pain displays in medical consultations (Victoria University of Wellington). Retrieved from http://dx.doi.org/10063/7830

Lamb, S. (1999a). Constructing the victim: Popular images and lasting labels. In S. Lamb (Ed.), New versions of victims: Feminists struggle with the concept (pp. 108-138). New York: New York University Press.

Lamb, S. (Ed.). (1999b). New versions of victims: Feminists struggle with the concept. New York: New York University Press.

Lamerichs, J., \& te Molder, H. F. M. (2003). Computer-mediated communication: From a cognitive to a discursive model. New Media \& Society, 5(4), 451-473. https://doi.org/10.1177/146144480354001

Larsen, T. (2013). Dispatching emergency assistance: Callers' claims of entitlement and call takers' decisions. Research on Language \& Social Interaction, 46(3), 205-230. https://doi.org/10.1080/08351813.2013.810401

Latané, B., \& Darley, J. (1970). The unresponsive bystander: Why doesn't he help? Englewood Cliffs, N.J.: Prentice-Hall. 
LeCouteur, A., \& Oxlad, M. (2011). Managing accountability for domestic violence: Identities, membership categories and morality in perpetrators' talk. Feminism \& Psychology, 21(1), 5-28. https://doi.org/doi:10.1177/0959353510375406

Lee, S.-H. (2011). Managing non-granting of customers' requests in commercial service encounters. Research on Language \& Social Interaction, 44(2), 109-134. https://doi.org/10.1080/08351813.2011.567091

Lerner, G. H., \& Kitzinger, C. (2015). Or-prefacing in the organization of self-initiated repair. Research on Language and Social Interaction, 48(1), 58-78. https://doi.org/10.1080/08351813.2015.993844

Levine, M., \& Cassidy, C. (2009). Groups, identities, and bystander behavior: How group processes can be used to promote helping. In S. Stürmer \& M. Snyder (Eds.), The Psychology of Prosocial Behavior (pp. 209-222). https://doi.org/10.1002/9781444307948.ch11

Levine, M., Prosser, A., Evans, D., \& Reicher, S. (2005). Identity and emergency intervention: How social group membership and inclusiveness of group boundaries shape helping behavior. Personality and Social Psychology Bulletin, 31(4), 443-453. https://doi.org/10.1177/0146167204271651

Levinson, S. C. (2013). Action formation and ascription. In T. Stivers \& J. Sidnell (Eds.), The Handbook of Conversation Analysis (pp. 103130). West Sussex, UK: Wiley.

Lindholm, J., Börjesson, M., \& Cederborg, A. C. (2014). "What happened when you came to Sweden?" Attributing responsibility in police interviews with alleged adolescent human trafficking victims. Narrative Inquiry, 24(2), 181-199. https://doi.org/10.1075/ni.24.2.01lin

Lindström, A. (2005). Language as social action: A study of how senior citizens request assistance with practical tasks in the Swedish home help service. In A. Hakulinen \& M. Selting (Eds.), Studies in Discourse and Grammar (Vol. 17, pp. 209-230). https://doi.org/10.1075/sidag.17.11lin

Lindström, A., \& Weatherall, A. (2015). Orientations to epistemics and deontics in treatment discussions. Journal of Pragmatics, 78, 3953. http://dx.doi.org/10.1016/j.pragma.2015.01.005 
Löfstrand, C. H. (2009a). Supporting young crime victims: Discursive environments and formula narratives. Journal of Youth Studies, 12(6), 711-729. https://doi.org/10.1080/13676260903081632

Löfstrand, C. H. (2009b). Understanding victim support as crime prevention work: The construction of young victims and villains in the dominant crime victim discourse in Sweden. Journal of Scandinavian Studies in Criminology \& Crime Prevention, 10(2), 120. https://doi.org/10.1080/14043850903316220

MacLeod, N. (2016). "I thought I'd be safe there": Pre-empting blame in the talk of women reporting rape. Journal of Pragmatics, 96, 96-109. https://doi.org/10.1016/j.pragma.2016.03.008

Mandelbaum, J. (2013). Storytelling in conversation. In J. Sidnell \& T. Stivers (Eds.), The Handbook of Conversation Analysis (pp. 492507). West Sussex, UK: Blackwell Publishing Ltd.

Manning, R., Levine, M., \& Collins, A. (2007). The Kitty Genovese murder and the social psychology of helping: The parable of the 38 witnesses. American Psychologist, 62(6), 555-562. https://doi.org/10.1037/0003-066X.62.6.555

Mawby, R. (1988). Victims' needs or victims' rights: Alternative approaches to policy-making. In M. Maguire \& J. Pointing (Eds.), Victims of crime: A new deal? (pp. 127-137). Milton Keynes: Open University Press.

Mawby, R. (2007). Public sector services and the victim of crime. In S. Walklate (Ed.), Handbook of victims and victimology (pp. 209239). Devon, UK: Willan Publishing.

McNeill, A., Pehrson, S., \& Stevenson, C. (2017). The rhetorical complexity of competitive and common victimhood in conversational discourse. European Journal of Social Psychology, 47(2), 167179. https://doi.org/10.1002/ejsp.2255

Meyer, S. (2015). Seeking help for intimate partner violence: Victims' experiences when approaching the criminal justice system for IPVrelated support and protection in an Australian jurisdiction. Feminist Criminology, 6(4), 268-290. https://doi.org/10.1007/s10826-010-9410-7.

Mondada, L. (2008). Using video for a sequential and multimodal analysis of social interaction: Videotaping institutional telephone calls. Forum: Qualitative Social Research, 9(3). http://dx.doi.org/10.17169/fqs-9.3.1161 
Mondada, L. (2013a). Displaying, contesting and negotiating epistemic authority in social interaction: Descriptions and questions in guided visits. Discourse Studies, 15(5), 597-626. https://doi.org/10.1177/1461445613501577

Mondada, L. (2013b). The conversation analytic approach to data collection. In J. Sidnell \& T. Stivers (Eds.), The Handbook of Conversation Analysis (pp. 32-56). New York: John Wiley \& Sons Incorporated.

Mondada, L. (2014a). Requesting immediate action in the surgical operating room: Time, embodied resources and praxeological embeddedness. In P. Drew \& E. Couper-Kuhlen (Eds.), Studies in Language and Social Interaction (pp. 269-302). https://doi.org/10.1075/slsi.26.11mon

Mondada, L. (2014b). The local constitution of multimodal resources for social interaction. Journal of Pragmatics, 65, 137-156. http://dx.doi.org/10.1016/j.pragma.2014.04.004

Moore, J. (2016). Knowledge as an interactional tool in the management of client empowerment. Patient Education and Counselling, 99(6), 911-916. https://doi.org/10.1016/j.pec.2015.10.001

Näslund, S. (2016). Tacit tango: The social framework of screen-focused silence in institutional telephone calls. Journal of Pragmatics, 91, 60-79. http://dx.doi.org/10.1016/j.pragma.2015.10.008

New Zealand Council of Victim Support Groups. (2019, March 15). Victim Support official page: Christchurch shooting victims' fund. Retrieved from Givealittle website: https://givealittle.co.nz/cause/christchurch-shooting-victims-fund

Newbold, G., \& Cross, J. (2008). Domestic violence and pro-arrest policy. Social Policy Journal of New Zealand, (33), 1-14.

Othman, S., Goddard, C., \& Piterman, L. (2014). Victims' barriers to discussing domestic violence in clinical consultations: A qualitative enquiry. Journal of Interpersonal Violence, 29(8), 1497-1513. https://doi.org/10.1177/0886260513507136

Perloff, L. S., \& Fetzer, B. K. (1986). Self-other judgments and perceived vulnerability to victimization. Journal of Personality and Social Psychology, 50(3), 502-510. http://dx.doi.org/10.1037/00223514.50.3.502

Pomerantz, A. (1980). Telling my side: "Limited access' as a "fishing" device. Sociological Inquiry, 50(3-4), 186-198. https://doi.org/10.1111/j.1475-682X.1980.tb00020.x 
Potter, J. (2002). Two kinds of natural. Discourse Studies, 4(4), 539-542. https://doi.org/10.1177/14614456020040040901

Potter, J. (2012). Re-reading discourse and social psychology: Transforming social psychology. British Journal of Social Psychology, 51(3), 436-455. https://doi.org/10.1111/j.2044-8309.2011.02085.x

Potter, J., Edwards, D., \& Wetherell, M. (1993). A model of discourse in action. American Behavioral Scientist, 36(3), 383-401. https://doi.org/10.1177/0002764293036003008

Potter, J., \& Hepburn, A. (2003). "I'm a bit concerned": Early actions and psychological constructions in a child protection helpline. Research on Language and Social Interaction, 36(3), 197-240. https://doi.org/10.1207/S15327973RLSI3603_01

Potter, J., \& Wetherell, M. (1987). Discourse and social psychology: Beyond attitudes and behaviour. London, UK: SAGE Publications Ltd.

Powell, A., \& Murray, S. (2008). Children and domestic violence: Constructing a policy problem in Australia and New Zealand. Social \& Legal Studies, 17(4), 453-473. https://doi.org/10.1177/0964663908097080

Powell, A., Henry, N., Flynn, A., \& Henderson, E. (2013). Meanings of "sex" and "consent": The persistence of rape myths in Victorian rape law. Griffith Law Review, 22(2), 456-480. http://dx.doi.org/10.1080/10383441.2013.10854783

Psathas, G. (1999). Studying the organization in action: Membership categorization and interaction analysis. Human Studies, 22(2-4), 139-162. https://doi.org/10.1023/A:1005422932589

Pudlinksi, C. (2005). The mitigation of advice: Interactional dilemmas of peers on a telephone support service. In C. Baker, M. Emmison, \& A. Firth (Eds.), Calling for Help: Language and social interaction in telephone helplines (pp. 109-131). Amsterdam, The Netherlands: John Benjamins.

Quinney, R. (1972). Who is the victim? Criminology, 10(3), 314-323. https://doi.org/10.1111/j.1745-9125.1972.tb00564.x

Rahman, A. (2019, March 17). Islamic Women's Council repeatedly lobbied to stem discrimination. Radio New Zealand. Retrieved from https://www.radionz.co.nz/news/on-the-inside/384911/islamicwomen-s-council-repeatedly-lobbied-to-stem-discrimination 
Raymond, G., \& Heritage, J. (2006). The epistemics of social relations: Owning grandchildren. Language in Society, 35(5), 677-705. https://doi.org/10.10170S0047404506060325

Raymond, G., \& Zimmerman, D. (2007). Rights and responsibilities in calls for help: The case of the Mountain Glade Fire. Research on Language and Social Interaction, 40(1), 33-61. https://doi.org/10.1080/08351810701331232

Reynolds, E., \& Fitzgerald, R. (2015). Challenging normativity: Reappraising category bound, tied and predicated features. In R. Fitzgerald \& W. Housley (Eds.), Advances in membership categorisation analysis (pp. 99-122). London, UK: SAGE Publications Ltd.

Riley, S., Rodham, K., \& Gavin, J. (2009). Doing weight: Pro-ana and recovery identities in cyberspace. Journal of Community \& Applied Social Psychology, 19(5), 348-359. https://doi.org/10.1002/casp.1022

Robinson, J. (2016). Accountability in social interaction. In J. Robinson (Ed.), Accountability in social interaction (pp. 1-44). Oxford, UK: Oxford University Press.

Rønneberg, K., \& Svennevig, J. (2010). Declining to help: Rejections in service requests to the police. Discourse \& Communication, 4(3), 279-305. https://doi.org/10.1177/1750481310373217

Roose, R., Verschelden, G., Vettenburg, N., \& Vanthuyne, T. (2012). Working with volunteers in victim support: Mirror or camouflage? International Social Work, 55(2), 269-281. https://doi.org/10.1177/0020872811408574

Rossano, F., \& Liebal, K. (2014). "Requests" and "offers" in orangutans and human infants. In P. Drew \& E. Couper-Kuhlen (Eds.), Studies in language and social interaction (pp. 335-364). https://doi.org/10.1075/slsi.26.13ros

Ruusuvuori, J. (2013). Emotion, affect and conversation. In J. Sidnell \& T. Stivers (Eds.), The Handbook of Conversation Analysis (pp. 330349). West Sussex, UK: Blackwell Publishing Ltd.

Sabina, C., Cuevas, C. A., \& Rodriguez, R. M. (2014). Who to turn to? Helpseeking in response to teen dating violence among Latinos. Psychology of Violence, 4(3), 348-362. https://doi.org/10.1037/a0035037 
Sacks, H. (1966). The search for help: No one to turn to (Ph.D., University of California, Berkeley). Retrieved from ProQuest Dissertations \& Theses Global.

Sacks, H. (1967). The search for help: No one to turn to. In E. S. Shneidman (Ed.), Essays in self destruction (pp. 203-223). New York, NY: Science House.

Sacks, H. (1972a). On the analyzability of stories by children. In J. J. Gumperz \& D. Hymes (Eds.), Directions in sociolinguistics: The ethnography of communication (pp. 325-345). New York, NY: Holt, Rinehart and Winston, Inc.

Sacks, H. (1972b). An initial investigation of the usability of conversational data for doing Sociology. In D. N. Sudnow (Ed.), Studies in social interaction (pp. 31-74). New York, NY: Free Press.

Sacks, H. (1979). Hotrodder: A revolutionary category. In G. Psathas (Ed.), Everyday language: Studies in ethnomethodology (pp. 7-14). New York: Irvington.

Sacks, H. (1984). On doing 'being ordinary.' In J. M. Atkinson \& J. Heritage (Eds.), Structures of social action (pp. 413-429). Cambridge, UK: Cambridge University Press.

Sacks, H. (1995). Lectures on conversation (G. Jefferson, Ed.). Oxford, UK: Blackwell.

Schegloff, E. A. (1972). Notes on a conversational practice: Formulating place. In D. N. Sudnow (Ed.), Studies in social interaction (pp. 75119). New York: The Free Press.

Schegloff, E. A. (1986). The routine as achievement. Human Studies, 9(2-3), 111-151. https://doi.org/10.1007/BF00148124

Schegloff, E. A. (1987). Analysing single episodes of interaction: An exercise in conversation analysis. Social Psychology Quarterly, 50(2), 101114. http://dx.doi.org/10.2307/2786745

Schegloff, E. A. (1989). Harvey Sacks - Lectures 1964-1965 an introduction/memoir. Human Studies, 12(3), 185-209. https://doi.org/10.1007/bf00142761

Schegloff, E. A. (1996). Some practices for referring to persons in talk-ininteraction: A partial sketch of a systematics. In B. A. Fox (Ed.), Studies in Anaphora (pp. 437-486). Amsterdam: John Benjamins.

Schegloff, E. A. (1997). Whose text? Whose context? Discourse \& Society, 8(2), 165-187. https://doi.org/10.1177/0957926597008002002 
Schegloff, E. A. (2007a). A tutorial on membership categorization. Journal of Pragmatics, 39(3), 462-482. https://doi.org/10.1016/j.pragma.2006.07.007

Schegloff, E. A. (2007b). Sequence Organisation in Interaction. Cambridge, UK: Cambridge University Press.

Schegloff, E. A., Jefferson, G., \& Sacks, H. (1977). The preference for selfcorrection in the organization of repair in conversation. Language, 53(2), 361-382. https://doi.org/10.2307/413107

Schegloff, E. A., \& Lerner, G. H. (2009). Beginning to respond: Wellprefaced responses to wh-questions. Research on Language and Social Interaction, 42(2), 91-115. https://doi.org/10.1080/08351810902864511

Sidnell, J. (2007). 'Look'-prefaced turns in first and second position: Launching, interceding and redirecting action. Discourse Studies, 9(3), 387-408. https://doi.org/10.1177/1461445607076204

Sidnell, J. (2013). Basic conversation analytic methods. In J. Sidnell \& T. Stivers (Eds.), The Handbook of Conversation Analysis (pp. 7798). Hoboken, NJ: Wiley Blackwell.

Sidnell, J. (2017). Action in interaction is conduct under a description. Language in Society, 46(03), 313-337. https://doi.org/10.1017/S0047404517000173

Simmonds, L. (2009). What victims want! Victim Support, and objective or relative approach to victims' needs. Social \& Public Policy Review, $3(2), 11-29$.

Smithson, J., Sharkey, S., Hewis, E., Jones, R. B., Emmens, T., Ford, T., \& Owens, C. (2011a). Membership and boundary maintenance on an online self-harm forum. Qualitative Health Research, 21(11), 1567-1575. https://doi.org/10.1177/1049732311413784

Smithson, J., Sharkey, S., Hewis, E., Jones, R., Emmens, T., Ford, T., \& Owens, C. (2011b). Problem presentation and responses on an online forum for young people who self-harm. Discourse Studies, 13(4), 487-501. https://doi.org/10.1177/1461445611403356

Speer, S. A. (2002). What can conversation analysis contribute to feminist methodology? Putting reflexivity into practice. Discourse \& Society, 13(6), 783-803. https://doi.org/10.1177/0957926502013006757 
Stevanovic, M. (2011). Participants' deontic rights and action formation: The case of declarative requests for action. Interaction and Linguistic Structures, (52).

Stevanovic, M., \& Peräkylä, A. (2012). Deontic authority in interaction: The right to announce, propose, and decide. Research on Language and Social Interaction, 45(3), 297-321. https://doi.org/10.1080/08351813.2012.699260

Stevanovic, M., \& Peräkylä, A. (2014). Three orders in the organization of human action: On the interface between knowledge, power, and emotion in interaction and social relations. Language in Society, 43(02), 185-207. https://doi.org/10.1017/S0047404514000037

Stivers, T. (2004). "No no no" and other types of multiple sayings in social interaction. Human Communication Research, 30(2), 260-293. https://doi.org/10.1111/j.1468-2958.2004.tb00733.x

Stivers, T. (2007). Alternative recognitionals in person reference. In N. J. Enfield \& T. Stivers (Eds.), Person reference in interaction (pp. 73-96). https://doi.org/10.1017/CBO9780511486746.005

Stokoe, E. (2003). Mothers, single women and sluts: Gender, morality and membership categorization in neighbour disputes. Feminism \& Psychology, 13(3), 317-344. https://doi.org/10.1177/0959353503013003006

Stokoe, E. (2004). Gender and discourse, gender and categorization: Current developments in language and gender research. Qualitative Research in Psychology, 1(2), 107-129. https://doi.org/10.1191/1478088704qp007oa

Stokoe, E. (2009). Doing actions with identity categories: Complaints and denials in neighbor disputes. Text \& Talk - An Interdisciplinary Journal of Language, Discourse Communication Studies, 29(1), 75-97. https://doi.org/10.1515/TEXT.2009.004

Stokoe, E. (2012). Moving forward with membership categorization analysis: Methods for systematic analysis. Discourse Studies, 14(3), 277303. https://doi.org/10.1177/1461445612441534

Stokoe, E. (2013a). Overcoming barriers to mediation in intake calls to services: Research-based strategies for mediators. Negotiation Journal, 29(3), 289-314. https://doi.org/10.1111/nejo.12026

Stokoe, E. (2013b). The (in)authenticity of simulated talk: Comparing roleplayed and actual interaction and the implications for communication training. Research on Language and Social 
Interaction,

$46(2)$,

$165-185$.

https://doi.org/10.1080/08351813.2013.780341

Stokoe, E. (2014). The conversation analytic role-play method (CARM): A method for training communication skills as an alternative to simulated role-play. Research on Language and Social Interaction, 47, 255-265. https://doi.org/10.1080/08351813.2014.925663

Stommel, W., \& Koole, T. (2010). The online support group as a community: A micro-analysis of the interaction with a new member. Discourse Studies, 12(3), 357-378. https://doi.org/10.1177/1461445609358518

Svensson, K. (2007). Victim support in a changing welfare state. Social Work and Society, 5(2), 123-134.

Tajfel, H. (1974). Social identity and intergroup behaviour. Social Science Information, 13(2), 65-93. https://doi.org/10.1177/053901847401300204

Tajfel, H., \& Turner, J. (1986). The social identity theory of intergroup behavior. In S. Worchel \& W. Austin (Eds.), Psychology of intergroup relations (pp. 7-24). Chicago: Nelson Hall.

Täuber, S., \& van Zomeren, M. (2012). Refusing intergroup help from the morally superior: How one group's moral superiority leads to another group's reluctance to seek their help. Journal of Experimental Social Psychology, 48(1), 420-423. https://doi.org/10.1016/j.jesp.2011.08.014

Taylor, A. (2006). Victim assistance services in Aotearoa New Zealand. Te Awatea Review, 4(2), 11-12.

Taylor, S. (2010). Narratives of identity and place. East Sussex, UK: Routledge.

te Molder, H. (2005). "I just want to hear somebody right now". Managing identities on a telephone helpline. In C. Baker, M. Emmison, \& A. Firth (Eds.), Calling for help: Language and social interaction in telephone helplines (pp. 153-172). Amsterdam, The Netherlands: John Benjamins.

Tennent, E., \& Weatherall, A. (2019). Disclosing violence in calls for help. Gender \& Language, 13(2), 270-288. https://doi.org/10.1558/genl.35106

Tennent, E., \& Weatherall, A. (in press, b). Feminist conversation analysis: Examining violence against women. In J. Baxter \& J. Angouri 
(Eds.), The Routledge Handbook of Language, Gender and Sexuality.

Thell, N., \& Jacobsson, K. (2016). "And how old are you?”: Age reference as an interpretative device in radio counselling. Journal of Aging Studies, 39, 31-43. https://doi.org/10.1016/j.jaging.2016.09.001

Towns, A. J., \& Adams, P. J. (2009). Staying quiet or getting out: Some ideological dilemmas faced by women who experience violence from male partners. British Journal of Social Psychology, 48(4), 735-754. https://doi.org/10.1348/014466608X398762

van Dijk, J. (1988). Ideological trends within the victims movement: An international perspective. In M. Maguire (Ed.), Victims of crime: A new deal? (pp. 115-126). Milton Keynes: Open University Press.

Vayreda, A., \& Antaki, C. (2009). Social support and unsolicited advice in a bipolar disorder online forum. Qualitative Health Research, 19(7), 931-942. https://doi.org/10.1177/1049732309338952

Venäläinen, S. (2016). "She must be an odd kind of woman": Gendered categorizations in accounts of lethal intimate partner violence in Finnish tabloid news. Feminism \& Psychology, 26(4), 426-443. https://doi.org/10.1177/0959353516655370

Victim Support. (2018). Annual Report 2017/18. Retrieved from http://victimsupport.org.nz/wp-content/uploads/2018/11/VSAnnual-Report-2018-Web.pdf

Wakin, M. A., \& Zimmerman, D. H. (1999). Reduction and specialization in emergency and directory assistance calls. Research on Language and Social Interaction, 32(4), 409-437. https://doi.org/10.1207/S15327973rls3204_4

Walklate, S. (1989). Victimology: The victim and the criminal justice process. London, UK: Unwin Hyman Ltd.

Walklate, S. (1990). Researching victims of crime: Critical victimology. Social Justice, $17(3 \quad$ (41)), 25-42. https://www.jstor.org/stable/29766556

Watson, D. R. (1978). Categorization, authorization, and blame-negotiation in conversation. Sociology, 12(1), 105-113. https://doi.org/10.1177/003803857801200106

Watson, D. R. (1983). The presentation of victim and motive in discourse: The case of police interrogations and interviews. Victimology: An International Journal, 8(1-2), 31-52. 
Watson, D. R. (1986). Doing the organization's work: An examination of aspects of the operation of a crisis intervention center. In S. Fisher \& A. D. Todd (Eds.), Discourse and Institutional Authority: Medicine, Education, and Law (pp. 91-120). Norwood, New Jersey: Ablex Publishing Company.

Weatherall, A. (2015). "But whose side are you on?" Doing being independent in telephone-mediated dispute resolution. In F. H. G. Chevalier \& J. Moore (Eds.), Producing and managing restricted activities: Avoidance and withholding in institutional interaction (pp. 151-179). Amsterdam, The Netherlands: John Benjamins Publishing Company.

Weatherall, A. (2016). Interpretative repertoires, conversation analysis and being critical. In C. Tileagă \& E. Stokoe (Eds.), Discursive psychology: Classic and contemporary issues (pp. 15-28). Milton Park: Routledge.

Weatherall, A., \& Stubbe, M. (2015). Emotions in action: Telephonemediated dispute resolution. British Journal of Social Psychology, 54(2), 273-290. https://doi.org/10.1111/bjso.12082

Weiss, K. G. (2011). Neutralizing sexual victimization: A typology of victims' non-reporting accounts. Theoretical Criminology, 15(4), 445-467. https://doi.org/10.1177/1362480610391527

Wetherell, M. (1998). Positioning and interpretative repertoires: Conversation analysis and post-structuralism in dialogue. Discourse \& Society, 9(3), 387-412. https://doi.org/10.1177/0957926598009003005

Wetherell, M., Stiven, H., \& Potter, J. (1987). Unequal egalitarianism: A preliminary study of discourse and employment opportunities. British Journal of Social Psychology, 26, 59-71. http://dx.doi.org/10.1111/j.2044-8309.1987.tb00761.x

Whalen, J. (1995). A technology of order production: Computer-aided dispatch in public safety communications. In P. Ten Have \& G. Psathas (Eds.), Situated order: Studies in the social organization of talk and embodied activities (pp. 187-230). Washington, D.C.: International Institute for Ethnomethodology and Conversation Analysis \& University Press of America.

Whalen, J., \& Whalen, M. R. (2011). Integrated customer service: Reinventing a workspace. In M. H. Szymanski \& J. Whalen (Eds.), Making work visible: Ethnographically grounded case studies of 
work practice (pp. 181-204.). New York: Cambridge University Press.

Whalen, J., \& Zimmerman, D. H. (1998). Observations on the display and management of emotion in naturally occurring activities: The case of "hysteria" in calls to 9-1-1. Social Psychology Quarterly, 61(2), 141-159. https://doi.org/10.2307/2787066

Whalen, J., Zimmerman, D., \& Whalen, M. R. (1988). When words fail: A single case analysis. Social Problems, 35(4), 335-362. https://doi.org/10.2307/800591

Whalen, M. R., \& Zimmerman, D. (1990). Describing trouble: Practical epistemology in citizen calls to the police. Language in Society, 19(4), 465-492. https://doi.org/10.1017/S0047404500014779

Wiggins, S. (2016). Discursive psychology. London: SAGE Publications.

Wiggins, S., McQuade, R., \& Rasmussen, S. (2016). Stepping back from crisis points: The provision and acknowledgment of support in an online suicide discussion forum. Qualitative Health Research, 26(9), 1240-1251. https://doi.org/10.1177/1049732316633130

Wilkinson, S. (2011). Gender, routinization and recipient design. In S. A. Speer \& E. Stokoe (Eds.), Conversation and gender (pp. 112-134). Cambridge, NY: Cambridge University Press.

Wilkinson, S., \& Kitzinger, C. (2006). Surprise as an interactional achievement: Reaction tokens in conversation. Social Psychology Quarterly, 69(2), 150-182. https://doi.org/10.1177/019027250606900203

Wilkinson, S., \& Kitzinger, C. (2014). Conversation analysis in language and gender studies. In S. Ehrlich, M. Meyerhoff, \& J. Holmes (Eds.), Handbook of language, gender, and sexuality (pp. 141-160). Somerset, US: Wiley-Blackwell.

Wooffitt, R. (1992). Telling tales of the unexpected: The organisation of factual discourse. Savage, Md.: Barnes \& Noble Books.

Wootton, A. J. (1981). Two request forms of four year olds. Journal of Pragmatics, 5(6), 511-523. https://doi.org/10.1016/03782166(81)90016-3

Wowk, M. T. (1984). Blame allocation, sex and gender in a murder interrogation. Women's Studies International Forum, 7(1), 75-82. http://dx.doi.org/10.1016/0277-5395(84)90087-6

Wroe, L. E. (2018). 'It really is about telling people who asylum seekers really are, because we are human like anybody else': Negotiating 
victimhood in refugee advocacy work. Discourse \& Society, 29(3), 324-343. https://doi.org/10.1177/0957926517734664

Young, I. F., \& Sullivan, D. (2016). Competitive victimhood: A review of the theoretical and empirical literature. Current Opinion in Psychology, 11, 30-34. https://doi.org/10.1016/j.copsyc.2016.04.004

Zimmerman, D. (1992). The interactional organization of calls for emergency assistance. In P. Drew \& J. Heritage (Eds.), Talk at work (pp. 418469). Cambridge, UK: Cambridge University Press.

Zinken, J., \& Ogiermann, E. (2013). Responsibility and action: Invariants and diversity in requests for objects in British English and Polish interaction. Research on Language \& Social Interaction, 46(3), 256-276. https://doi.org/10.1080/08351813.2013.810409 


\section{APPENDIX:TRANSCRIPTION KEY}

\begin{tabular}{|c|c|}
\hline Symbol & Description \\
\hline CLTKR CALLR & Speaker identification for call-taker and caller \\
\hline$(0.2)$ & Numbers in brackets represent silences in seconds \\
\hline$()$. & Silence less than one-tenth of a second \\
\hline $\begin{array}{l}\text { [word] } \\
\text { [word] }\end{array}$ & $\begin{array}{l}\text { Square brackets represent overlapping talk - talk } \\
\text { by different speakers that occurs at the same time }\end{array}$ \\
\hline $\begin{array}{l}\text { word }= \\
\text { =word }\end{array}$ & $\begin{array}{l}\text { Equals signs represent 'latched' talk. This can be a } \\
\text { continuation of talk within a turn or across } \\
\text { different lines on the transcript }\end{array}$ \\
\hline wo: : : rd & $\begin{array}{l}\text { Colons indicate a sound-stretch; more colons } \\
\text { represent a longer stretch }\end{array}$ \\
\hline$>$ word $<$ & Arrows surrounding talk indicate faster speech \\
\hline Word- & Dash represents a sound cut-off \\
\hline WORD & Capitalisation indicates greater volume \\
\hline${ }^{\circ}{ }^{\text {word }}{ }^{\circ}$ & $\begin{array}{l}\text { Speech between degree signs is quieter relative to } \\
\text { the rest of talk }\end{array}$ \\
\hline word & Underlining represents emphasis \\
\hline$\sim$ word & Words within tildes represent 'wobbly voice' \\
\hline \#word\# & Words within hashes represent 'creaky voice' \\
\hline word. & $\begin{array}{l}\text { Full-stop indicates falling intonation at the end of } \\
\text { a unit of talk }\end{array}$ \\
\hline word, & $\begin{array}{l}\text { Comma indicates continuing intonation at the end } \\
\text { of a unit of talk }\end{array}$ \\
\hline
\end{tabular}




\begin{tabular}{|c|c|}
\hline Symbol & Description \\
\hline word? & $\begin{array}{l}\text { Question mark indicates rising intonation at the } \\
\text { end of a unit of talk }\end{array}$ \\
\hline word! & $\begin{array}{l}\text { Exclamation mark indicates sharply rising } \\
\text { intonation at the end of a unit of talk }\end{array}$ \\
\hline$\uparrow$ word & $\begin{array}{l}\text { Upward arrows before talk indicate a sharply } \\
\text { increased pitch }\end{array}$ \\
\hline wo $:$ rd & $\begin{array}{l}\text { Underlining and colons represent intonation } \\
\text { contours within words }\end{array}$ \\
\hline . hh hhh & $\begin{array}{l}\text { Breathiness is represented with the letter ' } h \text {.' The } \\
\text { length indicates the relative length of breathiness. } \\
\text { Preceded by a full-stop indicates an in-breath; } \\
\text { without this an exhalation is represented }\end{array}$ \\
\hline wo $(\mathrm{h}) \mathrm{rd}$ & $\begin{array}{l}\text { 'h' within words represents breathiness (often } \\
\text { laughter or crying) within a spoken utterance }\end{array}$ \\
\hline . snih Huhh & These represent sniffing and sobbing respectively \\
\hline( & $\begin{array}{l}\text { Empty brackets represent spoken words unable to } \\
\text { be transcribed }\end{array}$ \\
\hline (word) & Words in brackets represent uncertain hearings \\
\hline$(($ ring $))$ & Double brackets represent transcriber comments \\
\hline
\end{tabular}

